\title{
Towards a structural typology of verb classes
}

\author{
Dieter Wunderlich (Berlin), March 2005
}

1. Introduction: The grammar is a set of structural generalizations

2. Prototypical transitive verbs are in the center of a grammar

3. Intransitive Verbs reflect sematic classes

3.1 Two or four classes of intransitive verbs?

3.2 The relationship between intransitives and transitives

3.3 On the possible decomposition of transitive verbs

3.4 The active-inactive type of argument linking

4. Further argument linking types for transitive verbs

4.1 The inverse type

4.2 The salience or voice type

4.3 The positional type

4.4 The generalized case type

Head vs. dependent marking

Accusative-ergative mixed systems

The emergence of dative

5. The lexical marking of verbs

5.1 Two classes of lexically marked dative verbs

5.2 Two classes of experiencer verbs with an expletive argument

6. Ditransitive verbs: the emergence of a third argument

6.1 How complex are ditransitive verbs semantically?

Two types of primitive ditransitive verbs

Derived ditransitives

6.2 Some general constraints

6.3 The number of syntactic arguments is reduced

Serial verb constructions

Noun incorporation

6.4 The recipient is treated like the object of a transitive verb

The recipient is the more salient object semantically

The recipient is marked by accusative.

The Theme is marked obliquely

The recipient is the primary object in a double object construction

6.5 The recipient is treated differently from the object of a transitive verb

The recipient is marked as goal by means of a preposition

The recipient is marked as alienable possessor of the theme

The recipient is marked by dative

6.6 The English 'dative' alternation

7. Summary 


\section{Introduction: The grammar is a set of structural generalizations}

What one needs to know about verbs is whether they have one, two, three or even more arguments: intransitive laugh has one argument, transitive see has two arguments, and ditransitive give has three arguments. If one is concerned with a particular language, one also needs to know how these arguments are realized. Turning from English to Turkish, to Georgian or to one of the indigenous languages of America, one finds quite different argument linking types, i.e. ways in which the arguments of a verb are realized. This paper tries to summarize some recent work on both argument structure and argument realization.

The first question is how certain we are that every language has verbs. The majority of linguists is convinced that the existence of two well-distinguished lexical categories, namely verbs and nouns, belongs to the most certain universals of human language. Some linguists, however, dispute such a universal claim. They present two kinds of counter-evidence: (i) Some languages do not exhibit clear differences between morphological means that apply to verbs and those that apply to nouns (Sasse 1992 on Cayuga, an Iroquoian language). (ii) Other languages exhibit large sets of lexical roots that function as verbs when combined with an aspect or tense marker, but function as nouns when combined with a definite article (Broschart 1995 on Tongan, an Oceanic language). See also the survey of such reservations in Sasse (1993). A closer inspection of these 'counter-examples', however, shows that these languages do not represent exceptions to the above-mentioned universal. Their grammar shows clear asymmetries between verbs and nouns, in the morphological behavior, the incorporation of nouns into verbs, and the forming of new nominal items derived from verbs (Wunderlich 1996).

There is of course some semantic background for the distinction of verbs and nouns. Prototypically, verbs (such as sleep, stay, hit, give) denote temporally changing entities (events or states) in which one or more objects are participating, while nouns (such as man, house, bottle, salt) denote temporally constant entities (objects determined merely spatially) which can participate in events or states. Usually, a complex scene where a man is sleeping is decomposed into the temporal predicate SLEEP (with an argument slot) and some instance of the nontemporal predicate MAN (an argument that fills the slot); SLEEP is associated grammatically with a verb and MAN with a noun, rather than the other way around. Nearly every language encodes ' $a \operatorname{man}_{\mathrm{N}}$ sleeps $_{\mathrm{V}}$ ' rather than 'a sleep $\mathrm{N}_{\mathrm{N}}$ occurs-to-man $\mathrm{V}_{\mathrm{V}}$ '.

However, the classification into verbs and nouns is not purely semantic-driven. Given the rich conceptual variation into punctual vs. extended events, on-going activities vs. achievements, permanent vs. temporally restricted states, masses vs. individual objects, concrete vs. abstract activities/objects one must wonder why there are just two major lexical classes rather than, say, eight or ten. Moreover, a closer inspection of the vocabulary of a language shows that some items seem to be wrongly classified: nouns such as journey, war, and game denote events rather than objects, while verbs such as resemble, exist, be above or be tall do not denote events. One point to be made here is that some languages (such as English) in addition to verbs and nouns also have prepositions (above p $_{\mathrm{P}}$ and adjectives $\left(\operatorname{tall}_{\mathrm{A}}\right)$, so that a more detailed classification arises. Other languages, such as Chinese, for instance, do not make such a clear addition to the grammar.

More important is another point: lexical categories evolve in a set of lexical items from generalization towards certain structural patterns, a fact that can be summarized by a distinctive grammatical feature by which the lexicon is partitioned into two classes, a designated one (such as verbs), and the remaining (unmarked or default) class (called nouns). Such a classification is more robust and more economical than a purely semantic 
classification, however, it leaves certain 'less motivated' assignments, which in the history of a language may survive as relics. A child that starts out to learn the words of a language seems to need only a short time to detect the verb class vs. the noun class, and as soon as this happens, the child produces overgeneralizations, i.e., classifies not always in accordance with the language to be learned. If one has acquired the basic classification of the vocabulary, there is no further need to motivate it semantically. Only for a new item the question arises to which class it belongs, which is mostly decided on the basis of semantic (or even phonological) similarity to another already existing group of items - if a semantically similar word is classified as a verb, the new item will also be assigned to verbs. Furthermore, semantic factors continue in playing a contextual role when the particular meanings of items are in focus.

Within the class of verbs, various kinds of semantic subclassification come into mind: verbs with animate or inanimate arguments, verbs of movement, position or placement, verbs of manipulation, experience, perception, communication, and so on. Nearly none of these possible semantic factors is decisive for the further grammatical subclassification of verbs, except animacy in some languages. For instance, the Algonquian languages from North America make a formal distinction between stems with animate and those with inanimate objects (e.g. waapam 'see sth. animate' vs. waapaht 'see sth. inanimate' in Plains Cree).

The most robust subclassification of verbs concerns the number of arguments: intransitive verbs have one, transitive verbs have two, and ditransitive verbs have three nominal arguments. (Verbs with zero valency are extremely rare - one possible semantic class of this kind are weather verbs, such as Latin pluit 'it rains', however, note that English uses here an expletive pronoun, which masks the verb to be intransitive.) Besides that, verbs are subclassified of whether they take a clausal complement (verbs of mental attitudes), which under some conditions can also be reduced to an infinitive or a similar non-finite verb form (he hopes to win vs. he hopes that he will win). Furthermore, at least some languages have a subclass of verbs that take a locational argument, e.g., a prepositional phrase (he sits on the bank, he puts the cans on the bank). Sometimes one also finds a class of verbs that take prepositional objects in which the preposition is lexically fixed (without contributing a particular meaning): an jdn denken 'think at someone', auf etw. hoffen 'hope for sth.', an etw. glauben 'believe in sth.'

If two nominal arguments occur with a verb, the meaning of the verb sometimes requires one argument to be animate and the other to be inanimate (read, sew, enter), however, more than often this is not the case. The second argument of see, for instance, can be inanimate or animate; in the latter case, the two arguments can in principle be exchanged, thereby shifting the intended reading (the man saw the lion and the lion saw the man mean different things). It is even possible that a verb has three arguments that are similar in their nature, consider send or introduce where any ordering of the three nominal arguments is possible (the neighbor sent/introduced the woman to a specialist; a specialist sent/ introduced the neighbor to the woman; etc.).

If the number of arguments counts, there must be some way to make the arguments recognizable in their specific role: which nominal functions as which argument. In English, this decision is made by position: usually the 'subject' precedes the verb, and the 'object' follows it. Other languages primarily use morphological case on nominals, or they use pronominal affixes or clitics attached to the verb. The particular device that maps argument roles onto morphosyntactic patterns is called 'argument linking'. Several types of argument 
linking are known, some of which will be discussed in section 4. Each argument linking type represents an economic way of avoiding ambiguities with verbs having more than one nominal argument. As we will see, each of these devices simultaneously enforces a certain subclassification of verbs according to structural parameters.

In any case, the classification of verbs seems to depend more on the possible realization patterns for their arguments than on inherent semantic features. Sometimes, however, it is possible to use a formal device to mark an exceptional semantic class of verbs. For instance, German has a small class of intransitive experiencer verbs with accusative marking, which is unusual for intransitives: mich friert 'I am cold', mich fröstelt 'I am shivering with cold'.

Among the various argument linking types one type is found that seems to be rather uneconomical: the portmanteau-type. A portmanteau affix simultaneously specifies more than one type of information. For instance, Latin passive is realized by a set of suffixes that inform us about both passive and person-number (ama-mini 'you (pl) are loved', with -mini '2pl.PASS'). Another type of portmanteau affix simultaneously specifies more than one argument. Hungarian uses the single suffix -lak/-lek to express the combination $\mathrm{I} \rightarrow$ you $^{1}$, similarly, Ayacucho Quechua uses the suffix $-y k i$ to express this combination, see $(1 \mathrm{a}, \mathrm{b})$.

$\mathrm{I} \rightarrow$ you portmanteau suffixes in Hungarian and in Quechua

a. szeret-lek 'I love you (sg/pl).'

b. riku-yki

'I see you.'

To express the combination I $\rightarrow$ you is very special because here the speaker 'acts upon' the addressee in the propositional content similar to the speech act itself, so it does not wonder that a portmanteau morpheme adapted to this special task is found in several languages. However, if all possible combinations of subject values and object values are expressed by portmanteaux, the number of these affixes increases, and it is not possible for the learner to make any separate generalizations about subjects and objects. That portmanteau affixes in general are uneconomic can be seen from a simple calculation. With three persons (1st, 2nd, and 3rd person) and two numbers (singular and plural) one would need at most 6 affixes for the subject and 6 affixes for the object (together 12 affixes); however, there are 28 possible combinations (if all reflexive settings such as $\mathrm{I} / \mathrm{we} \rightarrow \mathrm{I} / \mathrm{we}$ and you $\rightarrow$ you are excluded). The portmanteau linking type, therefore, is strongly disfavored.

However, Kiowa, a Tanoan-Kiowa language spoken in west central Oklahoma, obviously exhibits this type, as illustrated by the examples in (2). Here, the prefixes simultaneously specify person and number of the two arguments of a transitive verb (2a), and in addition, they specify the number (dual or plural) of a third argument (2b).

(2) Portmanteau prefixes in Kiowa: only one prefix is allowed. (Watkins 1984)

a. Transitive verbs: a single prefix encodes information about both arguments (góp 'hit').

\begin{tabular}{|c|c|c|c|}
\hline èm-góp & é-góp & dó-góp & gò-góp \\
\hline I hit you/him & you/he hit me & you/he/they hit us & we/he/they hit you \\
\hline èm: $1 \mathrm{sg} \rightarrow 2 \vee 3 \mathrm{sg}$ & é: $2 \vee 3 \mathrm{sg} \rightarrow 1 \mathrm{sg}$ & dó: $2 \vee 3 \rightarrow 1 \mathrm{pl}$ & gò: $1 \mathrm{pl} \vee 3 \rightarrow 2 \mathrm{sg}$ \\
\hline
\end{tabular}

The arrow is used to express subject $\rightarrow$ object information. 
b. Ditransitive verbs: a single prefix encodes information about all three arguments (o 'give', kut 'book')

\begin{tabular}{|c|c|c|c|}
\hline kút né-ó & kút nén-ó & kút bédê-ó & kút gyâ-ó \\
\hline $\begin{array}{c}\text { you/he gave me } \\
\text { two books }\end{array}$ & $\begin{array}{c}\text { I gave you/him } \\
\text { two books }\end{array}$ & $\begin{array}{c}\text { you }(\mathrm{pl}) \text { gave me/us/ } \\
\text { him two books }\end{array}$ & $\begin{array}{c}\text { they gave me/us/ } \\
\text { him some books }\end{array}$ \\
\hline né: $2 \vee 3 \mathrm{sg} / 1 \mathrm{sg} / \mathrm{dl}$ & nén: $1 \mathrm{sg} / 2 \vee 3 \mathrm{sg} / \mathrm{dl}$ & bédê: $2 \mathrm{pl} / 1 \vee 3 \mathrm{sg} / \mathrm{dl}$ & gyâ: $3 \mathrm{pl} / 1 \vee 3 \mathrm{sg} / \mathrm{pl}$ \\
\hline
\end{tabular}

The situation is not so bad from the perspective of the speaker (i.e., in terms of economy) because nearly all prefixes are ambiguous (e.g., cover both 2 nd person and $3 \mathrm{sg}$ ), but this is certainly not welcomed from the perspective of the hearer. Therefore, Kiowa is not a language that invites people to participate. Indeed, the population is small and isolated (according to the 1990 census, only about 1,000 middle-aged and older speakers out of a population of 6,000). Probably, the observed prefixes are the result of massive fusion (forced by the pressure towards 'one prefix only'), and the portmanteau type observed in this language is not a real candidate of typological variation.

In the following, I will disregard such extreme but unfelicitious cases and rather concentrate on the structural conditions that are frequent. I will start with prototypical transitive verbs in section 2 because these verbs belong to the core of a grammar. I will then turn to intransitive verbs, including their relationship to transitive ones, in section 3; properties of these verbs determine what is known as active-inactive type. Further argument linking types, which all are based on transitive verbs, are considered in section 4 . Section 5 demonstrates the possibility of marking special semantic classes by exploiting the morphosyntactic means available for a language. Finally, section 6 discusses how a third argument can be integrated, and thus extends the typology of section 4 .

\section{Prototypical transitive verbs are in the center of a grammar}

Transitive verbs seem to be one of the most ingenious inventions of human language, because they denote a relation between two participants of an event, and because this relation is structurally asymmetric. Therefore, transitive verbs are in the center of a grammar; if they were absent from the lexicon, a grammar would be much simpler than it actually is. Typical (or canonical) transitive verbs are chase, hit, kill, eat, kiss, and many more. Obviously they do not form a characteristic class by semantic similarities in a certain field of human activities (hunting-gathering, nourishing, social and sexual behavior), but rather reflect a very deep structural generalization (which must have been an important step in the evolution of human language). In addition, every language allows for the enrichment of the class of transitive verbs by less canonical items such as see, hear, meet, ask, obtain, surround, and furthermore, for the derivation of new transitive verbs such as enlarge and to open, although the languages widely differ in the details. So what is the common property of transitive verbs?

Canonical transitive verbs are two-place predicates with two clearly distinguished argument roles, which is illustrated with the verb eat in (3). ${ }^{2}$

2 We say that apple denotes a certain individual fruit, which is represented as $\lambda \mathrm{x}$ APPLE(x), where $\mathrm{x}$ counts as the referential argument of the noun. It is manipulated (specified and bound) by the functional categories on the noun, such as determiners and quantifiers (the apple, every apple). Similarly, one can say that eat denotes a certain individual event, which one would have to represent as $\lambda \mathrm{y} \lambda \mathrm{x} \lambda \mathrm{e} \operatorname{EAT}(\mathrm{x}, \mathrm{y})(\mathrm{e})$, where e counts as the referential argument of the verb. It is manipulated (specified and bound) by the functional categories on the verb, such as 
$\mathrm{x}$ (= the eater) is the higher argument, and $\mathrm{y}(=$ the eaten) is the lower argument.

The $\lambda \mathrm{s}$ abstract over these arguments, thus representing the argument roles or slots. These $\lambda$-roles $(\lambda \mathrm{y}, \lambda \mathrm{x})$ must be saturated in the course of composition, i.e. the two arguments must be realized by some linguistic expressions.

For instance, we can first apply 'eat' on 'the apple', and then apply the result on 'John', which yields 'John eats the apple'.
a. (eat the apple):
$\lambda \mathrm{y} \lambda \mathrm{x} \operatorname{EAT}(\mathrm{x}, \mathrm{y})($ the.apple $)=\lambda \mathrm{x} \operatorname{EAT}(\mathrm{x}$, the.apple)
b. (John (eats the apple)):
$\lambda \mathrm{x} \operatorname{EAT}(\mathrm{x}$, the.apple) $(\mathrm{John})=\operatorname{EAT}(\mathrm{John}$, the.apple $)$

An important observation is that transitive verbs are always asymmetric. It is easy to make a semantic distinction between the eater and the eaten, but to make a semantic distinction between the two persons who marry each other is not so easy. MARRY is a symmetric predicate (if John married Anne, than Anne also married John), nevertheless, the verb marry is in the same way grammatically asymmetric as eat: in 'John married Anne', 'John' realizes the higher argument, and 'Mary' the lower one. This is the cost for putting marry into the class of transitive verbs.

The source for the generalization yielding the concept of transitive verbs is of course semantic. In a prototypical transitive verb (such as eat rather than marry), the higher argument functions as agent or actor ('the participant which performs, effects, instigates, or controls the situation denoted by the predicate', Foley \& Van Valin 1984:29), while the lower argument functions as patient, or undergoer, or affected. Several theories have tried to postulate a semantic hierarchy of thematic or eventive roles, which is mapped onto a grammatical hierarchy (such as subject-object, nominative-accusative). Thematic hierarchies often include several possible roles such as agent, patient, theme, experiencer, beneficiary, recipient, goal, source, but it has controversially been discussed how these roles are demarcated and what their exact ordering is (Grimshaw 1990, Jackendoff 1990). There are two proposals that reduce the number of thematic roles to just two (in accordance with the fact that a transitive verb has two arguments): the two protoroles in Dowty's (1991) account are determined by the relative weight of several semantic factors, while the two macroroles (actor and undergoer) in the account of Foley \& Van Valin (1984) reflect both semantic and grammatical factors. Eventive roles (Pustejovsky 1991, among others) account for the participation of arguments in the possible subevents, such as an ungoing activity and a change of state. A summary is given in (5).

The asymmetry of transitive verbs

\begin{tabular}{|c|c|c|}
\hline hierarchy: & $\begin{array}{c}\text { the lower argument } \\
\text { (nearer to the verb) }\end{array}$ & the higher argument \\
\hline $\begin{array}{c}\text { protoroles: } \\
\text { macroroles: }\end{array}$ & $\begin{array}{c}\text { protopatient } \\
\text { undergoer }\end{array}$ & $\begin{array}{c}\text { protoagent } \\
\text { actor }\end{array}$ \\
\hline conceptual inferences: & affected & controller \\
\hline eventive roles: & specifies the result & $\begin{array}{c}\text { specifies the ongoing } \\
\text { activity }\end{array}$ \\
\hline
\end{tabular}

aspect, tense, and mood. Since this article is concerned with the argument structure of verbs, which I believe to be essentially independent of the verb's capacity to denote events, the referential argument of verbs is disregarded. 


\begin{tabular}{|c|c|c|}
\hline grammatical roles: & object & subject \\
\hline case (accusative system): & accusative & nominative \\
case (ergative system): & nominative & $-\mathrm{hr}$ \\
\hline features: & $+\mathbf{h r}$ & $+\mathbf{l r}$ \\
\hline
\end{tabular}

As a facon de parler, it is often convenient to use the semantic notions of agent vs. patient, or the more structural notions of subject vs. object. However, one must be careful for avoiding misinterpretations: in 'a wall surrounds the garden', the higher argument, namely 'the wall', is certainly not an agent semantically, and in 'the bear was killed', 'the bear' is considered to be the (grammatical!) subject, although it certainly functions as patient. The most neutral way is to encode the asymmetry (i.e. the hierarchy of roles) by two simple relational features: $+\mathrm{hr}$ 'there is another role which is higher than this one' (for short: 'there is a higher role') characterizes the lower argument, while $+1 \mathrm{lr}$ 'there is a lower role' characterizes the higher argument (Wunderlich 1997). ${ }^{3}$ These features, representing 'abstract case', have the advantage that their positive value corresponds to the information of morphological case: accusative bears the feature $+\mathrm{hr}$ (thus marking the lower argument), and ergative bears the feature $+\operatorname{lr}$ (thus marking the higher argument). The subject of an intransitive verb is designated as $-\mathrm{hr},-\mathrm{lr}$; therefore, neither accusative nor ergative are compatible with this argument. However, the nominative (bearing no feature specification) is compatible with an intransitive subject; it is indeed compatible with any argument. But in the morphology usually the most specific option is chosen: if accusative is possible, then it should be chosen.

This specification of accusative and ergative conforms to the traditional way in which these notions are used cross-linguistically. If the agent (A) is realized like the subject of an intransitive verb $(\mathrm{S})$, and the patient $(\mathrm{P})$ is realized differently (by means of a morphological case, a postposition, or a pronominal affix), the marker that encodes $\mathrm{P}$ is called 'accusative' (ACC). However, if $\mathrm{P}$ is realized like $\mathrm{S}$, and $\mathrm{A}$ is realized differently, the marker that encodes A is called 'ergative' (ERG), see (6). The respective other type of realization (regardless of whether it is specifically marked or simply unmarked, for instance, if the stem is used) is called 'nominative' (NOM).

\begin{tabular}{|c|c|c|}
\hline The definitions of & \multicolumn{2}{|c|}{ 'accusative' (ACC } \\
\hline & $\mathrm{ACC}$ & NOM \\
\hline intransitive & & $\mathrm{S}$ \\
\hline transitive & $P$ & A \\
\hline
\end{tabular}

vs. 'ergative' (ERG)
\begin{tabular}{|c|c|}
\hline NOM & ERG \\
\hline $\mathrm{S}$ & \\
$\mathrm{P}$ & $\mathrm{A}$ \\
\hline
\end{tabular}

The accusative is illustrated with a German example (7), and the ergative with Basque (8). Note that the auxiliar in Basque agrees with all the structural cases occurring with a verb; ' $E$ ' indicates agreement with ergative, and ' $N$ ' indicates agreement with nominative.

\footnotetext{
$+\mathrm{hr}$ could as well be spelled out as 'I am a lower role'. The particular choice of notation is due to a historical accident. In any case, the comparative features are different from Kiparsky's $(1992,1998)$ superlative features such as +HR 'I am the highest role' (which is identical to our -hr). The reason to deviate from Kiparsky's proposal is a more principled conception of markedness. As we will see in the following, the plus values in our system correlate with marked instances, and the minus values with unmarked instances. This is in line with phonological conventions according to which, e.g., a voiced consonant (such as d, b or $\mathrm{g}$ in contrast to $\mathrm{t}, \mathrm{p}, \mathrm{k}$ ) is marked by a plus value (+voiced) rather than by a minus value such as -voiceless.
} 
(7)

Accusative in German
a. intr.: Hans schläft.
'John sleeps.'
b. trans.: Hans sieht ein-en Mann.
John sees a-ACC man
'John sees a man.'

(8) Ergative in Basque
a. intr.
Jon joan da.
John go.PERF AUX.3N
'John went.'
b. trans.

$\begin{array}{lll}\text { Jon-ek zopa jan du. } & \text { zoup eat.PERF } & \text { AUX.3N.3sgE } \\ \text { John-ERG } & \text { soup } \\ \text { 'John ate the soup.' } & \end{array}$

The definition in (6) suggests that accusative and ergative are complementary to each other, so it must wonder why accusative and ergative are unevenly distributed among the languages of the world. Languages with accusative are more frequent than those with ergative. It seems that $\mathrm{A}$ is the more prominent argument, and that it is preferred to realize the more prominent argument by nominative because it can then function much easier as syntactic pivot, steering the formation of more complex structures (coordinations as well as subordinations such as relative clauses and verb + clausal complements, as in the so-called control verb construction of the type I want to see him). This inherent asymmetry is expressed by the scale $+\mathrm{hr}>+\mathrm{lr}$ 'It is better to mark a lower argument (an object) than a higher argument (the subject)', see section 4.4 below.

It is important to notice that accusative and ergative are not at all universal notions. Although the majority of languages seem to have developed some device that can properly be described by these terms, there are nevertheless many languages with well-defined argument linking types of different properties. It is therefore interesting to study these different types and to see how they frame possible generalizations of verb classes.

One further remark is at place here. Proponents of a semantic account to argument structure often deny that the arguments of a verb are strictly ordered. I think that conceptually such an assumption is much simpler than the alternative of assuming variation in ordering, or considering the arguments to be an unordered set. One reason is that a strict lexical ordering allows for a simple mapping onto linear syntactic order. As one can indeed observe, the default ordering in the syntax mostly conforms to argument hierarchy, regardless of whether the arguments are marked by case or not. For instance, in (7b) and (8b) the object follows the subject, and so it does in the respective English translations. Moreover, the Barss \& Lasnik (1986) tests - if properly adapted to the language under question - are able to identify the ranking of arguments independently in most cases. These tests include anaphoric binding, bound pronouns, weak crossover, negative polarity items, and multiple questions, and are briefly illustrated in (9).

(9) Tests for argument hierarchy. (The co-indexed expressions are assumed to refer to the same entity.)

a. The ape sees himself.

*Himself sees the ape.

b. All mothers like their $_{\mathrm{i}}$ baby.

*Their ${ }_{\mathrm{i}}$ mothers like all childs . $_{\mathrm{i}}$ 
c. Which man beats his $_{\mathrm{i}}$ son?

*Whose $\mathrm{i}_{\mathrm{i}}$ son did his $\mathrm{s}_{\mathrm{i}}$ father beat?

d. No one ate anything.

*Anyone ate nothing.

e. Who prefers what? What disturbs who?

*What does who prefer? *Who does what disturb?

These tests can also be applied to show the relative ordering of two objects in a verb with three arguments. It is still open to discussion to what extent these tests are sensitive to the semantic hierarchy of arguments, to a morphological asymmetry or to the linear syntactic order. I will come back to this issue in section 4.1 about inverse morphology.

\section{Intransitive Verbs reflect semantic classes}

Intransitive verbs are simpler than transitive ones because they have only one argument. As I pointed out above, a grammar does not start with the intransitives because they do not show the features of ordering and asymmetry. However, the intransitives are interesting for their own. They most clearly show the possibilities and effects of semantic classification, they constitute the basis of intransitivizing vs. transitivizing morphology, and they give rise to one of the major types of argument linking.

\subsection{Two or four classes of intransitive verbs?}

Regarding the grammatical behavior of intransitive verbs, many languages exhibit exactly two classes, whereby two types of semantic criteria play a role. In Lakhota, a Siouan language, one finds a distinction between agentive and nonagentive intransitives (10): in the 1 st or 2 nd person, agentive verbs encode their subject differently from nonagentive verbs (which is discussed in more detail in section 3.4). By contrast, in the Mayan language Yukatek one finds a distinction according to inherent aspect (11): inherently imperfective verbs take the perfect marker $-(n) a h$ but are unmarked in the imperfect, whereas inherently perfective verbs take the imperfect marker $-V l$ (with the vocalic segment $\mathrm{V}$ underlying vowel harmony) but are unmarked in the perfect.

(10) Intransitive verbs of Lakhota, ordered according to agentivity (Van Valin 1977)

$\begin{array}{llll}\text { a. } & \text { agentive verbs } & \text { b. nonagentive verbs } \\ \text { hi } & \text { arrive } & \text { hãska } & \text { be tall } \\ \text { iyotaka } & \text { sit down } & \text { hixxpaya } & \text { fall down } \\ \text { psica } & \text { jump } & \text { ile } & \text { burn } \\ \text { slohã } & \text { crawl } & \text { khata } & \text { be hot } \\ \text { thasosa } & \text { spit } & \text { puza } & \text { be dry }\end{array}$

(11) Intransitive verbs of Yukatek, ordered according to telicity (Krämer \& Wunderlich 1999)

a. inherently imperfective verbs

$\begin{array}{ll}\text { Paalkab }^{?} & \text { run } \\ \text { balak }^{?} & \text { roll } \\ \text { héPesíin }^{?} & \text { sneeze } \\ \text { kirits }^{2} & \text { squeak } \\ \text { naay } & \text { dream } \\ \text { nóok }^{?} & \text { snore } \\ \text { ook }^{2} \text { ot } & \text { dance }\end{array}$

b. inherently perfective verbs

$\begin{array}{ll}\text { Peem-el } & \text { descend } \\ \text { Pok-ol } & \text { enter } \\ \text { kim-il } & \text { die } \\ \mathrm{k}^{?} \text { uch-ul } & \text { arrive } \\ \text { lub }^{?} \text {-ul } & \text { fall } \\ \text { luk }^{2} \text {-ul } & \text { leave, escape, flee } \\ \text { naats }^{2} \text {-al } & \text { approach }\end{array}$




\begin{tabular}{|c|c|c|c|}
\hline tóos & rain & sih-il & be born \\
\hline Peh & laugh & $\mathrm{t} \int^{\mathrm{i}} \mathrm{iih}-\mathrm{il}$ & grow \\
\hline $\mathrm{ik}^{?}$ nal & fly & waak $^{?}$-al & explode, burst \\
\hline
\end{tabular}

Obviously, these two languages, Lakhota and Yukatek, make a different cut in the set of intransitives verbs. The two classes of Lakhota contain both inherently imperfective and inherently perfective verbs, and the two classes of Yukatek contain both agentive and nonagentive verbs. These examples thus suggest a semantic cross-classification of intransitive verbs into four classes, a classification which seems to be exhaustive, although most languages do not reflect all these possibilities in their grammar.

It has to be noticed that the intransitive classes of a language derive from certain generalizations forced by prototypical instances; however, in the course of lexicalization and subsequent semantic shift certain items may be 'wrongly' classified under the semantic perspective; they are said to be idiomatic. Furthermore, note that one of the classes of Lakhota includes statives, whereas the statives of Yukatek form a separate class.

The possible cross-classification in the set of intransitive verbs, suggested by the above examples, is summarized in (12), illustrated with some English verbs. The distinction agentive-nonagentive can be represented by the feature [control], which is associated with the subject of the verb; [+control] verbs denote an event that is brought about by an agent. Transversely, the distinction perfective-imperfective can be represented by the feature [telic], which is associated with the event denoted by the verb; [+telic] verbs denote an event that brings about a certain result. (Therefore, one could decompose these verbs by means of the predicate BECOME, so that DIE is represented as BECOME DEAD.) Since control is often associated with an on-going activity, and a result is often associated with a nonagent, there is a semantic correlation between [+control] and [-telic], and vice versa. Correspondingly, one finds more items in the [+control,-telic] class and in the [-control, + telic] class than in the two other ones.

\begin{tabular}{l} 
Cross-classification of intransitive verbs \\
\begin{tabular}{|l|l|l|}
\hline & $\begin{array}{l}\text { agentive }([+ \text { control] }]), \\
\lambda \mathrm{x}^{+ \text {contr }} \text { VERB }(\mathrm{x})\end{array}$ & $\begin{array}{l}\text { nonagentive [-control], } \\
\lambda \mathrm{x}^{- \text {-ontr }} \text { VERB(x) }\end{array}$ \\
\hline [+telic]; BECOME & $\begin{array}{l}\text { come, stand up } \\
\text { [-telic] }\end{array}$ & $\begin{array}{l}\text { unaccusatives': } \\
\text { arrive, die, fall, grow }\end{array}$ \\
\hline
\end{tabular} \\
\hline
\end{tabular}

In the syntactic literature, often a distinction is made between 'unaccusative verbs' and 'unergative verbs', considering them as would-be transitives. The 'unaccusatives' are considered to have an underlying object that cannot receive accusative; correspondingly, the 'unergatives' are considered to have an underlying subject that cannot be realized by ergative (just because accusative and ergative are special for transitive verbs). ${ }^{4}$ This distinction seems to correlate best with the two classes characterized by [+control,-telic] and $[-$ control,+telic]. The notion of an 'underlying object' of an intransitive verb, however, remains doubtful, since what is meant is a semantic distinction somewhat reflected in the grammatical behavior of verbs.

4 The unaccusative verbs were first called 'ergative' verbs (Burzio 1981, 1986, den Besten 1984, Keyser \& Roeper 1984). The notions 'unaccusative'/'unergative' go back to Perlmutter \& Postal (1984). 
Nearly every language shows some grammatical reflexes of unaccusativity vs. unergativity. In German, one finds a distribution of the properties given in (13) roughly into two classes, which have been associated with the notions 'unergative' and 'unaccusative' (Haider 1985). The members of one large class of intransitives can be passivized, can undergo er-nominalization, have haben 'have' as the perfect auxiliary, and their participles cannot function as attribute. The members of another large class of intransitives behave in every respect conversely: they cannot be passivized, cannot undergo er-nominalization, have sein 'be' as the perfect auxiliary, and their participles can function as attribute. This distribution is illustrated with the examples in (14).

(13) The grammatical behavior of intransitive verbs in German (tendencies)

\begin{tabular}{|l|c|c|}
\hline & $\begin{array}{c}\text { unergatives } \\
(+ \text { control,-telic })\end{array}$ & $\begin{array}{c}\text { unaccusatives } \\
(- \text { control,+telic })\end{array}$ \\
\hline have a passive & yes & no \\
undergo er-nominalization & yes & no \\
allow an attributive participle & no & yes \\
select the perfect auxiliary & haben & sein \\
\hline
\end{tabular}

(14)

\begin{tabular}{|l|l|}
\hline \multicolumn{1}{|c|}{ unergatives } & \multicolumn{1}{|c|}{ unaccusatives } \\
\hline Im Sommer wurde oft getanzt. & *Im Sommer wurde schnell gewachsen. \\
passive of 'In the summer they often danced.' & passive of 'In the summer they grew fast.' \\
die besten Tänzer & *die langsamsten Wachser \\
'the best dancers' & 'the slowest growers' \\
*die in der Luft getanzten Schmetterlinge & die am Haus gewachsenen Pflanzen \\
the in the air danced butterflies & the at the house grown plants \\
Sie haben oft getanzt. & Sie sind schnell gewachsen. \\
perfect of 'They danced often.' & perfect of 'They grew fast.' \\
\hline
\end{tabular}

However, as (15) illustrates, there are also verbs that undergo passive but select for the auxiliary sein 'be', and (16) illustrates verbs that do not undergo passive but select for the auxiliary haben 'have'. Aufstehen 'stand up' is both agentive and telic, whereas liegen 'lie' is both nonagentive and static.

(15) $[+$ control, +telic $]$ intransitives in German

a. Von niemandem wurde aufgestanden. passive of 'Nobody stood up.'

b. Er ist schnell aufgestanden. perfect of 'He stood up fast.'

(16) $[$-control,-telic] intransitives in German

a. *Von niemandem wurde im Bett gelegen. passive of 'Nobody lied in the bed.'

b. Er hat im Bett gelegen. perfect of 'He lied in the bed.'

These examples suggest that the possibility of passive depends on the feature [+contr], whereas the auxiliary sein 'be' is selected if the feature [+telic] is present. (Again, there may be idiomatic verbs for which no prediction can be made on semantic grounds.) If that is true, 
the set of the four criteria would be characteristic for the four classes in (12) rather than the two classes in (13), which have been suggested by syntacticians. Since er-nominalization patterns with the possibility of passive, and the possibility of an attributive participle patterns with the sein auxiliary, no more than four classes need to be assumed. These four classes turn out to be determined by semantic rather than syntactic criteria, as Kaufmann (1995a) has pointed out.

\subsection{The relationship between intransitives and transitives}

Many intransitive verbs can be transitivized, and many transitive verbs can be intransitivized. Some of these shifts have no overt marking on the verb. However, many languages have a transitivization marker, and often one finds two (or even more) of these markers: the causative, which adds an agent who functions as the causer, and the applicative, which adds an affected object of some sort (an object on which the results are spelled out, a beneficiary, a possessor, a location or even an instrument). The transitive verbs formed from intransitives are mostly prototypical in the sense of section 2 , and those that undergo intransitivization (either marked or unmarked) again are mostly prototypical transitives. Thus, the property of control can be assumed to play a crucial role: [+control] marks the presence of an agent, and [-control] marks the presence of an affected object. The relationship between transitives and intransitives can then be systematicized as in (17); this relationship is overwhelmingly symmetric.

(17) Intransitive-transitive shifts

\begin{tabular}{|c|c|cc|}
\hline & +control & -control \\
\hline intransitive & $\lambda \mathrm{x} \operatorname{VERB}(\mathrm{x})$ & $\lambda \mathrm{y}$ & $\operatorname{VERB}(\mathrm{y})$ \\
$\theta$ & $\theta$ & $\theta$ & \\
transitive & $\lambda \mathrm{y} \lambda \mathrm{x} \operatorname{VERB}(\mathrm{x}, \mathrm{y})$ & $\lambda \mathrm{y} \lambda \mathrm{x} \operatorname{VERB}(\mathrm{x}, \mathrm{y})$ \\
\hline
\end{tabular}

The four possibilities represented in (17) are the following:

(a) [+control] intransitives can add a lower argument, a so-called 'cognate' or 'internal' object (dream a nightmare, dance Tango);

(b) [-control] intransitives can add a higher argument, an agent or causer (dry the shirts, gallop a horse);

(c) transitive verbs with dominant subject-related meaning allow the object to be bound existentially (the so-called antipassive or object deletion), thus yielding a [+control] intransitive (he was eating, I can see again);

(d) transitive verbs with dominant object-related meaning allow the subject to be lacking (the so-called anticausative middle), thus yielding a [-control] intransitive (break, ring).

(18) illustrates these possibilities with examples from German.

intransitive transitive

a. Sie fuhr schnell. $\quad \rightarrow \quad$ Sie fuhr den Fiat schnell.

'She drove fast.' $\quad$ 'She drove the Fiat fast.'

b. Die Wäsche trocknete. $\rightarrow \quad$ Sie trocknete die Wäsche.

'The shirts dried.'

c. Sie aß langsam.

'She ate slowly.'
'She dried the shirts.'

$\leftarrow \quad$ Sie aß die Suppe langsam.

'She ate the soup slowly.' 


\section{d. Die Glocken läuteten. $\quad \leftarrow \quad$ Sie läutete die Glocken.' \\ 'The bells were ringing.' 'She rung the bells.'}

For [-control] verbs it is not always clear whether the basic verb is intransitive or transitive, i.e., whether it belongs to class (b) or (d). Intransitive trocknen 'dry' is a +telic verb derived from the adjective trocken 'dry', and denotes a process that takes place without human instigation; it is therefore feasible to classify it as basically intransitive. Verbs of this class can easily be transitivized, and this is the background to consider them to have an 'underlying object' - the subject of the intransitive verb becomes object of the transitive verb; thus, the transitive verb always has an object-related meaning. By contrast, läuten 'ring', although it also derives from an adjective (laut 'loud'), is [-telic]; it became idiomatic (for ringing bells) in the history of German and was already transitive in Old High German, denoting a process that usually needs a human instigator; it is therefore feasible to classify it as basically transitive. (This is not necessarily true for English ring.)

A further possibility not considered so far is that the two variants coexist, forming a hybrid verb. This can especially be expected for deadjectival verbs. From adjectives both intransitive and transitive verbs are derivable, and it is only due to conceptual reasons whether the verb is preferred to be intransitive (welken 'fade', reifen 'ripe') or transitive (leeren 'empty', öffnen 'open'); nothing excludes that both options are equally possible, regardless of whether they are differently marked or not. Such a hybrid pattern for deadjectival verbs could have been generalized to cover also underived verbs such as brechen 'break', which also has two options.

For the transitive variants of basically intransitive verbs it is evident that they are lexically decomposed. Class-a transitive verbs, derived from an agentive intransitive (an unergative) verb, not only add a cognate object but also some predicate that licenses this object. The predicate COGNATE in (19a) allows participants that have an internal relationship to the event denoted by the base predicate; e.g., possible cognates of DRIVE are vehicles (drive a car), transported persons/objects (drive the minister/the luggage), or distances (drive a mile). Similarly, class-b transitive verbs, being in variance with a nonagentive intransitive (an unaccusative) verb, have the predicate АCT (denoting some unspecific action) to license the causer/agent.

(19) The decomposition of transitive verbs derived from intransitives

a. fahren 'drive': $\quad \lambda \mathrm{y} \lambda \mathrm{x}^{+ \text {contr }}\{\operatorname{DRIVE}(\mathrm{x}) \& \operatorname{COGNATE}(\mathrm{y})\}$

b. trocknen 'dry': $\quad \lambda \mathrm{y}^{\text {-contr }} \lambda \mathrm{x}\{\operatorname{ACT}(\mathrm{x}) \& \operatorname{BECOME~DRY}(\mathrm{y})\}$

In general, transitive verbs can undergo the passive, which binds the subject existentially (be eaten, be broken), and they can undergo inherent reflexivization, which identifies the object with the subject (wash, dress). In the Germanic languages, the passive is marked by a synthetic construction (using an auxiliary), and it is possible for most derived transitives, as shown in (20). With respect to inherent reflexivization (21), German and English differ: German usually marks this operation by an overt reflexive, while English does not. (Note that English has no lexical reflexives such as sich schämen 'be ashamed', or sich fürchten 'fear'.)

(20) Passive of derived transitives of German and English

a. Das Auto wurde schnell gefahren.

'The car was driven fast.'

$\lambda \mathrm{y} \exists \mathrm{x}\{\operatorname{DRIVE}(\mathrm{x}) \& \operatorname{COGNATE}(\mathrm{y})\}$ 
b. Die Wäsche wurde im Garten getrocknet.

'The shirts were dried in the garden.'

$\lambda \mathrm{y} \exists \mathrm{x}\{\mathrm{ACT}(\mathrm{x}) \& \operatorname{BECOME} \operatorname{DRY}(\mathrm{y})\}$

(21) Inherent reflexives

a. Das Auto fuhr sich gut.

the car drove itself well

'The car drove well.'

b. Die Haare trockneten sich mühsam.

the hairs dried themselves troublesome

'It was troublesome to dry the hair.'

Cross-linguistically, the relationship between intransitives and transitives is subject to great variation. Some languages always mark transitive verbs by means of a transitivization affix, other languages classify into basic intransitives and basic transitives, but they always mark a shift. There are also languages that mark a shift only in a few instances (such as German in the inherent reflexives). At the extreme end, one may find languages that never mark a shift. Near to this extreme is Basque, which never marks intransitivization, as illustrated in (22b). The intransitive use of 'clean' has two readings: the passive reading (i), and the inherent reflexive reading (ii); these readings are made explicit by proper semantic representations.

(22) Intransitive readings in Basque (Joppen \& Wunderlich 1995:144)
a. Jon-ek kotxe-a garbi-tu du. John-ERG car-DET clean-PERF AUX.3N.3sgE
b. Garbi-tu da. clean-PERF AUX.3N
i. 'Someone cleaned it.'
$\lambda \mathrm{y} \exists \mathrm{x}\{\operatorname{ACT}(\mathrm{x}) \& \operatorname{BECOME} \operatorname{CLEAN}(\mathrm{y})\}$
ii. 'He cleaned/washed himself.'
$\lambda \mathrm{x}\{\operatorname{ACT}(\mathrm{x}) \&$ BECOME CLEAN $(\mathrm{x})\}$

Basque also has a class of hybrid verbs that shift between intransitive and transitive readings without any marking (including igo 'move.up/take.up', jais 'move.down/take.down', hil 'die/kill.PERF', among others), as shown in (23).

(23) Intransitive-transitive hybrids in Basque (Joppen \& Wunderlich 1995:143)
a. Jon igo-tzen da.
John move.up-IMPF AUX.3N
'John moves up.'
b. Jon-ek maleta-k igo-tzen ditu.
John-ERG suitcase-pl take.up-IMPF AUX.3plN.3sE
'John takes the suitcases up.'

However, Basque also has developed the causative morpheme -eraz (from the verb eragin 'make/let'), which is productively used with all types of verbs. For the hybrid class of verbs one can assume that the transitive member is causativized without marking, probably because these verbs are historically old. If these verbs are intransitively used, they receive the two intransitive readings available for all transitive verbs (as demonstrated in (22b)), and furthermore, a third 'anticausative' reading because of their nature as hybrids (iii). 
(24) Three intransitive readings with Basque hybrids (Joppen \& Wunderlich 1995:144) Itziar hil da. Itziar die/kill.PERF 3N.AUX

i. 'Someone has killed Itziar.' $\quad \lambda y \exists x\{\operatorname{ACT}(x) \& \operatorname{BECOME} \operatorname{DEAD}(\mathrm{y})\}$

ii. 'Itziar has killed herself.' $\quad \lambda \mathrm{x}\{\operatorname{ACT}(\mathrm{x}) \& \operatorname{BECOME~} \operatorname{DEAD}(\mathrm{x})\}$

iii. 'Itziar has died.' $\quad \lambda y \operatorname{BECOME~} \operatorname{DEAD}(\mathrm{y})^{5}$

Thus, the lack of a covert device necessarily produces ambiguity, which has to be resolved by the respective contexts.

\subsection{On the possible decomposition of transitive verbs}

As we have seen above, transitive verbs derived from intransitive ones (or from intransitive adjectives) can be decomposed into at least two predicates, one that characterizes the higher argument (the subject), and another one that characterizes the lower argument (the object). The question is whether a similar decomposition is also possible for basic transitives. There are indeed two classes of verbs where this seems to be possible, the production and the annihilation verbs. Production verbs denote an event in which something comes into existence, while annihilation verbs denote an event in which something vanishes. Thus, 'bake a cake' could be analyzed that a cake comes into existence by the activity of baking, and 'eat a cake' - that a cake disappears by the activity of eating. (The naive ontology incorporated into a language does not necessarily conform to the law of mass preservation!) This proposal is represented in (25).

(25) Production and annihilation verbs

a. bake: $\lambda \mathrm{y} \lambda \mathrm{x}\{\operatorname{BAKE}(\mathrm{x}) \& \operatorname{BECOME} \operatorname{EXIST}(\mathrm{y})\}$

b. eat: $\quad \lambda \mathrm{y} \lambda \mathrm{x}\{\operatorname{EAT}(\mathrm{x}) \&$ BECOME NON-EXIST $(\mathrm{y})\}$

However, nothing in the grammatical behavior of these transitive verbs hinges upon such a decomposition; one could as well consider bake and eat to be non-decomposed. Moreover, there are many transitive verbs (such as love, hit) for which a decomposition doesn't make sense. Therefore, for the time being, I assume that basic transitive predicates (such as LOVE, HIT) do exist. I find Kratzer's (1996) proposal that transitive verbs are basically intransitive and add an agent only by means of the active voice not particularly illuminating (for more specific critical remarks, see Wunderlich 2001).

\subsection{The active-inactive type of argument linking}

The semantic classification of intransitive verbs can also be transferred to transitive verbs, which is motivated by the fact that the subject usually is the controller and the object the affectee. Various indigenous American (Amerindian) languages have two sets of pronouns or pronominal affixes to be attached to the verb: items of one set are used to mark a 1st or 2nd person transitive subject, while items of the other set are used to mark a 1st or 2nd person object. (The 3rd person usually is unmarked, except in the plural.) If it comes to mark the only argument of an intransitive verb, items of both sets can be used, depending on whether it is more similar to the subject or to the object of a transitive verb. These markers can neither be said to be accusative nor to be ergative because there is a clear split in the intransitives and the definition given in (6) of section 2 fails. Therefore, this type of

\footnotetext{
It is a matter of dispute how this medial reading is derived (see Kaufmann 2004).
} 
argument linking is assumed to reflect the active or inactive status of an argument rather than its position in the argument hierarchy. ${ }^{6}$

For illustration, (26) represents the full set of personal affixes of Dakota, a group of Siouan dialects spoken in North and South Dakota as well as in other regions in the US and Canada. In the dual 'I and you (sg)' no distinction is made. There are three further affixes: $w i c^{h} a$-, which is only used for animate $3 \mathrm{pl}$ objects (and therefore can truly be classified as accusative), - pi, which is separated from person and encodes plural, and the portmanteau prefix $c^{h} i$ - to be used for the special communicative situation $1 \rightarrow 2$.

Personal affixes of Dakota (Schwartz 1979)
\begin{tabular}{|c|c|c|c|}
\hline & active [+act] & inactive [-act] & accusative [+hr] \\
\hline 1 & wa- & ma- & - \\
\hline 2 & ya- & ni- & - \\
\hline 1dl.incl & \multicolumn{3}{|c|}{$\tilde{\text { u}}(\mathrm{k})-$ - } \\
\hline 3pl.anim & - & - & - \\
\hline
\end{tabular}

-pi : Plural $[+\mathrm{pl}]$

$\mathrm{c}^{\mathrm{h}_{\text {i- }} \text { : Portmanteau } 1 \rightarrow 2}$

The use of these affixes is demonstrated in (27) to (29). It should become clear from these examples that the prefix ma- ' 1 sg' can mark the subject of an intransitive verb, the patient (object) of a transitive verb, and the recipient of a ditransitive verb. Therefore one can conclude that ma-encodes the inactive status of the 1st person rather than its semantic role (as patient or recipient) or its grammatical function (as subject or object).

(27) Intransitive verbs in Dakota
a. wa-niwa
'I swim'
wa-niwa-pi
'we swim'
b. ma-t'a 'I die'
ma-t'a-pi 'we die'
(Active)
(Inactive)

(28) Transitive verbs in Dakota
a. wa-kte 'I killed him' wic $^{\mathrm{h}} \mathrm{a}-\mathrm{wa}$-kte
'I killed them'
b. ma-kte 'he killed me' ma-kte-pi 'they killed me'/'he killed us'
c. ma-ya-kte 'you killed me'

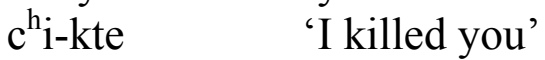

(Active)

(Inactive)

(Mixed)

(29) Ditransitive verbs in Dakota
a. wa-k'u wich ${ }^{\mathrm{h}} \mathrm{a}-w a-k$ 'u
'I gave it to him'
b. ma-k'u ma-k'u-pi

(Active)

(Inactive)

\footnotetext{
6 Actually, one needs more evidence for the conclusion that we have it to do with the active type. Chocktaw, a Muskogean language of Oklahoma and Mississippi, has a similar split in the intransitives. Nevertheless, the markers on the Chocktaw verb are classified as accusative (applied to inactive intransitives) and nominative (applied to active intransitives) because there exists a third set of markers, namely dative (Davies 1986). Dakota and the other languages subsumed under the active type do not have such a third set of markers. We assume that the accusative-marked intransitives of Chocktaw are lexically marked (see section 5 below).
} 


$$
\begin{array}{ll}
\text { c. ma-ya-k'u } & \text { 'you gave it to me' } \\
\text { chi-k'u } & \text { 'I gave it to you' }
\end{array}
$$

(Mixed)

As one can see from these examples, the argument role of a 1 st or 2 nd person is always made explicit; thus, the main task of an argument linking device is fulfilled. (The role of a 3rd person singular, however, must be specified by additional syntactic nominals.)

One clear disadvantage of this type of argument linking is the necessity of classifying intransitive verbs according to their semantic properties. What are the exact conditions under which a verb is classified into the active class? Mithun (1991) investigated for a number of active type languages which semantic factor is responsible for the active/nonactive classification of intransitive verbs. Some of her results are summarized in (30): active ([+act]) is the marked option for dynamic verbs in Guaraní (a Tupi-Guarani language spoken in Argentina, Bolivia and Paraguay), for verbs with a participant which instigates the situation denoted by the verb (Lakhota) or controls it (Caddo in Western Oklahoma), or for an inherently imperfective verb with an agent argument in a broad sense (Mohawk, an Iroquoian language of Canada). Only in Central Pomo (which belongs to the Pomoan family), [+affected] of human beings (corresponding to [-act]) is the marked option. The complementary class always contains all other verbs (including the borderline cases), and is thus the default class. Inherently stative verbs are [-act] in Guaraní, Lakhota, Caddo and Mohawk, but [-aff] (corresponding to [+act]) in Central Pomo.
a. Guaraní:
dynamic $[+$ act $]$
b. Lakhota:
instigator $[+$ act $]$
c. Caddo:
controller $[+\mathrm{act}]$
vs. stative $[-$ act $]$
d. Mohawk:
agent \& non-perfect [+act]
vs. non-instigator [-act]
e. Central Pomo: non-patient [-aff]
vs. non-controller [-act]
vs. non-agent or perfect [-act]
vs. patient [+aff]

This variation demonstrates the difficulties to support a split that is required for grammatical reasons by a semantic partition. As a reaction to these problems, the intransitive split is often lexicalized in the course of historical development, so that the decision becomes independent of semantic factors. This is observed for Cherokee (an Iroquoin language) by Scancarelli (1987). (Similar observations have been made for the choice of sein 'be' as the perfect auxiliary in German, which is often lexicalized.)

On the other hand, a semantic split allows one to distinguish between the possible readings of an intransitive verb, as shown in (31) for Lakhota. In quite a similar way the choice of the German perfect auxiliary sometimes can distinguish between possible readings of a verb, as shown for the same semantic contrast in (32).

(31) Different semantic readings for an intransitive verb in Lakhota (Foley \& van Valin 1984:96)
a. wí cexélka
1sg.INACT slip/slide
b. há: cexélka
'I'm slipping.'
1sg.ACT slip/slide
'I'm sliding.'

(32) Different semantic readings for an intransitive verb in German
a. Er ist gerutscht.
b. Er hat gerutscht.
he is slipped/slid
'He was slipping.'
he has slipped/slid
'He was sliding.'

Furthermore, if the feature [+act] (or conversely, [+aff]) is semantically interpreted, it becomes possible to mark exceptions from canonical transitive verbs. For instance, 
transitive experiencer verbs of Lakhota can be marked by means of double-inactive, as shown in (33).

(33) Double-inactive in Lakhota (Mithun 1991)

i-ni-ma-ta

?-2.INACT-1.INACT-PROUD

'I am proud of you'

For Central Pomo not only double-inactive verbs (34a) but also double-active verbs are reported; with regard to the latter we have to assume that no participant is affected (34b).

(34) Double-inactive and double-active in Central Pomo (Mithun 1991)

a. to=wa mto 'yáqan?

1.INACT $=\mathrm{Q}$ 2.INACT remember

'Do you remember me?'

b. mul ?a 'yáq-an-ka-w chó-w.

3.ACT 1.ACT remember-IMPF-CAUS-PERF not-PERF

'I couldn't think of him.'

These observations suggest that the semantic reading of the active or inactive markers is the most relevant factor. However, Central Pomo also allows a person-related split in a certain class of emotional verbs; here, the 1st person (higher in its person status) is always marked as affected (i.e. inactive), regardless of whether he/she functions as the source or target of emotion $(35 \mathrm{a}, \mathrm{b})$. It is obvious that a quite different semantic factor must be at work here, because a 3rd person could be as much affected as a 1 st person.

(35) Person-related split in Central Pomo (Mithun 1991)

a. Mul qadála to 'údaw.

3.ACT hate=IMMEDIATE 1.INACT really

'I [+aff] really hate him [-aff]'

b. To qadál-m-ad=a mul.

1.INACT hate-NON.EMPATHETIC-IMPF=IMMEDIATE 3.ACT

'He [-aff] hates me [+aff]'

Therefore, it seems to be more appropriate to consider the inactive marker to be associated with a grammatical rather than a semantic feature, which then invites for contextual conditions of arbitrary semantic nature, so that something like the person-related split of Central Pomo can have evolved.

This conclusion is supported by the observation that the 'different subject' (DS) marking of Lakhota not only reflects differences in the reference to persons but also about their active/inactive status. (36a) illustrates coordination by means of the 'same subject' marker $-y$; here, one and the same person is active in both events. In (36b) the DS marker -qan encodes that two different persons are involved, whereas in (36c) it encodes that just one person is active in one but inactive in the other event - therefore the $1 \mathrm{sg}$ person must be repeated.

(36) Coordination in Lakhota (Foley \& van Valin 1984:119)
a. Há:
káluhu-y
si:má:mérqaki:hi.
1sg.ACT go-home-SS went.to.bed
'I went home and then went to bed.' 
b. Há: káluhu-qan mí:p mérqaki:hi.

1sg.ACT go-home-DS 3sg.ACT went.to.bed 'I went home and he went to bed.'

c. Há: xá: qákki-qan wi qa:lál tá:la.

1 sg.ACT water bathe-DS 1sg.INACT sick.become

'I took a bath and got sick.'

\section{Further argument linking types in transitive verbs}

In this chapter, four further types of argument linking are introduced. The inverse type (section 4.1) encodes whether the subject or the object is higher on a person scale than the respective other argument; that is, two independent scales are mapped onto each other, and this ingenious solution makes it possible that in principle only one set of person affixes is needed. By contrast, in the salience type (section 4.2) several sets of person affixes are needed, one for each semantic or grammatical role if it is the most salient one; this type exhibits certain similarities with the voice type, and therefore I put them together. In the positional type (section 4.3) it is the syntactic position that is grammaticalized for certain arguments, and no person affixes are needed. Finally, the by far largest type is the generalized case type (section 4.4), including several varieties of accusative and ergative marking systems. Implicit in the distinction of these types is the claim that they cannot be reduced to each other, and also cannot be seen as subtypes of a more comprehensive type on an abstract level. Only the positional type could in a certain perspective be related to accusative. And the salience or voice type, which is still badly defined, could turn out either as a subclass of another type or as the collection of several, hitherto undetected well-defined but distinct types. No one has ever tried to make a survey which to some extent is complete.

\subsection{The inverse type}

The inverse type of argument linking is best-known from the Algonquian languages, which stretch from Labrador south into present North Carolina and west across the Plains into Alberta and Montana; Plains Cree, the language with which we will illustrate this type, belongs to a group of Canadian dialects stretching westwards. Most remarkable for the Algonquian languages is the way in which the roles of subject and object are determined for verbs with two animate arguments (TA). Consider (37a) with the reading 'we see the dog', and (37b) with the inverted reading 'the dog sees us': this difference is triggered by the theme (or voice) markers that directly follow the stem, whereas the person-number morphemes are not altered. $/-\bar{a} /$ is called a 'direct' morpheme (where the higher person is subject), and /-ikw/ is called an 'inverse' morpheme (where the higher person is object). By contrast, transitive inanimate stems (TI) do not undergo such an alternation because an inanimate object can never become subject of 'see', see (37c).

(37) Transitive verbs in Plains Cree (Wolfart 1973, Wolfart \& Carroll 1981, Dahlstrom 1991, Fabri 1996)

a. Ni-wāp-am-ā-nān atim.

1- see-TA-DIR-1pl dog

'We see the dog.'

b. Ni-wāp-am-iko-nān atim.

1- see-TA-INV-1pl dog

'The dog sees us.' 
c. Ni-wāp-aht-ē-naan.

1 -see-TI-LOC.PERS-1 $\mathrm{pl}$

'We see it.'

A first observation concerns the central role of animacy. Plains Cree classifies transitive verbs according to whether the object is animate or inanimate by means of derivational suffixes. Similarly, intransitive verbs are classified according to whether their subject is animate or inanimate. (38) shows some derived stems of Ojibwe (a related Algonquian language), which are based on the adjectival root biin 'clean'.

Some derived stems in Ojibwe (Valentine 2001)
\begin{tabular}{|l|c|c|c|}
\hline & animate & inanimate & \\
\hline Intransitives: the subject is ... & biin-zi (IA) & biin-ad (II) & 'be clean' \\
\hline Transitives: the object is ... & biin-ih (TA) & biin-toon (TI) & 'make clean' \\
\hline
\end{tabular}

These four classes of verbs are differently inflected insofar as only animates can be 1st or 2nd person. There is only one set of person-number affixes available, and these affixes always fill the same positions. The transitive animate verbs therefore need a further device for determining whether an affix relates to the subject or the object.

One can furthermore see a strong person hierarchy at work. In the prefixes, 2 nd person has preference over 1st person, as attested by the examples in (39) in which 1st and 2nd person are combined (1st inclusive person refers to 'I and you'); and both these persons have preference over 3 rd person. This suggests the scale $2>1>3$.

(39) Preference of 2nd person is Plains Cree
a. Ki-tasam-i-n.
b. Ki-tasam-iti-n.
2-feed-DIR-1
2-feed-INV-1
'You feed me.'
'I feed you.'
c. Ki-tasam-i-nān.
d. Ki-tasam-iti-nān.
2-feed-INV-1pl
e. Ki-tasam-ā-naw.
2-feed-DIR-1pl
'We feed you(sg/pl).'
2-feed-DIR-1.incl
'We (incl.) feed him.'

In the suffixes, however, it is preferred to express the plural of the 1st person rather than that of the 2nd person, as shown by $(39 \mathrm{c}, \mathrm{d})$; accordingly, one has to postulate the scale $\mathrm{pl} / 1$ $>\mathrm{pl} / 2$.

In addition, all 3rd person arguments must be ranked to each other. Only one proximate 3rd person (the foregrounded one) is possible in a certain stretch of discourse, all other 3rd persons must be obviative (sometimes called 4th person) and cannot be marked for plural. Obviative must be marked on nouns or noun phrases, too, so that the hearer gets informed about the obviation status of a nominal referent. It mostly suffices, however, to use verb forms in order to indicate the grammatical role of the participants. The use of /-ê/ and /-ikw/ in (40) is consistent with the ranking $3>$ obv.

Obviative in Plains Cree
a. wāpam-è (w)-ak
see-DIR-3pl
'They see him ${ }_{\text {obvv. }}$
b. wāpam-ikw-ak
see-INV-3pl
'He ${ }_{\text {obv }}$ sees them.'

As has become evident up to now, the grammatical function of the person-number morphemes in TA-verbs wholly depends on the theme marker directly attached to the stem. The set of theme markers in the independent mode (characterizing unembedded sentences) is represented in (41); all instances below the shadowed diagonal encode direct 
constellations (where the subject is higher on the person scale than the object), whereas all instances above it encode inverse constellations (where the subject is lower than the object). The person hierarchy is extended here to $2>1>3>\mathrm{obv}>$ inanimate, so including further variants of the $3^{\text {rd }}$ person. It is never possible that subject and object have an equal person status; note that reflexives in which subject and object are identical are realized by intransitive verbs.

Theme markers in Plains Cree (independent forms)

\begin{tabular}{|c|c|c|c|c|c|}
\hline $\mathrm{O} \backslash \mathrm{S}$ & 2 & 1 & 3 & obv & inanimate \\
\hline 2 & & -iti & & \multirow{3}{*}{-ikw } & \\
\hline 1 & $-i$ & & & & \\
\hline 3 & \multicolumn{2}{|c|}{$-\bar{a}$} & & & \\
\hline obv & \multicolumn{2}{|c|}{-im-ā } & $-\overline{\mathrm{e}}$ & more forms & \\
\hline inanim & \multicolumn{2}{|c|}{$-\overline{\mathrm{e}}$} & & & \\
\hline
\end{tabular}

To account on the function of the theme markers more formally, one can introduce the feature [+hp] 'there is a higher person', which expresses relative salience analogously to the feature $[+\mathrm{hr}]$ 'there is higher role'. The theme marker then associates one of the argument roles with this feature. More precisely, a direct marker associates the lower role with this feature, while an inverse marker associates the higher role with this feature. This is shown in (42).

$$
\begin{array}{llll}
\text { a. direct } & & \\
& \lambda y & \lambda x & \operatorname{VERB}(x, y) \\
& +h r & -h r & \\
-\bar{a}: & +h p & & \\
& 3 & 1 &
\end{array}
$$

b. inverse

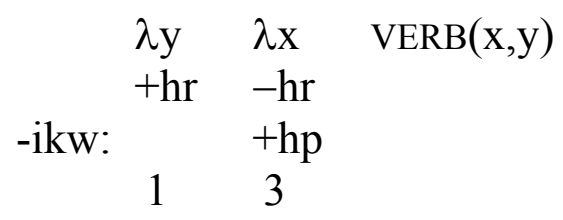

The last line indicates a possible distribution of person values. The direct voice is compatible with the $1^{\text {st }}$ person assigned to the higher role (the subject), whereas the inverse voice requires the $1^{\text {st }}$ person to be assigned to the lower role (the object).

In principle it would be possible to have only one direct and one inverse marker. Actually, however, there are several markers. They can be represented as partly generalized portmanteau morphemes bearing information about both arguments, as shown in (43); only $-i k w$ is a fully generalized inverse morpheme.

\begin{tabular}{lll}
\multicolumn{2}{l}{ Theme markers } & \\
direct & $-\overline{\mathrm{a}}$ & $1 / 2 \rightarrow 3$ \\
& $-\mathrm{i}$ & $2 \rightarrow 1$ \\
& $-\overline{\mathrm{e}}$ & $3 \rightarrow \mathrm{obv}$ \\
inverse & $-\mathrm{ikw}$ & $\mathrm{INV}$ \\
& $-\mathrm{iti}$ & $1 \rightarrow 2$
\end{tabular}

$$
\begin{aligned}
& \text { +hp/+hr } \\
& +\mathrm{hp},+1 /+\mathrm{hr} \\
& +\mathrm{hp},+ \text { obv/+hr } \\
& \text { +hp/-hr } \\
& \text { +hp, +1/-hr }
\end{aligned}
$$

Indeed, theme markers (that also classify verbs according to the semantic value of their arguments) may have been derived from former portmanteau morphemes, thereby regularizing the inflectional patterns. Dahlstrom (1988) reports that the conjunct (dependent) forms of Plains Cree underwent a rapid change during the second half of the 
$19^{\text {th }}$ century. (The conjunct forms lack a person prefix, but instead have sometimes an initial conjunct marker, $\bar{e}-$ or $k \bar{a}$-.) Presently they exhibit the same theme markers as the independent forms (except some combinations with $1 \mathrm{sg}$ and $2 \mathrm{sg}$, which lack a theme marker), but that was not always the case: they showed much more irregular portmanteaus in the 1855 translation of the Gospel according to St. John.

As a whole, the morphology of the inverse type can be described as symmetric. The lexical asymmetry of transitive verbs is outbalanced by the person hierarchy, so that, disregarding the theme markers, no asymmetry remains: each person-number affix can relate to either subject or object.

The conjunct forms are interesting also for another point. Since they do not have a position for a person prefix (because this position is used to encode the conjunct status), ambiguities would arise if only the suffixes known from the independent forms were available. The conjunct forms indeed exhibit more person-number suffixes, and some of them (in forms without a theme marker) are truly portmanteau morphemes, as illustrated in (44).

(44) Singular conjunct forms in Plains Cree
a. è-wāpam-at
b. ē-wāpam-isk
CONJ-see-2sg $\rightarrow 3$ sg
'that you saw him'
CONJ-see-3sg $\rightarrow 2 \mathrm{sg}$
'that he saw you'

In principle it seems possible that portmanteau forms collapse, for instance, $3 \rightarrow 2 \mathrm{sg}$ and $1 \rightarrow 2$ sg could be expressed by the same suffix; such a suffix would have to be classified as 2sg.accusative. The sporadic emergence of accusative morphemes indeed has been observed, although not in Cree. But in the conjunct mood of Ojibwe (dialect of Manitoulin Island, Lake Huron), the two accusative morphemes $-i$ (1.ACC) and -inin (2.ACC) have developed (Valentine 2001). These morphemes, interesting as they are, must nevertheless be judged as sporadic because similar morphemes have already been attributed to ProtoAlgonquian by Goddard (1979), but the general system obviously was robust enough to reject further generalization of accusative.

Recall that every use of a transitive verb requires a different person status of the two arguments in order to outbalance the subject-object asymmetry. If two nouns are expressed in a clause (such as 'man' and 'duck' in (45)), one must be marked as obviative. Together with the possibility of direct vs. inverse marking, this leads to four versions, demonstrated in (45).

(45) Four-way transitive alternation in Plains Cree (Wolfart 1981:30)

a. wāpam-ēw nāpēw siisiip-a.

see-DIR man duck-OBV

'The man sees the duck (obv)'

b. wāpam-ik nāpēw siisiip-a.

see-INV man duck-OBV

'The duck (obv) sees the man' [ $\approx$ 'The man is seen by the duck']

c. wāpam-ēw nāpēw-a siisiip.

see-DIR man-OBV duck

'The duck sees the man (obv)'

d. wāpam-ik nāpēw-a siisiip.

see-INV man-OBV duck

'The man (obv) sees the duck' [ [“'The duck is seen by the man'] 
Although passive may be used to properly translate the inverse construction, the latter would wrongly be classified as 'some kind of passive'. Besides the transitive inverse form, Cree has an impersonal passive, in which the transitive animate stem is inflected intransitively, shown in (46).

$$
\begin{aligned}
& \text { wāpam-aw nāpēw / siisiip. } \\
& \text { see-3 man / duck } \\
& \text { 'The man/the duck was seen.' }
\end{aligned}
$$

Moreover, the inverse construction does not alter the syntactic status of the two arguments. This conclusion is forced by the observation that Plains Cree does not show any syntactic subject-object asymmetry of the kind known from English or other case-based languages (Dahlstrom 1991). English exhibits so-called weak cross-over effects: for instance, a subject can bind the possessor of the object (47a), while the object cannot bind the possessor of the subject (47b); the intended meaning of (47b) can only be expressed by the passive in (47c).

(47) Weak cross-over effects in English
a. Anna loves her $_{\mathrm{i}}$ son.
Which $_{\mathrm{i}}$ woman loves her ${ }_{\mathrm{i}}$ son?
b. ${ }^{*} \operatorname{Her}_{\mathrm{i}}$ son loves Anna ${ }_{\mathrm{i}}$.
*Which i $_{\text {woman does }}$ her $_{\mathrm{i}}$ son love?
c. Anna is loved by her i $_{\mathrm{i}}$ son.
Which ${ }_{i}$ woman is loved by her ${ }_{i}$ son?

No such restriction holds for Plains Cree. Not only the subject can bind the possessor of the object, but also the object can bind the possessor of the subject, as shown in (48b). ${ }^{7}$

(48) No weak cross-over effects in Plains Cree (Dahlstrom 1991: 99)
a. kahkiyaw iskwēw-ak sākih-ē-w-ak o-tānis-iwāw-a.
all woman-pl love-DIR-3-pl 3P-daughter-3plP-OBV
'All women love their $_{i}$ daughters.'
b. kahkiyaw iskwēw-ak sākih-ik-w-ak o-tānis-iwāw-a. all woman-pl love-INV-3-pl 3P-daughter-3plP-OBV

'Their ${ }_{\mathrm{i}}$ daughters love all $_{\mathrm{i}}$ women.' [ $\approx$ All women are loved by their daughters.]

This binding property is independent of position. The sentences in (49) are positional variants of (48b) but get the same reading.

(49) Different positions of quantifier and nouns (Dahlstrom 1991: 99,87).

a. o-tānis-iwāw-a sākih-ik-w-ak kahkiyaw iskwēw-ak.

3P-daughter-3plP-OBV love-INV-3-pl all woman-pl

'Their ${ }_{\mathrm{i}}$ daughters love all $\mathrm{i}_{\mathrm{i}}$ women.' [ $\approx$ All women are loved by their daughters.]

b. kahkiyaw sākih-ik-w-ak o-tānis-iwāw-a iskwēw-ak.

all love-INV-3-pl 3P-daughter-3plP-OBV woman-pl

'Their ${ }_{\mathrm{i}}$ daughters love all $_{\mathrm{i}}$ women.' [ $\approx$ all women are loved by their daughters.]

(49b) shows quantifier floating, with the quantifier in focus position before the verb. As Dahlstrom (1991) has pointed out, quantifier floating in Plains Cree is only possible for object quantifiers - thus, 'all woman' is a true object.

There are of course no logical restrictions for weak cross-over. Both formulas in (50), representing the meanings of $(48 \mathrm{a}, \mathrm{b})$, are sound.

7 The possessor of a noun is considered to be more salient than the possessed; therefore, the possessed noun usually gets an obviative marking. 
a. $\forall \mathrm{x} \forall \mathrm{y}$ [WOMAN(x) \& DAUGHTER_OF_x $(\mathrm{y}) \rightarrow \operatorname{LOVE}(\mathrm{x}, \mathrm{y})]$

b. $\forall \mathrm{x} \forall \mathrm{y}[\operatorname{WOMAN}(\mathrm{x}) \&$ DAUGHTER_OF_x $(\mathrm{y}) \rightarrow \operatorname{LOVE}(\mathrm{y}, \mathrm{x})]$

Nevertheless, (50b) cannot be expressed by an English active sentence. English, like many other languages, has acquired a syntactic notion of 'subject' and 'object', which is lacking in Plains Cree. Unlike English, 'subject' in Plains Cree always refers to the highest argument; neither case nor position can help us to identify the subject; only the theme marker determines which argument functions as subject. Therefore, disregarding all superficial differences, it is correct to say that inverse morphology represents a type of argument linking of its own, it neutralizes subject-object asymmetry and is therefore incompatible with case. A change into a case system is improbable, even if sporadic generalization to accusative may occur. We are unable to see Plains Cree as a mere 'notational' variant of English.

On the other hand, inverse morphology is clearly a marked option. It can emerge only under very specific circumstances, including head marking, a rigid classificatory system of verbs related to argument properties, a strong person hierarchy, and the existence of personnumber morphemes that are not specified for grammatical functions.

The major classification of verbs, being forced by the inverse morphology, is into transitive verbs that have an animate object and those that have not. Correspondingly, ditransitive verbs formed by various derivational means (causative, benefactive, comitative) are always classified as transitive animate (TA) in virtue of the fact that they add an animate argument. As we have seen, inverse morphology (which grammaticalizes person hierarchy) also forces the introduction of a fourth person (obviative) because no two arguments can have the same person status. We are therefore entitled to see a strong interaction between the emergence of structurally determined verb classes and the emergence of structural means that ensure an economical and at the same time unambiguous way of identifying arguments.

\subsection{The salience or voice type}

In the active type (section 3.4) we found two sets of pronominal affixes (active and inactive), while the inverse type (section 4.1) exhibits mainly one set of pronominal affixes together with direct and inverse morphemes, and further portmanteau morphemes that seem to undergo several changes. In contrast, the salience type exhibits several sets of pronominal affixes, together with the restriction that only one affix is possible at a verb, encoding the most salient argument. This type is exemplified by Arizona Tewa, a Tanoan language spoken in a number of pueblos along the Rio Grande in New Mexico and Arizona.

(51) Six sets of person prefixes in Arizona Tewa (Kroskrity 1985)

a. STAT: encodes the argument of an intransitive verb

b. REFL: identifies agent and patient of a transitive verb

c. POSS: encodes a possessor with respect to an intransitive verb

d. BEN: encodes a beneficiary argument with respect to a transitive verb

e. AGT: encodes the agent of a transitive verb

f. PAT: encodes the patient of a transitive verb

STAT and REFL are unproblematic because intransitives and reflexive transitives (such as 'he washes (himself)') only have one argument to be encoded. POSS adds an argument to an intransitive verb (52a), while BEN adds an argument to a transitive verb, without any further marking of the verb; these arguments count as the most salient ones - they are often in the 
focus of the predication, and there is no other way to make them visible. AGT and PAT encode the more salient person, as shown in (52b-f). 1st and 2 nd person are more salient than the 3rd person, and 'these girls' in (52f) is more salient than 'those boys' because of the proximate-distal contrast. With a PAT marking, the respective less salient agent receives an oblique marking (52c,e,f), which resembles the obviative marking of Cree (section 4.1).

(52) The one-prefix restriction of Arizona Tewa (Kroskrity 1985)
a. semele dín-han
pot 1sg.POSS-break
'My pot broke'
b. he'i-n sen-en dó-k ${ }^{\text {hw }} \varepsilon$ di
this-pl man-pl 1sg.AGT-hit
'I hit these men'
c. he'i-n sen-en-di dí-k ${ }^{\text {hw }} \varepsilon$ di
this-pl man-pl-OBL 1sg.PAT-hit
'These men hit me'
d. Ne'i kwiyó ná:-tay
this woman 2sg.AGT-know
'You know this woman'
e. Ne'i kwiyó -di wó:-tay
this woman-OBL 2sg.PAT-know
'This woman knows you'
$\begin{array}{llll}\text { f. né'i-n 'ayú-n 'o:'i-n 'enú-n-di 'ó:bé- }{ }^{\text {hw }}{ }^{2} \text { di } \\ \text { this-pl girl-pl that-pl boy-pl-OBL } & 3 \text { pl.PAT-hit }\end{array}$
'Those boys hit these girls'

The prefixes of the AGT set cannot be identified with active in the sense of the active type because they do not occur with intransitive verbs; likewise, the prefixes of the PAT set cannot be identified with inactive. Moreover, the elements of PAT cannot be identified with accusative, and the elements of AGT cannot be identified with ergative because there is no contrast to nominative, which would be required on the basis of the definitions given in (6), section 2. In principle, however, it is imaginable that one of these markers develops to accusative or ergative. ${ }^{8}$ A more detailled comparative study of the Kiowa-Tanoan languages seems to be promising, given the interesting situation that Kiowa represents an extreme portmanteau type (see section 1), Arizona Tewa is of the salience type, and both Tiwa and Towa, the two other Tanoan branches, have an inverse marker (see also Klaiman 1993).

Similar in its function, but much more systematic, is the so-called voice system of the Philippine languages, which we illustrate below with Tagalog. On the verb, only one argument is marked, which is the most prominent one syntactically (for instance, only this argument can be relativized); usually it is understood as definite. It can be the agent (actor voice AV), the patient (object voice OV), a location or recipient (LV), a beneficiary (BV) or an instrument (IV); the three latter voices can add an argument without any further marking on the verb - thus they have the combined effect of applicative+passive (except that no argument is demoted). Some of these markers are also found with intransitive verbs, which shows that they are sensitive to semantic roles (as in the active type).

\footnotetext{
8 One could assume the elements of STAT to be nominative, but then one would expect these elements to appear in (52f). Also, ergative should cover 3rd person and then possibly take precedence over PAT marking in (52f).
} 
The syntactic argument that corresponds to the designated (the most prominent) one is marked by the preclitic ang, which could be identified with nominative (pronouns and proper names have a different marker). All other structural arguments are marked by $n g$ (pronounced as /nang/), which often is called genitive (but could as well be called accusative), while locatives and recipients are marked by $s a$ (possibly to be analyzed as dative). In nominalizations, as well as in the recent past, one doesn't find any voice marking, and therefore no nominative ang can appear. The choice of the voice morphemes is often lexically determined.

All attempts to relate the Philippine voice system to either accusative or ergative have failed, and attempts to interprete the most prominent argument as topic or focus have failed, too. (There exists a different topic construction, and the tendency of being definite conflicts with the interpretation as focus.) However, one finds syntactic effects such as the possibility to get relativized. Systems similar to the Philippine voice system are found in other Austronesian languages, too, partly reduced or reorganized. The name voice reminds us at active and passive, which also promote one of the arguments to the most prominent one. However, passive binds the agent existentially (it could only be expressed by an oblique adjunct, such as English (He was seen) by the policeman), while the corresponding object voice $(\mathrm{OV})$ leaves the agent in a structural case.

The examples in (53) illustrate the five voices of Tagalog with the verb bili 'buy'; it should become clear that the voices neatly correspond to the semantic roles of the participants of a buying event. Thus, the voice affixes classify verbs according to their potential of bearing certain semantic roles; they cannot be considered to be pronominal affixes because they do not bear any information about person and number. (For phonological reasons, some of the prefixes surface as infixes; $<>$ indicates such a prefix. In (53a), for example, /um -/ is infixed to the stem bili.)

$$
\begin{aligned}
& \text { Voices in Tagalog (Foley \& van Valin 1984:135) } \\
& \text { a. B }<\text { um }>\text { ili ang=lalake ng=isda ng=pera sa=tindahan. } \\
& <\text { PERF. } A V>\text { buy NOM=man GEN=fish GEN=money LOC=store } \\
& \text { 'The man bought fish in the store with money.' }
\end{aligned}
$$
a. $B<$ um $>$ ili
ang=lalake $\mathrm{ng}=\mathrm{isda}$
ng=pera $\quad \mathrm{sa}=$ tindahan. $<$ PERF.AV $>$ buy $\mathrm{NOM}=$ man GEN=fish
GEN=money $\mathrm{LOC}=$ store
'The man bought fish in the store with money.'
b. $B<$ in $>$ ili $\quad$ ng=lalake ang=isda ng=pera sa=tindahan.
$<$ PERF.OV $>$ buy GEN=man NOM=fish GEN=money LOC=store
'The man bought the fish in the store with money.'
c. B<in $>$ ilh-an ng=lalake ng=isda ng=pera ang=tindahan. $<$ PERF $>$ buy $-\mathrm{LV}$ GEN=man GEN=fish GEN=money NOM=store
'The man bought fish in the store with money.'
d. $\mathrm{I}-\mathrm{b}<\mathrm{in}>\mathrm{ili} \quad \mathrm{ng}=$ lalake $\mathrm{ng}=\mathrm{isda}$ ang=bata.
$\mathrm{BV}-<\mathrm{PERF}>$ buy $\mathrm{GEN}=$ man $\quad \mathrm{GEN}=$ fish $\quad \mathrm{NOM}=$ child
'The man bought fish for the child.'
e. Ip-in-an-bili ng=lalake $n g=i s d a \quad$ ang=pera $\quad s a=$ tindahan.
IV-PERF-?-buy GEN=man GEN=fish NOM=money $\quad$ LOC=store
'The man bought fish in the store with the money.'

The person from whom one buys something is also marked by the location clitic $s a$; correspondingly, it is advanced to the most prominent argument by the location voice (LV), as shown in $(54 b)$. 
(54) Source in Tagalog (Foley \& van Valin 1984:63) $<$ PERF.AV $>$-buy $\quad$ GEN=fish $\quad$ LOC $=$ child $\quad \mathrm{NOM}=$ man
'The man bought some fish from the child.'
a. $\mathrm{B}<$ um $>$ ili $\quad \mathrm{ng}=\mathrm{isda} \quad \mathrm{sa}=$ bata ang=lalake.
b. $\mathrm{B}<$ in $>$ ilh-an $\mathrm{ng}=$ lalake $\mathrm{ng}=$ isda ang=bata.
$<$ PERF $>$ buy-LV GEN man GEN fish NOM child
'The man bought some fish from the child.'

With the verb bigay 'give', the clitic $s a$ marks the recipient as a goal $(55 \mathrm{a}, \mathrm{b})$. The examples in (55) also illustrate how relativization functions in Tagalog: the recipient can be relativized in the location voice (LV; 55a), and the patient can be relativized in the object voice $(\mathrm{OV} ; 55 \mathrm{~b})$, but the patient cannot be relativized if the verb shows actor voice (AV; $55 \mathrm{c})$.

(55) Relative clauses in Tagalog (Foley \& van Valin 1984:141)
a. bata-ng $\quad b<$ in $>$ igy-an ng=lalake $n g=i s d a$ child-COMP $<$ PERF $>$ give-LV GEN=man $\quad$ GEN= fish 'the child which was given fish by the man'
b. isda-ng $\quad \mathrm{i}-\mathrm{b}<\mathrm{in}>$ igay $\quad \mathrm{ng}=$ lalake $\mathrm{sa}=$ bata fish-COMP $\quad$ OV $-<$ PERF $>$ give $\quad$ GEN $=$ man $\quad$ LOC $=$ child 'the fish which was given to the child by the man'
c. *isda-ng nag-bigay ang=lalake sa=bata fish-COMP PERF.AV-give NOM=man LOC=child

The common properties of voice systems seem to be the following: only one argument can be marked on the verb, and the choice is made according to semantic roles, and, possibly, semantic values (such as person or definiteness). However, unlike passive, no other argument gets demoted, which is particularly true for Tagalog. Arizona Tewa fuses voice with person-number, whereas Tagalog does not. In Tagalog, the argument that is marked on the verb achieves a special grammatical status, i.e., functions as a syntactic 'pivot'. Regrettably, the information about Arizona Tewa is too poor for evaluating whether the designated argument gets a similar syntactic function. It is therefore not yet possible to describe the general profile of the voice type more accurately. It might also be the case that Arizona Tewa and Tagalog actually belong to different types.

\subsection{The positional type}

The positional type is found in various languages, particularly in English, Chinese, West African and Oceanic languages, but also in other parts of the world, often combined with some residuals of agreement. Recall that the default ordering of arguments usually follows the argument hierarchy, with the highest argument in the first position and the lowest argument in the last position (independently of where the verb is positioned). It is this default ordering that is structurally fixed in the positional type.

Argument position also depends on the information status of arguments. Topics, which express something which has already been given in the context, are mostly realized in the initial position, sometimes followed by the focus element, which expresses the new thing, but there are many more means to express focus differently, whereas topics usually are preferred in the first position. 
Under the condition that arguments should be recognizable even if of one of them is topicalized, the order SVO turns out to be the most robust type. If the object is topicalized, one gets the order $\mathrm{O}_{\mathrm{T}} \mathrm{SV}$, which clearly differs from SVO because two nominal arguments precede the verb. Thus, the roles of $\mathrm{S}$ and $\mathrm{O}$ can always be distinguished, as illustrated in the Chinese example (56).

(56) SVO and object topicalization in Chinese

a. wo kan-le shu le.

I read-ASP book ASP

'I read books.'

b. shu, wo kan-le.

book I read-ASP

'The book(s), I read.'

The SOV type (verb-final) would yield the ordering $\mathrm{O}_{\mathrm{T}} \mathrm{SV}$ as well, which, however, produces ambiguity because the first nominal could be $\mathrm{S}$ or $\mathrm{O}$. Therefore, SOV type languages usually use morphological case to make the distinction. In the verb-initial languages one often finds VOS to be the basic order, but then no real distinction is possible between $\mathrm{O}_{\mathrm{T}} \mathrm{VS}$ and $\mathrm{S}_{\mathrm{T}} \mathrm{VO}$ because one can only recognize that one of the arguments is topicalized but doesn't know which one. Again, certain ambiguities are unavoidable. Therefore, the positional type of argument linking is restricted to SVO languages: the subject is realized pre-verbally, and the object in the position which immediately follows the verb. This post-verbal position could as well be considered a variant of accusative marking.

The SVO type has a further advantage: one can form series of predications with a shared subject such as $\mathrm{S}\left(\mathrm{V}_{1} \mathrm{O}_{1}\right)\left(\mathrm{V}_{2} \mathrm{O}_{2}\right) \ldots$ - such a series is called a serial verb construction (see section 6.3). In such a series it is possible that one of the verbs gets grammaticalized for a specific function. As Peyraube (1996) points out, already in the earliest Chinese inscriptions (more than 3,000 years old) one finds SVO together with serial verbs SVOV+complement and certain markers ('prepositions') that appear in either the first or the second V-position. Modern Chinese shows constructions such as those in (57): $\mathrm{S}$ ba $\mathrm{O}_{1} \mathrm{VO}_{2}$, and $\mathrm{SVO}_{1}$ gei $\mathrm{O}_{2}$. Here, $b a$ (in one of its several functions) marks a possessor of $\mathrm{O} 2$, and gei (formerly 'give') marks a goal. ('CL' stands for classifier.)
ba and gei in Chinese (Sybesma 1999: 137,105)
a. Li Si ba Lao Li duan-le tui.
Li Si BA Lao Li break-ASP leg
'Li Si broke Lao Li's legs.'
b. Zhang San song yi-ben shu gei Li Si. Zhang San give one-CL book to $\mathrm{Li} \mathrm{Si}$
'Zhang San gave a book to Li Si.'

Obviously, the main verb in both (57a) and (57b) has three arguments. We will see in section 6.3 that the serial verb construction is one of the possible ways to express a third argument in the positional type. Another way is the double object construction to be discussed in section 6.4; it is also found in Chinese (58a). The observation that gei can optionally appear in this construction (58b) and also occurs in the ba-variant (58c) leads Sybesma (1999) to the conclusion that all realizations of Chinese song 'give' go back to an underlying change of location (rather than a change of possession) structure (see also sections 6.1 and 6.6). 
(58) Further variants of expressing 'give' in Chinese (Sybesma 1999: 100ff., 136)

a. Zhang San song Li Si yi-ben shu. Zhang San give Li Si one-CL book

'Zhang San gave Li Si a book.'

b. Zhang San song gei Li Si yi-ben shu.

c. Zhang San ba zhei-ben shu song gei Li Si.

Zhang San BA this-CL book give to Li Si

'Zhang San gave this book to Li Si.'

These examples show that the SVO type can pave the way to more complex constructions, including the possibility of introducing prepositions for marking arguments. It is even conceivable that such a preposition develops to a case marker. Chinese $b a$ seems to function as an accusative marker in some instances (such as (59a)), while in other instances (such as $(59 \mathrm{~b}, \mathrm{c}))$ it is not so clear whether this is true.

(59) $\quad b a$ as a possible accusative marker in Chinese (Sybesma 1999:137ff.)

a. Ta ba zhu mai-le.

he BA pig sell-ASP

'He sold the pigs.'

b. Ta bahuaping cha-le yi-ba hua. he BA vase stick-ASP one-CL ${ }^{\text {bunch flower }}$

'He stuck a handful of flowers into the vase.'

c. Ba ge zei pao-le.

BA CL thief escape-ASP

'A thief escaped.'/ 'They had a thief escape.'

\subsection{The generalized case type}

Let us now turn to the most frequent type of argument linking, which is so wide-spread that many linguists take it to be the universal type. In any case, it is the central type for all theories about argument structure. In systems of this type the fundamental lexical asymmetry of transitive verbs is preserved in morphology and syntax.

In section 2 we introduced the notions 'accusative' and 'ergative': a marker is called 'accusative' if it encodes objects (patients) differently from subjects (agents or the subjects of intransitive verbs), and it is called 'ergative' if it encodes transitive subjects (agents) differently from objects and intransitive subjects. Both 'accusative' and 'ergative' are contrasted with 'nominative'. We also introduced the two features [+hr] and $[+1 \mathrm{r}]$ that encode the argument hierarchy and, simultaneously, characterize the two alternatives: accusative marks [+hr] argument roles, and ergative marks $[+\mathrm{lr}]$ argument roles. Furthermore, we argued that marking the lower role is preferred over marking the higher role, which results in the preference scale $+\mathrm{hr}>+\operatorname{lr}$ (for convenience: ACC $>$ ERG).

An argument linking system that conforms to these conditions is called a 'generalized case' system. It can be accusative-based, ergative-based, or both (i.e., a mixed system). Moreover, there can be different ways to spell out the accusative or ergative poperty: The verb can be combined with pronominal affixes or agreement morphemes that belong to an ACC or ERG set (head marking), or the nominal arguments (pronouns or full NPs) themselves are combined with prepositions, postpositions, or proper morphological case (dependent marking). The notion of generalized case thus includes both affixation on the verb and affixation on the syntactic complements. It is even possible to subsume the 
positional SVO type under generalized case: the position next to the verb is reserved for objects; thus, it can be characterized as accusative (bearing the feature [ $+\mathrm{hr}]$ ).

\section{Head vs. dependent marking}

In all the morphologically realized types discussed in the preceding sections (i.e., the active type, the inverse type and the salience type), the arguments are marked on the verb by means of pronominal affixes; such a mechanism is called head marking. There can be two sets of pronominal affixes (active and inactive), only one set of pronominal affixes (in the inverse type), or several sets (in the salience type). In section 4.1 we have found that portmanteau morphemes can be generalized to accusative; in principle, it is also possible that inactive affixes or elements of the PAT set of Arizona Tewa develop to accusative - all these instances lead to an accusative head marking. Head marking is one of the characteristics of languages with 'rich' morphology. It is possible that pronominal affixes develop to pure agreement markers, which need to be complemented by free syntactic elements that agree with them in terms of person and number.

By contrast, dependent marking usually does not emerge within sets of pronominal elements, but rather from elements that are attached to a noun phrase in order to specify its argument role. In section 4.3, I argued that Chinese $b a$ could be regarded as being in the process of becoming an accusative marker. Similarly, a topic marker could get reanalyzed as an accusative morpheme. There are various ways in which systems with generalized case may have developed.

In principle, however, the emergence of head marking and the emergence of dependent marking are independent of each other. We find languages with both kinds of marking, languages that have only one of these kinds, and languages with no marking (except by position), see (60). Basque exhibits ergative, dative and nominative, both on the auxiliary verb and on free nominals. Yimas (a language of New Guinea) exhibits ergative, accusative, dative and nominative sets of pronominal affixes, but has no case marker on nouns. In Japanese we find accusative, dative and nominative postpositions with nouns, but no agreement morphemes on the verb. Chinese, an 'isolating' language, represents the positional type SVO, without agreement and case (except some tendency towards an accusative preposition). If both case and agreement are lacking, the language may nevertheless show 'rich' morphology; an example is the Paleosibirian language Nivkh: the only way to mark an argument in Nivkh is incorporation of the lowest argument (see section 6.3 below).

Head marking and dependent marking are independent of each other

\begin{tabular}{|l|l|l|}
\hline & with 'agreement' & without 'agreement' \\
\hline with case & Basque (E, D, N) & Japanese (A, D, N) \\
\hline without case & Yimas (E, A, D, N) & $\begin{array}{l}\text { Chinese: isolating (SVO) } \\
\text { Nivkh: polysynthetic (SOV) }\end{array}$ \\
\hline
\end{tabular}

Accusative-ergative mixed systems

Pure accusative systems are found in several Indo-European languages but also in many other families around the world. A pure ergative system is found in Basque as well as in many more languages, but more than often ergative occurs together with accusative. Such a system is called a mixed system.

Yimas (New Guinea) exhibits three sets of pronominal affixes in the 1st and 2nd person. As the examples in (61) show, we can properly call $m a$ - an accusative morpheme and $k a$ - an 
ergative morpheme because both contrast with ama-, which is used with intransitive verbs. However, the 3rd person lacks accusative. Since an inflected verb usually begins with a nominative form, accusative and ergative never cooccur with a transitive verb. A detailed analysis of the pronominal affix paradigms of Yimas is presented in Wunderlich (2001).

(61) Accusative and ergative in Yimas (Foley 1991)
a. ama-tmuk-t.
$1 \mathrm{sgN}$-fall-perf
b. pu-na-tpul.
'I fell down.'
3plN-1sgA-hit
c. pu-ka-tpul.
3plN-1sgE-hit
'I hit them.'
d. na-mpu-tpul.
3sgN-3plE-hit
'They hit him.'

However, accusative and ergative can cooccur with a transitive verb of Dyirbal, a PamaNyungan language of Australia (Northeast Queensland). This language has morphological case, and there again is a split between $1^{\text {st }} / 2^{\text {nd }}$ person and $3^{\text {rd }}$ person. Pronouns of the $1^{\text {st }}$ and $2^{\text {nd }}$ person are marked by accusative $(-n a)$, while demonstratives as well as full nouns are marked by ergative $(-\eta g h u)$.

(62) The linker inventory of Dyirbal (incomplete; Dixon 1994:10/14)

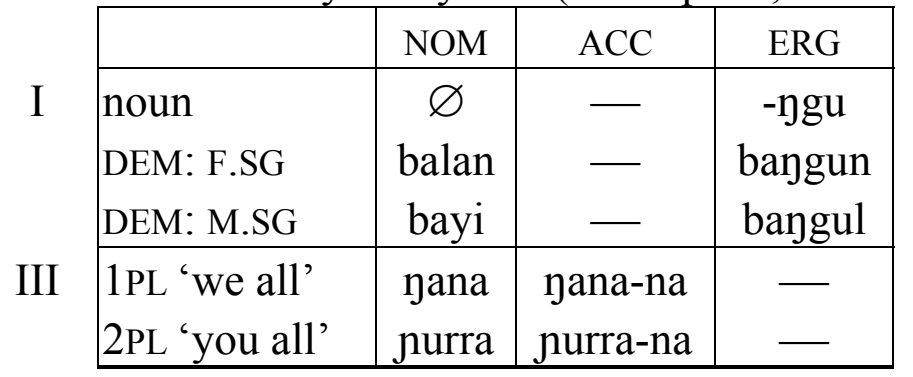

The reader can easily verify that this kind of split allows four combinations, summarized in (63). ('loc' indicates $1^{\text {st }}$ or $2^{\text {nd }}$ person, which are often comprehended as local person because they refer to the speech participants.)

(63) Four possible case patterns in Dyirbal

\begin{tabular}{|l|l|}
\hline $\begin{array}{l}\text { Direct setting (loc/3) } \\
\text { 'We see the man.' }\end{array}$ & $\begin{array}{l}\text { Inverse setting (3/loc) } \\
\text { 'The man sees us.' } \\
\text { ERG NOM }\end{array}$ \\
\hline $\begin{array}{l}\text { Symmetric setting (loc/loc) } \\
\text { 'The man sees him.' }\end{array}$ & $\begin{array}{l}\text { Symmetric setting (3/3) } \\
\text { 'TOM man sees him.' }\end{array}$ \\
\hline
\end{tabular}

In Udi, a Northeast Caucasian language, one finds these four case patterns, too, yet for slightly different reasons. As in Dyirbal, there exist no ergative $1^{\text {st }}$ and $2^{\text {nd }}$ person pronouns, and accusative is restricted to definite, animate or pronominal objects. The examples in (64) illustrate these possibilities. (The consonant t' which precedes the case ending is a stem augment. The subject marker on the verb is infixed to the verb stem $u k$.)

(64) The four-way case split of Udi (Schulze 2001)
a. se-t'-in s/um-ax $\quad \mathrm{u}<$ ne $>\mathrm{k}$-sa.
DIST-t'-ERG bread-ACC $<3 \mathrm{sgN}>$ eat-PRES

'(S)he eats the bread.' 


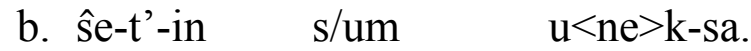

DIST-t'-ERG bread.NOM $<3 \mathrm{sgN}>$ eat-PRES

'(S)he eats bread.'

c. $z u \quad s / u m-a x \quad u<z u>k-s a$.

I.NOM bread-ACC $<1 \mathrm{sgN}>$ eat-PRES

'I eat the bread.'

d. $\mathrm{zu} \quad \mathrm{u} / \mathrm{um}<\mathrm{zu}>\mathrm{k}-\mathrm{sa}$.

I.NOM bread.NOM $<1 \mathrm{sgN}>$ eat-PRES

'I eat bread.'

Also in Hindi one finds these four case patterns, but here the ergative is restricted to perfect, whereas accusative (similar to Udi) is found with human, specific animate or definite inanimate objects.

(65) The four-way case split of Hindi (Mohanan 1994)
a. niinaa-ne baalikaa-ko uthaa-y-aa.
Nina.F-ERG girl-ACC lift-PERF-M
'Nina lifted up a/the girl.'
b. niinaa baalikaa-ko uthaa-eg-ii.
Nina.F.NOM girl-ACC lift-FUT-F
'Nina will lift up a/the girl.'
c. niinaa-ne roTii khaa-y-ii.
Nina.F-ERG bread.F.NOM eat-PERF-F
'Nina ate bread.'
Nina.F.NOM banana.M.NOM eat-FUT-F
'Nina will eat a banana.'
d. niinaa kelaa khaa-eg-ii.

The different case patterns thus signal the distribution of values such as animate/nonanimate, perfect/non-perfect to the hearer. Linguists are surprised how much similarities of splits are found in languages from different parts of the world. On a different theoretical background, Aissen (1999) and Stiebels $(2000,2002)$ proposed to consider these similarities as resulting from the harmonic alignment of scales. I follow here the proposal made by Stiebels.

First we assume a scale of morphological features to be selected in order to mark a certain property by grammatical means; cross-linguistically, accusative is more preferred than ergative, see (66a). Secondly, we assume a scale of contextual features interacting in the realization of the respective property, such as person, animacy, definiteness, or aspect; in each of these domains, the respective plus-valued feature is considered to be more salient, see (66b). The two scales are harmonically aligned, if higher features are combined with higher features, and lower features with lower features, which yields, among others, acc/loc $>$ acc/3 ('accusative is preferred for a local person') and erg/3 > erg/loc ('ergative is preferred for the 3rd person'). Finally, in accordance with the assumption that a grammar has to be restrictive, we express the reverse ranking as a markedness hierarchy, e.g. *ACC/3 "* ACC/loc ('accusative for the 3rd person is more strongly blocked than accusative for a local person'). This yields a whole collection of markedness hierarchies, see (66c). 
(66) Harmonic alignment of morphological and semantic scales (Stiebels 2000, 2002) 9

a. Morphological scale:

$+\mathrm{hr}>+\mathrm{lr}$ (for mnemotechnical ease: $\mathrm{ACC}>\mathrm{ERG}$ )

It is better to mark a lower argument (an object) than a higher argument (the subject).

b. Contextual semantic scales:

$$
\begin{array}{ll}
\text { person: } & \text { loc }>3 \\
\text { animacy: } & + \text { anim }>\text {-anim } \\
\text { definitess: } & + \text { def }>\text {-def } \\
\text { aspect: } & \text { +perf }>\text {-perf }
\end{array}
$$

c. Contextualized markedness hierarchies:

$$
\begin{aligned}
& \text { *ERG/loc »*ERG/3 *ACC/3 »*ACC/loc }
\end{aligned}
$$

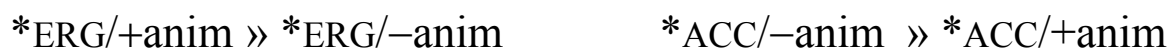

$$
\begin{aligned}
& * \mathrm{ERG} /+ \text { def } \gg * \mathrm{ERG} /- \text { def } \quad * \mathrm{ACC} / \text {-def } » * \mathrm{ACC} /+\mathrm{def} \\
& \text { *ERG/+perf »*ERG/-perf *ACC/-perf »*ACC/+perf }
\end{aligned}
$$

A split in the realization of ergative (accusative) occurs if the requirement MARK(ERG) (or $\operatorname{MARK}(\mathrm{ACC})$ ) intervenes between the two markedness constraints; moreover, it is possible that this takes place differently in the various scales. Each of the hierarchies in (66c) allows exactly three options, as shown in (67).

a. $\operatorname{MARK}(\mathrm{ACC}) » * \mathrm{ACC} / 3 » * \mathrm{ACC} /$ loc: All three persons have accusative.

b. $* A C C / 3 » \operatorname{MARK}(\mathrm{ACC}) » * A C C /$ loc: Only $1^{\text {st }}$ and $2^{\text {nd }}$ person have accusative.

c. *ACC/3 »*ACC/loc » MARK(ACC): Accusative is absent.

The reader will realize that the collection in (66c) includes all the conditions that account for the splits reported above. For instance, ${ }^{*} E R G / \operatorname{loc} » \operatorname{MARK}(E R G) »{ }^{*} E R G / 3$ is relevant for both Dyirbal and Udi (where ergative exists only for the $3^{\text {rd }}$ person), and *ACC/-def $»$ MARK(ACC) "* ACC/+def is relevant for both Udi and Hindi (where accusative does not occur with indefinite objects).

A split can also occur between two coexisting linking devices. Consider the examples in (68) from Warlpiri, a Pama-Nyungan language spoken by a few people in the northern territory of Australia. With the nouns we find ergative case, yet the agreement is accusativebased: -rna '1sg' agrees with the subject of both intransitive and transitive verbs (68a-c), while $-j u$ ' $1 \mathrm{sg}$ ' agrees with the object (68d); consequently, $-j u$ has to be classified as accusative (A), and -rna as nominative (N).

(68) Ergative case and accusative agreement in Warlpiri (Andrews 1985: 106f.)

a. Ngaju ka-rna parnka-mi.

I.NOM PRES-1sg.N run-NONPAST

'I am running.'

b. Ngajlu-rlu ka-rna yankirri wajilipi-nyi.

I-ERG PRES-1sg.N emu.NOM chase-NONPAST

'I am chasing an Emu.'

9 For convenience, I use the case names ERG and ACC rather than the respective features, which would be more adequate in the general framework. 


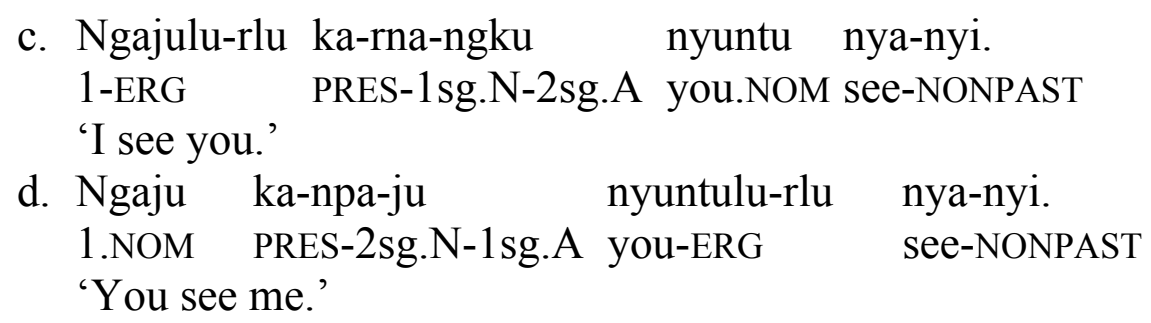

Such a mixed system in which head-marking exhibits the accusative type and case-marking the ergative type is found in several languages, whereas the reverse constellation does not exist. This fact again follows from harmonic alignment; this time we have to regard the two scales given in $(69 a, b)$, remembering that argument affixes on the verb are of pronominal nature.

(69) Harmonic alignment regarding pronouns and nouns

a. $\mathrm{ACC}>\mathrm{ERG}$ (as above)

b. pro $>\mathrm{N}$

Pronouns are referentially more salient than nouns.

c. ${ }^{*}(\mathrm{ACC} / \mathrm{N}) » *(\mathrm{ACC} / \mathrm{pro})$

Accusative marking on nouns is more strongly blocked than that on pronouns.

d. * $*$ ERG/pro $) » *(E R G / N)$

Ergative marking on pronouns is more strongly blocked than that on nouns.

Thus, the invention of a generalized case system comes as a fortune. It is a purely structural (or abstract) system with regard to argument hierarchy, which nevertheless enables the speakers to react on different semantic weights of the arguments in manyfold ways.

\section{The emergence of dative}

Many linguists still consider dative to be a semantic or lexical-inherent case, for them, dative is not a case that emerges in certain structural configurations. However, there is overwhelming evidence that dative is a structural case: dative often marks the medial argument of a ditransitive verb (the recipient of 'give', 'send' etc., or the causee of a causativized transitive verb), a dative argument can alternate with nominative, can be coindexed with an agreement morpheme, or can be suppressed in certain constructions. On the basis of these diagnostics, Wunderlich (2000) argued that dative is a structural case in Hungarian; similar arguments can be put forward for other languages, too. Of course, there exist many languages that do not have a dative, and, as Eisenbeiß (2002) has shown, the acquisition of dative always follows the acquisition of accusative in an accusative-based language like German. Dative can also appear in a pure ergative language such as Basque; and here the acquisition of ergative precedes that of dative.

We claim that dative is a general structural option for generalized case languages, but whether it arises or not depends on several historical circumstances. One advantage of having the two features $[+\mathrm{hr}]$ and $[+\mathrm{lr}]$ is the possibility to combine them and thus to characterize the medial argument of a ditransitive verb; correspondingly we define dative by the feature combination $[+\mathrm{hr},+\mathrm{lr}] .{ }^{10}$ Such a decompostion of dative also conforms to Dowty's (1991) observation that a dative argument accumulates properties of both protoagent (being a controller) and proto-patient (being affected), and it makes at once clear that the existence of a dative presupposes the existence of either accusative or ergative. (70)

10 In the preceding paragraphs, I used ACC and ERG instead of $+\mathrm{hr}$ and $+\mathrm{lr}$ for mnemotechnical reasons. Dative would then be the combination [ACC,ERG]; to avoid unnecessary confusion, I go back to the original features. 
illustrates that dative can independently arise in an accusative or an ergative system, but it is certainly facilitated in a mixed system (which already uses the two features in order to mark case). Dative cannot appear in a language of the active or inverse type.

(70) Encoding argument roles and generalized case

\begin{tabular}{|c|c|c|c|c|c|}
\hline intransitives & \multicolumn{2}{|c|}{ transitives } & \multicolumn{3}{|c|}{ ditransitives } \\
\hline$\lambda x \operatorname{VERB}(x)$ & $\lambda y$ & $\lambda \mathrm{x} \operatorname{VERB}(\mathrm{x}, \mathrm{y})$ & $\lambda z$ & $\lambda y$ & $\lambda \mathrm{x} \quad \operatorname{VERB}(\mathrm{x}, \mathrm{y}, \mathrm{z})$ \\
\hline$-\mathrm{hr}$ & $+\mathrm{hr}$ & $-\mathrm{hr}$ & $+\mathrm{hr}$ & $+\mathrm{hr}$ & $-\mathrm{hr}$ \\
\hline$-1 \mathrm{r}$ & $-1 \mathrm{r}$ & $+\operatorname{lr}$ & $-1 \mathrm{r}$ & $+1 \mathrm{r}$ & $+\operatorname{lr}$ \\
\hline NOM & ACC & NOM & ACC & DAT & NOM \\
\hline & $\mathrm{NOM}$ & ERG & NOM & DAT & ERG \\
\hline
\end{tabular}

We call the case patterns associated with the argument roles in (70) 'canonical' because they offer an optimal distinction by case. Such a canonical system is very effective and also robust enough to allow various aberrations ('noncanonical' patterns) in order to mark minor lexical classes.

\section{The lexical marking of verbs}

Many languages with generalized case, either head-marking or dependent-marking, use the respective markers to establish minor lexical classes, for instance, classes of noncanonical 'transitive' verbs. In section 3.4 we have seen that active type languages allow doubleinactive as well as double-active verbs, which deviate semantically from canonical transitives. Similarly, languages with generalized case can establish classes such as nominativedative verbs, double-accusative verbs, ergative-marked intransitives, and so on. We consider these special classes to be lexically marked, where the presence of such a marker (weakly) correlates with some semantic factor. For instance, ergative-marked intransitives (which occur in Hindi-Urdu) are expected to be agentive rather than nonagentive. In many instances, the presence of a lexical marker is not totally idiosyncratic; on the other hand, the semantic properties alone usually do not suffice to predict the membership in such a class. It often happens that the presence of lexical marking can only be motivated on historical grounds, or by some kind of analogy. Paul (1919) cites many examples where a particular verb shifts between canonical case and lexically marked case several times in the history of German.

A positional system lacks the possibility of lexical marking. Verbs such as 'help', 'like' etc, which are lexically marked in such closely related languages as Icelandic and German, are canonically transitive in English. A positional system thus clearly reduces the set of lexical classes. Similarly, the inverse type of argument linking, crucially consisting in the mapping from a semantic scale onto argument hierarchy, does not show lexical marking, except in the classification of animate and inanimate stems (e.g., cars are animate). Not only that I couldn't find any documentation of such a marking, one cannot even conceive of it regarding the function of direct and inverse markers. This does not exclude that semantic classes of verbs are often characterized by other (e.g., derivational) means.

\subsection{Two classes of lexically marked dative verbs}

The existence of dative decomposed into the feature combination $[+\mathrm{hr},+\mathrm{lr}]$ allows the introduction of two subclasses in the set of 2-place verbs by means of lexical marking. The two classes are symmetric to each other: either the lower argument is exceptionally marked by $[+1 \mathrm{r}]$, or the higher argument is exceptionally marked by $[+\mathrm{hr}]$. The processing of these 
features in the context of the other inherent features yields the combination $[+\mathrm{hr},+\mathrm{lr}]$ in both instances. Obviously, these two types of noncanonical datives must be semantically distinct.

The first class is exemplified by the NOM-DAT verbs of German (such as helfen 'help', folgen 'follow', danken 'thank'). These verbs seem to invite the inference that the object is a controller on its own, i.e., behaves itself as an active being in the event denoted by the verb. Indeed, the verbs often have an animate object that is independently in action (active object verbs). (71b) illustrates this class. The inherent features are all those that are not overridden by the lexical feature. Similar verbs are found in several languages, even in an ergative language such as Basque in which they compete with ERG-NOM verbs; however, in Basque this class is small and unproductive (Joppen \& Wunderlich 1995).

(71) NOM-DAT verbs in German

a. Sie folgte ihm.

She.NOM followed he.DAT

'She followed him.'

$\begin{array}{llll}\text { b. } & \lambda \mathrm{y} & \lambda \mathrm{x} & \operatorname{FOLLOW}(\mathrm{x}, \mathrm{y}) \\ \text { designated: } & +\mathrm{lr} & & \\ \text { inherent: } & & +\mathrm{lr} & \\ & +\mathrm{hr} & -\mathrm{hr} & \\ \text { case : } & \text { dat } & \text { nom } & \end{array}$

The second class is exemplified by the DAT-NOM verbs of German (such as gefallen 'like', schmecken 'taste, enjoy', schmerzen 'pain', gehören 'belong'). These verbs seem to invite the inference that the subject is affected, i.e. is an experiencer rather than an agent. Indeed, many verbs of this class are experiencer verbs, and those verbs that alter between dative subject and accusative object (such as schmecken 'taste, enjoy') have a slightly more active reading with accusative (see (72)), which is expected from a semantic point of view. Yet, this class also includes verbs that do not have an experiencer subject (such as gehören 'belong'), and, on the other hand, many experiencer verbs (such as fürchten 'fear', mögen 'like') are instead found in the canonical class of transitives, which indicates that this class cannot be defined on semantic grounds. Such an ambivalence with regard to a semantic background is characteristic for all types of lexical marking.

(72) Alternating DAT-NOM and NOM-ACC in German

$\begin{array}{llll}\text { a. Mir } & \text { schmeckte } & \text { der Braten/ } & \text { ?der Thymian. } \\ \text { I.DAT } & \text { enjoyed } & \text { the.NOM roast meat/ ?the thyme } \\ \text { b. Ich } & \text { schmeckte } & \text { den Thymian/ ?den Braten. } \\ \text { I.NOM } & \text { tasted } & \text { the.ACC thyme/ ?the roast meat }\end{array}$

The functioning of the lexical marking in this class is illustrated in (73). The lower argument resists accusative because of the requirement that each clause should exhibit nominative case. On the surface, the shift from (72a) to (72b) seems to involve at least two features, but in fact it can be described by the loss of just one lexical feature. This must have happened to English like historically, regarding that the cognate Icelandic likar 'like' still behaves as a DAT-NOM verb.

(73) DAT-NOM verbs in German

a. Ihm gefiel der Roman.

he.DAT liked the.NOM novel

'He liked the novel.' 
b.

$\begin{array}{llll} & \lambda y & \lambda x & \operatorname{LIKE}(\mathrm{x}, \mathrm{y}) \\ \text { designated: } & & +\mathbf{h r} & \\ \text { inherent: } & +\mathrm{hr} & & \\ & -\mathrm{lr} & +\mathrm{lr} & \\ \text { case: } & \text { NOM } & \text { DAT } & \end{array}$

Many languages exhibit productive classes of experiencer DAT-NOM verbs (or ACC-NOM verbs if dative is lacking), and especially are they found in ergative languages, perhaps because the shift from ergative to dative affects only one argument.

Some languages also exhibit intransitive verbs with accusative marking; the lexical feature is again $+\mathrm{hr}$ ('being affected'), here yielding accusative because an intransitive verb does not have the inherent feature +lr. German examples are mich friert 'I am cold' and mich fröstelt 'I am shivering', both clearly experiencer verbs. In Choctaw, a Muskogean language of Oklahoma and Mississippi, all nonagentive intransitives (such a 'be hungry', 'sweat', 'be tall', 'be old') are marked accusative (Davies 1986), in contrast to agentive verbs, which canonically realize nominative.

Chocktaw also exhibits several transitive verbs that alternate between two case patterns with regard to the pronominal (or agreement) affixes on the verb. Some examples are given in (74).

(74) Case pattern alternations in Choctaw

a. NOM-ACC and NOM-DAT (Davies 1986: 110,112)
i. Chi-alikchi-li-tok.
ii. Chim-alikchi-li-to $\mathrm{k}$.
2A-doctor-1N-past
2D-doctor-1N-past
'I doctored you.'
'I doctored you.'
anoksita 'admire', shilli 'comb', akammi 'corral', mokoffi 'let loose', ...

b. NOM-DAT and ACC-DAT (Davies 1986: 128, 121)
i. Chi-nokkilli-li-h.
ii. Chi-sa-nokkilli-h.
2D-hate-1N-pred
2D-1A-hate-pred
'I hate you.'
'I hate you.'

komota 'fear', nokpalli 'desire', noktalha 'mistrust', nokowa 'angry at', ...

c. NOM-DAT and DAT-ACC (Davies 1986: 112, 86)
i. Chim-ihaksi-li-tok.
ii. Chi-am-ihaksi-tok.
2D-forget-1N-past
'I forgot you.'
2A-1D-forget-past
'I forgot you.'

lhakoffi 'miss', ahchiba 'tired of', kania 'lose', achokma 'like', ...

The tree in (75) shows the assumed lexical markings. The members in class-a and class-b alternate between the presence or absence of just one feature, while the members in class-c alternate between the presence of a lexical feature on either the lower or the higher argument. Of course, some further assumptions are needed about how the grammar of Choctaw deals with these lexical features. For instance, the requirement of nominative must be lower-ranked than in German (where the lexical feature +hr on the higher argument leads to DAT-NOM rather than to DAT-ACC as in Choctaw). Wunderlich (2003), studying lexical marking in both Icelandic and German, accounts for all the occurring case patterns of these two languages on the basis of a few general constraints, which for Choctaw would only have to be re-ranked slightly. 
(75) Lexically marked transitive verbs of Choctaw

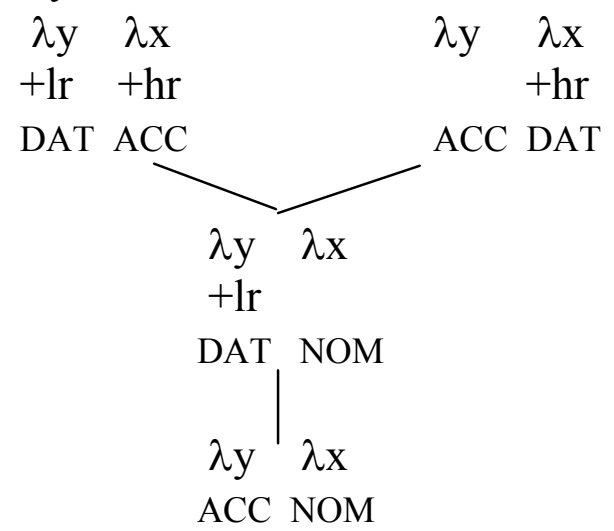

Interestingly, lexical marking in Choctaw only affects the morphology of verbs. Nouns (or noun phrases) saturating arguments only show nominative or accusative case (called 'oblique' by Davies), so that all the verbs shown in (74) realize their arguments syntactically by NOM-ACC, i.e., in the expected canonical way. This, again, demonstrates that verb-external syntax is much more regularizing than verb-internal morphology.

\subsection{Two classes of experiencer verbs with an expletive argument}

Another, totally different type of lexical marking is mimikry. We say it rains, but cannot put the question * what rains? because RAIN is a zero-place predicate, which doesn't allow any nominal argument. Therefore, the it in it rains is called an expletive argument; it fulfills a structural rather than a semantic condition on verbs in English. Here, a structurally intransitive verb mimics a zero-place predicate. Similarly, structurally transitive verbs can be used to mimic a one-place predicate. This is possible in two ways: either a higher or a lower argument role is added for purely structural reasons. German allows both options: a higher expletive is realized by es 'it', whereas a lower expletive is realized by a reflexive $(+$ refl).

The first option yields impersonal verbs: the true argument is shifted to a lower role and thus receives accusative, as if there were a real higher argument; this is demonstrated in (76). This shift invites the inference of being affected from some process, which is typical for experiencers.

(76) Impersonal transitives in German

a. Es ekelte mich. Es ekelte ihn.

it disgusted I.ACC it disgusted he.ACC

'I was disgusted.' 'He was disgusted.'

b. $\quad \lambda y \quad \lambda \mathbf{x} \quad$ BE_disgusted(y)

inherent: $\quad+\mathrm{hr}-\mathrm{hr}$

es

The second option yields the so-called inherent reflexives (such as sich erinnern 'remember'); their fake object is necessarily bound to the subject. This again invites for experiencer reading: one and the same argument is both agentive and affected.

(77) Inherent reflexives in German

a. Ich schämte mich.

Er schämte sich.

I.NOM was.ashamed myself

'I was ashamed.'

he.NOM was.ashamed himself

'He was ashamed.' 
$\begin{array}{llll}\text { b. } & \lambda \mathbf{y} & \lambda \mathrm{x} & \text { BE_ASHAMED(x) } \\ \text { inherent: } & +\mathrm{hr} & -\mathrm{hr} & \\ & +\mathrm{refl}\end{array}$

Some verbs allow both patterns without any shift in meaning, which suggests that these patterns themselves do not contribute to compositional meaning.
Alternation between impersonals and inherent reflexives
es ekelte ihn
er ekelte sich
'it made him sick'
es freute ihn
er freute sich
'he was pleased'
es wunderte ihn
er wunderte sich
'he was surprised'

German shows many more patterns with impersonals and inherent reflexives, including also dative reflexives (such as sich etw. aneignen 'take possession of sth.', sich etw. anmaßen 'usurp sth.' sich etw. verbitten 'beg to decline sth.'). Consider the examples in (79).

(79) Inherent dative reflexives in German

a. Ich eignete mir das an.

I.NOM got.possession 1.DAT.REFL that.ACC at

'I took possession of that./ I acquired that.'

b. Ich trank mir einen an.

I.NOM drunk I.DAT.REFL INDEF.ACC at

'I drunk too much.'

c. Ich arbeitete mir einen ab.

I.NOM worked I.DAT.REFL INDEF.ACC off

'I worked too much.' (Here, not only the reflexive but also einen is semantically empty.)

These examples exhibit the canonical NOM-DAT-ACC pattern. It becomes thus obvious that the introduction of expletive arguments preserves canonicality of case patterns, in contrast to lexical case marking, which introduces noncanonical case patterns. The two ways of lexical marking discussed in this chapter represent alternatives that are clearly distinct in their structural outcome.

\section{Ditransitive verbs: the emergence of a third argument}

Every language needs a device to express ditransitive verbs because already the most elementary transaction and communication events to be communicated by a single verb involve three participants: the giver, the recipient, and the given object, or the speaker, the addressee, and the uttered message. If such a device exists, it can easily be generalized to cover also the expression of more complex or derived three-participant events. In any case, the ditransitive option extends the grammatical potential of transitive verbs. It is the recipient or addressee who constitutes the third argument not found in a prototypical transitive verb.

The following survey will testify that it is not a simple step to go beyond the argument linking system developed for transitive verbs. Several variants are imaginable, either of the more conservative or the more innovative kind, but it also depends on the particular transitive system how a third argument is to be integrated. The problem of realizing a third argument can be reduced to transitive verbs, or the existing option for transitive verbs can be slightly extended. A positional system may introduce a third position, and a case system may introduce a third case. 
More precisely, I will present three major typological variants. First, the number of syntactic arguments is nontrivially reduced by a serial verb construction or by noun incorporation; both solutions are innovative for human language in general, although they are nearly absent in the Indo-European family (section 6.3). Secondly, the recipient is considered to be the primary object and therefore treated like the object of a transitive verb, which is perhaps the most conservative solution (section 6.4). Thirdly, the recipient is treated differently from the object of a transitive verb, mainly in two alternative ways: as the intended goal or as the intended possessor (section 6.5). These two ways also seem to underlie the English 'dative' alternation, which is discussed in section 6.6.

Before that, I will discuss the semantic decomposition of ditransitive verbs in section 6.1 , and a few of the general constraints that help us to understand the concept of ditransitive verb formation more theoretically (section 6.2).

\subsection{How complex are ditransitive verbs semantically?}

Why do we care about ditransitive verbs? On the one hand, all speakers of a civilized community must be able to express three-participant events of the kind one finds in transactions and communications. On the other hand, all argument linking types found in the languages around the world seem to have specialized on the basis of transitive verbs; how can they integrate a third argument?

From the semantic point of view the answer is relatively simple. An elementary threeparticipant event involves a transitive event directed to a person. One gives (or says) something to an intented recipient; similarly, one puts something to an intended location. All ditransitive events include a transitive action with an intended result, which itself is stative. It seems that mainly two types of two-place stative predicates have evolved in the conceptual history of mankind: $\operatorname{LOC}(\mathrm{z}, \operatorname{AT}(\mathrm{y}))$ and $\operatorname{POSS}(\mathrm{y}, \mathrm{z})$. Something is located at some place or object, or something is in the possession of some person. These two predicates can characterize the result of an action performed on z. Accordingly, they determine what one can observe in ditransitive verbs.

The combination of a transitive action with a two-place stative result usually is linked by means of a shared argument. If I sent a letter, and you received the letter, 'the letter' is the shared argument. Similarly, if I say 'hallo', and you hear 'hallo', this 'hallo' is shared in our minds. In order to integrate two predicates of this sort in just one (ditransitive) verb, the respective object must be the shared argument. What we have to find out is first, how the third argument is integrated semantically, and, then, how it is expressed. The latter problem is dealt with in the further sections.

\section{Two types of elementary ditransitive verbs}

As already indicated, all verbs with three arguments are semantically complex, they can be decomposed into two predicates: one describing a certain activity and the other describing a certain result. It seems that every language exhibits at least some of these verbs in its primitive lexical repertoire (with no sign of morphological derivation). A closer inspection of these underived ditransitive verbs yields that they belong to two well-defined semantic classes: change of possession and change of location verbs. The former express a transition into a state of possession (to be defined by BECOME POSS), while the latter express a transition into a state of location (to be defined as BECOME LOC).

Typical change of possession verbs are give, lend, and buy (and all the corresponding 'give' verbs in other languages, but also 'show' and 'ask' are often included). The third 
argument of these verbs is typically a recipient, a human or animate being who comes into the possession of an object. The three participating semantic roles can be called agent $(=x)$, recipient $(=\mathrm{y})$ and theme $(=\mathrm{z})$. (80b) shows possible semantic representations of these verbs.

(80) Change of possession verbs

a. Anna gave Max a book.

Anna bought Max a book.

$\mathrm{b}$ give: $\quad \lambda \mathrm{z} \lambda \mathrm{y} \lambda \mathrm{x} \lambda \mathrm{e}\{\operatorname{ACT}(\mathrm{x}) \& \operatorname{BEC} \operatorname{POSS}(\mathrm{y}, \mathrm{z})\}(\mathrm{e})$

buy: $\quad \lambda \mathrm{z} \lambda \mathrm{y} \lambda \mathrm{x} \lambda \mathrm{e}\{\operatorname{BUY}(\mathrm{x}, \mathrm{z}) \& \operatorname{BEC} \operatorname{POSS}(\mathrm{y}, \mathrm{z})\}(\mathrm{e})$

Typical change of location verbs are put, throw, push, and glue (and many similar verbs in other languages). The third argument of these verbs is typically a goal, an object or a place where the theme becomes located. Many languages have developed locative prepositions or locative cases to encode location in combination with verbs. Thus, what we actually observe in the English examples in (81a) is a third syntactic argument in form of a directional prepositional phrase (PP), and the goal is an argument of the preposition rather than of the verb itself. We can speak of 'indirect linking' in such a case.

(81) Change of location verbs

a. Anna put the glasses behind the tree.

Max threw the book behind the tree.

b. throw: $\quad \lambda \mathrm{P} \lambda \mathrm{y} \lambda \mathrm{x} \lambda \mathrm{e}\{\operatorname{THROW}(\mathrm{x}, \mathrm{y}) \& \mathrm{P}(\mathrm{y})\}(\mathrm{e})$

behind the tree: $\quad \lambda \mathrm{u}(\mathrm{BEC}) \mathrm{LOC}(\mathrm{u}, \mathrm{BEHIND} *$ the tree)

throw behind the tree: $\lambda \mathrm{y} \lambda \mathrm{x} \lambda \mathrm{e}\{\operatorname{THROW}(\mathrm{x}, \mathrm{y}) \& \mathrm{BEC} \operatorname{LOC}(\mathrm{y}, \mathrm{BEH} *$ the tree $)\}(\mathrm{e})$

(81b) shows how such an indirect linking takes place. The first line indicates that ditransitive throw requires a predicative argument $\mathrm{P}$, which, for instance, can be instantiated by the PP behind the tree. Semantically, this PP provides the predicate LOC with the specification of a BEHIND* region with respect to 'the tree'. The last line shows the full VP as a result of combining these two pieces of information.

Many languages allow that the prepositional content gets incorporated into the verb, as it happens in the English word enter. This verb can be decomposed into $\{\mathrm{GO}(\mathrm{x}) \&$ BECOME $\operatorname{LOC}(\mathrm{x}, \mathrm{IN} \mathrm{z}))\}$, where the thing that changes its position is the moving object (x) itself. Verbs that undergo the so-called locative alternation quite systematically incorporate the predicate LOC into the verb. (82a) shows the change of location verb in the same format as (81), and (82b) shows the variant in which the goal becomes a direct argument of the verb. (For reasons that cannot be discussed here in detail, the theme becomes oblique according to the Restriction on structural arguments in Wunderlich (1997:41), see (96) below. Notice also that German marks the alternation with the prefix be-, whereas English leaves it unmarked.)

(82) Locative alternation in English and German

a. Anna pasted all the photos at the wall.

Anna klebte all die Photos an die Wand. glue: $\lambda \mathrm{P} \lambda \mathrm{y} \lambda \mathrm{x} \lambda \mathrm{e}\{\operatorname{GLUE}(\mathrm{x}, \mathrm{y}) \& \mathrm{P}(\mathrm{y})\}(\mathrm{e})$

b. Anna pasted the whole wall with (the) photos.

Anna beklebte die ganze Wand mit (den) Photos. glue: $\lambda \mathrm{z} \lambda \mathrm{x} \lambda \mathrm{e} \exists \mathrm{y}\{\operatorname{GLUE}(\mathrm{x}, \mathrm{y}) \& \operatorname{BEC} \operatorname{LOC}(\mathrm{y}, \mathrm{z})\}(\mathrm{e})$

Some verbs (such as German schicken 'send') denote an event in which change of possession and change of location cooccur; these verbs have both options. 
(83) Change of possession \& location verbs

a. Anna schickte dem Verleger die Photos. Anna sent the.DAT publisher the.ACC photos

b. Anna schickte die Photos an den Verleger/ in die Bibliothek/auf den Speicher. Anna sent the.ACC photos at the publisher/ into the library/onto the store. 'Anna sent the photos to the publisher/to the library/to the store.' (It is a peculiarity of English that only to is possible here, see section 6.6 below.)

If the added argument is an animate being or a human person, the recipient reading is preferred, but if it is inanimate, the goal reading is preferred. ( $\$$ Anna schickte dem Speicher die Photos is odd.)

The two classes of primitive ditransitives verbs, then, can schematically be summarized by the semantic representations in (84), with the proviso that LOC in (84b) could be provided by a prepositional argument.

(84) Two classes of ditransitive verbs

a. $\operatorname{ACT}(\mathrm{x}) \& \operatorname{BECOME} \operatorname{POSS}(\mathbf{y}, \mathrm{z})$

b. $\operatorname{ACT}(\mathrm{x}) \&$ BECOME LOC $(\mathrm{z}, \mathrm{AT}(\mathrm{y}))$

$\mathrm{y}$ is a recipient - a medial argument

$\mathrm{y}$ is a goal - the lowest argument

As before, $\operatorname{ACT}(\mathrm{x})$ is assumed to be an unspecific agentive predicate, which encodes that $\mathrm{x}$ does something yielding some specific result. (Given the most unspecific verbs give and put one knows that some transitive action is involved, but can only infer from the context which kind of action.) One could instead assume an unspecific manipulation predicate MANIP(x,z), encoding that an action is done with respect to the theme $(=\mathrm{z})$, but such a move doesn't change anything in the analysis because it only introduces a shared argument. However, if one has it to do with verbs such as buy and throw, a more specific manipulation predicate is part of the verb meaning. In the result always a third argument is added, a recipient or a goal, sometimes also a source, as it happens with 'steal'. Jim stole his neighbour a knife denotes an event in the beginning of which the neighbour possessed the knife. Double object constructions of Chinese even preferently receive the source reading (Zhang XXXX).

That semantic decompositions such as those proposed in (84) are relevant becomes obvious if one considers two of the major classes of denominal verbs (Kiparsky 1998, Stiebels 1998): locatum verbs (such as to bridle/zäumen, to saddle/satteln, to sugar/zuckern, to salt/salzen), and location verbs (such as to cellar/kellern, to store/speichern, to shoulder/schultern, to bottle, to box).

(85) Two major classes of denominal verbs

a. Locatum verbs have the generalized reading $\{\mathrm{ACT}(\mathrm{x}) \& \operatorname{BECOME} \operatorname{POSS}(\mathrm{y}, \mathrm{z})\}$

b. Location verbs have the generalized reading $\{\mathrm{ACT}(\mathrm{x}) \& \operatorname{BECOME~} \operatorname{LOC}(\mathrm{z}, \mathrm{AT}(\mathrm{y}))\}$

The meaning of a denominal verb derives from one of the generally available semantic templates into which the respective noun is integrated as the lowest argument. Thus, to bridle the horse gets the reading 'supply a horse with a bridle' (i.e., make the horse to have a bridle), whereas to cellar the wine gets the reading 'put the wine into a cellar' (i.e., make the wine to be located in a cellar).

The possibility of deriving a semantically complex verb from a simple noun constitutes one of the major arguments for semantic decomposition. Without having some notion of semantic template, it would remain mysterious why speakers can so productively (and also regularly) turn nouns into verbs. The only open question in this field is: which of the several possible readings of a denominal verb is preferred, i.e. which semantic template is used. An 
important hint comes from the argument structure used with the verb. If one is confronted with the new sentence John matchboxed the crumbs, one will easily identify the reading that John collected the crumbs in a matchbox (following the template of location verbs), while the sentence John matchboxed the whole time (with matchbox as an intransitive verb) suggests a different reading, e.g. that John produced matchboxes, and John matchboxed the crumbs into a box (where matchbox itself is a change of location verb) suggests that John used a matchbox as a shovelling instrument. Given that both types of denominal verbs cited in (85) are productive, it is clear that both change of possession and change of location are available options. (The semantic templates used in the generation of denominal verbs probably derive from generalizations concerning semantic classes of simple verbs.)

The main topic of sections 6.3 to 6.5 below relates to the question of how a third argument is realized, given a certain argument linking potential for transitive verbs. In languages that amply use local prepositions, the problem of how a third argument is realized mainly reduces to the realization of the recipient.

\section{Derived ditransitives}

There are several possibilities of supplying an ordinary transitive verb with a third argument. These argument extension operations are often marked morphologically (e.g. by an affix added to the verb), but they can also be unmarked. These derivations include

- the causative (which adds a causer)

- the applicative (which adds a beneficiary, a locatum, or an instrument)

- the so-called possessor raising (which adds a possessor of the manipulated thing)

Except particles and prefixes (such as be-in the locative alternation), German does not have morphological means to perform these derivations, and the particles/prefixes usually have more than one semantic function (Stiebels 1996). Nevertheless we find all three types of derivations, a causative verb (86a), and a benefactive or possessor dative without further marking on the verb (86b-c), with the schematic representations in (87).

(86) a. Sie ließ ihn einen Brief schreiben.

'She let him write a letter.'

b. Sie kochte ihm eine Suppe.

'She cooked him a soup.' (alienable possession)

c. Sie verband ihm die Hand.

She bandaged he.DAT the hand

'She bandaged his hand.' (inalienable possession)

(87) a. $\operatorname{ACT}(\mathrm{x}) \& \operatorname{WRITE}(\mathrm{y}, \mathrm{z})$

b. $\operatorname{COOK}(\mathrm{x}, \mathrm{z}) \& \operatorname{BECOME} \operatorname{POSS}(\mathrm{y}, \mathrm{z})$

c. BANDAGE $(\mathrm{x}, \mathrm{z}) \& \operatorname{POSS}(\mathrm{y}, \mathrm{z})$

Since an extra argument must be licensed by some predicate, operations that add an argument are always incremental from the semantic perspective. The causative adds the higher predicate $\operatorname{ACT}(\mathrm{x})$, in which $\mathrm{x}$ is the causer (an agent), while the agent of the embedded verb ( $\mathrm{y}$ ) becomes a causee. (In the German verb complex schreiben lassen 'let write', the causee is realized by accusative.) The two other operations, illustrated in (86bc), add POSS (or BECOME POSS); in such a case the extra argument (y) is the medial one. The main difference is that the beneficiary in (86b) tends to be an alienable possessor (one who comes into possession), while the possessor in (86c) is of course an inalienable possessor (one to whose body the hand belongs). 
Most grammatical systems react to these argument extensions in the same way as they react to the basic 'give' type, probably on the basis of generalization. (For instance, the German sentences in (86b-c) display the same canonical ditransitive pattern NOM - DAT ACC as geben 'give'.) However, whether the causative is involved in this generalization, depends on how far the 'give' pattern is generalized. For instance, the causee in the Hungarian causative (88b) is differently realized from a recipient, see (88a). One has to assume that the Hungarian causative morpheme imports an instrumental marking.

(88) 'Give' and causative in Hungarian

a. Anna Péter-nek adott egy könyv-et.

Anna Peter-DAT gave a book-ACC

'Anna gave Peter a book.'

b. Anna Péter-rel olvas-tat egy könyv-et .

Anna Peter-INST read-CAUS a book-ACC

'Anna lets Peter read a book.'

The languages of the world widely differ in the way they add a higher argument (a 'new' subject) or a lower argument (a further object) to a transitive verb. Surveys on causative constructions can be found in Comrie (1985) and Dixon (2000), among others. I will briefly illustrate two ways of adding a lower argument, that of Bahasia Indonesia and that of Tzotzil, a Mayan language of Mexico.

Bahasia Indonesia has a very productive way of adding a third argument. Transitive verbs can be used with a prepositional phrase (89), or they can be suffixed with -kan (an applicative morpheme), which results in a double object (DO) construction (see also section 6.4 below). According to most of the object tests applied by Chung (1983), it is the first (the added) object that behaves like a transitive object.

(89) Transitive verbs with PP in Bahasia Indonesia (Chung 1983)

a. mereka mem-bawa daging itu [kepada dia $]_{P P}$. they TRANS-bring meat the to him

'They brought the meat to him.'

b. Ali mem-beli telefisi [untuk ibu-nja $]_{\mathrm{PP}}$.

Ali TRANS-buy television for mother-his

'Ali bought a televison for his mother.'

(90) Ditransitive extension in Bahasa Indonesia (Chung 1983)

a. mereka mem-bawa-kan dia daging itu.

they TRANS-bring-BEN him meat the

'They brought him the meat.'

b. Ali mem-beli-kan ibu-nja telefisi.

Ali TRANS-buy-BEN mother-his television

'Ali bought his mother a televison.'

In contrast to the derived ditransitives, a few basic ditransitives verbs can be used in the DO construction without -kan (beri 'give', kasih 'give', bajar 'pay'), but here -kan is used to mark the prepositional construction optionally, which is a curious idiomatic fact of Indonesia. 
(91) Alternation of 'give' in Bahasia Indonesia (Chung 1983:234)

a. Ali beri wanita itu surat.

Ali give woman the letter

'Ali gave the woman a letter.'

b. Ali beri (-kan) surat kepada wanita itu.

Ali give-BEN letter to woman the

'Ali gave a letter to the woman.'

The only possible way of forming ditransitive verbs in Tzotzil is be-suffixation applied to transitive verbs. The added argument, the recipient in $(92 a, b)$, is then marked by nominative agreement like the object of a transitive verb. In the last example (92c) the verb agrees with the possessor of the object (which in addition is realized by ergative on the noun).

(92) Ditransitive extension in Tzotzil (Aissen 1987: 107, 126)

a. Ch-a-k-ak'-be.

INCOMPL-2.NOM-1.ERG-give-DITRANS

'I'll give it to you.'

b. 'i-h-con-be xitom li Sune

COMPL-3.NOM-1.ERG-sell-DITRANS pig the Sun

'I sold pigs to Sun.'

c. Ch-i-s-toyilan-be j-jol.

INCOMPL-1.NOM-3.ERG-keep.lifting-DITRANS 1.ERG-head

'He kept lifting my head.'

In this language, 'give' is not a basic ditransitive but rather a transitive verb that has to undergo the applicative -be, which is generalized to cover also possessor raising. This observation nicely supports the assumption that recipients are a kind of possessors.

\subsection{Some general constraints}

If one accepts semantic decomposition in which at least two predicates are combined, the generative power of a language is increased. One therefore tries to find restrictions of the possible combinations, so that the generative power is not increased too much. (If everything is possible in a language, utterances would produce noise rather than articulated speech.) $\mathrm{s}$ more than it becomes an important theoretic task to restrict the possible combinations of predicates in a verb or verb-like complex (such as verb-verb compound or serial verb construction).

In the theory proposed as Lexical Decomposition Grammar (Wunderlich 1997), the semantic form (SF) of a verb is intended to be a minimal semantic decomposition, i.e., the meaning of the verb is decomposed only so far as is necessary for predicting argument hierarchy and other structural features that are grammatically relevant. Perhaps it is never possible to specify the conceptual meaning of a verb completely, at least, this would not be the aim of linguists who are interested in the structural impact of decomposition.

In order to determine argument hierarchy, SF decompositions of verbs must be asymmetric. Logically (conceptually), A \& B and B \& A would be equivalent, but as SF decompositions they are not. By convention, the first predicate in our representations is considered to be the higher predicate, so that A \& B is structured as [A [\& B]].

According to various work by Kaufmann (1995b), Kaufmann \& Wunderlich (1998), Wunderlich (2000) and Gamerschlag (2003), the semantic form (SF) of a simple or derived 
verb underlies at least the following constraints: the combination of predicates must denote a coherent situation (93a), a causal predicate has to precede the result predicate (93b), and there must exist some referential chain between the components (93c).

(93) a. COHERENCE. Subevents encoded by the predicates of a decomposed SF structure must be connected contemporaneously or causally/consequently.

b. ICONICITY. In a decomposed SF structure, cause precedes result, and consequences follow their instigation.

c. CONNEXION. In a decomposed SF structure, each predicate must share at least one argument with another predicate, either explicitly or implicitly.

COHERENCE requires that the two predicates in A \& B relate to the same time span, or they are connected by a causal relation. In the latter case, ICONICITY tells us which predicate has which function: in $\mathrm{A} \& \mathrm{~B}, \mathrm{~B}$ is the result of $\mathrm{A}$, or $\mathrm{B}$ belongs to a set of consequences enabled by A. Because of such a strong requirement, $\mathrm{ACT}(\mathrm{x}) \& \operatorname{BECOME} \operatorname{POSS}(\mathrm{y}, \mathrm{z})$ can only receive the interpretation that $\mathrm{ACT}(\mathrm{x})$ causes $\mathrm{y}$ to get into the possession of $\mathrm{z}$ because an ongoing activity and a transition (expressed by BECOME) can never be contemporaneous (at most they could overlap temporally). Therefore, a connecting predicate such as CAUSE need not be encoded explicitly.

Although serial verbs (see also 6.3) seem to form a syntactic construction, they nevertheless underlie the condition of coherence. It has been unanimously pointed out by all researchers concerned with serial verbs that they denote just one coherent event, in contrast to syntactic coordinations, which denote two independent events. For instance, a serial verb construction never allows a resumptive pronoun (94a), while a coordination often requires it (94b). This suggests that serial verbs are a lexical complex in which the argument that separates the two verbs is infixed, similarly to a particle verb, in which the particle often is separated from the verb. (The examples are from Edo, a Benue-Congo language of Nigeria.)

(94) Serial verb vs. coordination in Edo (Stewart 2001: 60)

a. Òzó lé èvbàré ré.

Ozo cook food eat

'Ozo cooked and ate food.'

b. Òzó lé èvbàré rrí ókè.

Ozo cook food eat it

'Ozo cooked food and ate it.'

CONNEXION requires that at least some of the arguments of different predicates are identified. Thus, $\operatorname{COOK}(\mathrm{x}, \mathrm{z}) \& \operatorname{BECOME} \operatorname{POSS}(\mathrm{y}, \mathrm{z})$ in $(87 \mathrm{~b})$ above characterizes a possible verb (e.g., 'John cooks porridge for Anne'), whereas $\operatorname{COOK}(\mathrm{x}, \mathrm{u}) \& \operatorname{BECOME} \operatorname{POSS}(\mathrm{y}, \mathrm{z})$ does not. ( $\S$ 'John cooks porridge and Anne gets a cake' cannot be expressed in a single verb.)

An internal argument of a predicate that is followed by another predicate in SF cannot be realized structurally. For instance, in the resultative construction in (95b) one cannot express the stuff that was drunk.

(95) Strong resultatives in English (Kaufmann \& Wunderlich 1998)

a. The guests drunk all of the red wine.

b. The guests drunk the wine cellar empty.

c. $\operatorname{DRINK}(\mathrm{x}, \mathrm{u}) \&$ BECOME EMPTY(z) 
The object $u$ of DRINK becomes nonstructural if a resultative is added that predicates of a different argument than $u$. Wunderlich (1997) proposed the constraint (96), which restricts the mapping of SF representations into morphosyntax.

(96) Structural Argument. An argument is structural only if it is either the lowest argument or (each of its occurrences) L(exically)-commands the lowest argument.

L-command is defined for the nodes in SF, which represent logical types, as follows: $\alpha$ L-commands $\beta$ if the node $\gamma$, which either directly dominates $\alpha$ or dominates $\alpha$ via a chain of nodes type-identical with $\gamma$, also dominates $\beta$.

With these preparations, one can establish the argument hierarchies for the two classes of ditransitive verbs outlined in (84), as well as for causativized transitives, in (97).

(97) Argument hierarchy of ditransitive verbs

a. Change of possession: $\quad \operatorname{ACT}(\mathrm{x}) \&$ BECOME POSS $(\mathrm{y}, \mathrm{z})$

argument hierarchy: $\quad \mathrm{x}>\mathrm{y}>\mathrm{z}($ agent $>$ recipient $>$ theme)

b. Change of location: $\quad \operatorname{ACT}(\mathrm{x}) \&$ BECOME LOC $(\mathrm{z}, \mathrm{AT}(\mathrm{y}))$ argument hierarchy: $\quad \mathrm{x}>\mathrm{z}>\mathrm{y}($ agent $>$ theme $>$ goal $)$

c. Causativized transitives: $\operatorname{ACT}(\mathrm{x}) \& \operatorname{VERB}(\mathrm{y}, \mathrm{z})$ argument hierarchy: $\quad \mathrm{x}>\mathrm{y}>\mathrm{z}$ (causer $>$ causee $>$ patient)

In these minimal representations it is sufficient to satisfy CONNEXION by implicit arguments: in fact, $x$ would have to act on $z$ in both (97a) and (97b), and on y in (97c).

In the remainder of this chapter I will briefly survey the various constructions by which three arguments can be realized. Several of these constructions can coexist in a language. Some ditransitive verbs may follow one of the patterns, while other verbs follow another pattern, or a single verb may allow variation according to contextual circumstances. It is also possible that the pattern found for dependent marking (morphological case) differs from that found for head marking (e.g., agreement).

\subsection{The number of syntactic arguments is reduced}

In this section two constructional types are considered which avoid the introduction of any further means for dealing with three structural arguments: serial verb construction and noun incorporation. As Mattissen (this volume) points out, these two constructions widely determine what is known as the polysynthetic type of language.

\section{Serial verb constructions}

The serial verb construction is found in many South-East Asian and West African languages, but also in other regions of the world. It is not restricted to particular language families and also occurs typically in Creole languages, as well as in sign languages. The examples in (98) from Yoruba, a Benue-Congo language of Nigeria, illustrate a serial verb construction encoding change of possession. The first verb is transitive and realizes subject and object positionally. The second verb with the meaning of 'give' shares these two arguments and adds a third one, which is always the recipient. Literally, the construction means 'Baba took the gown and then he gave $i t$ to the chief'. Such a construction is often the only way to realize the ditransitive verb 'give', but one never finds anaphoric pronouns in it, such as he and it in the English paraphrase given above. As already pointed out, several tests show that a serial verb construction denotes a single coherent event rather than the coordination of two independent events; such a construction is thus more similar to a single compound verb than to a syntactic coordination. 
(98) Change of possession: serial verbs in Yoruba, left-headed (Baker 1991:80f)

a. Bàbá fi èwù fún oba.

Baba take gown give chief

'Baba gave the gown to the chief.'

b. Ó ra isu fún mi.

3 sg buy yam give $1 \mathrm{sg}$

'He bought me a yam.'

Yoruba is a SVO positional type language, in which an object has to follow the verb; in other words, the verb phrase (constituted by the verb and its object) is left-headed. The serial verb construction is left-headed, too, i.e., the first verb constitutes the head, and therefore, the shared object has to be realized right-adjacent to the first verb. Consequently, the two verbs are separated by the shared object, although they function semantically as a compound. Most languages with serial verb constructions dominantly belong to the SVO type, however, Ijo, an Atlantic-Congo language, shows the rare case of a serial verb construction based on the SOV pattern (99). Here, the head is systematically to the right: the object precedes the verb, and the second verb constitutes the head of the serial verb, as indicated by the tense marking. Here, again, the two verbs are separated by a noun, but in this case by the recipient, an argument that belongs exclusively to the second verb.

(99) Change of possession: serial verbs in Ijo, right-headed (Williamson 1965:54)

Erí opúru-mo àki tobóú pìri-mi

$3 \mathrm{sg}$ crab-DET.PL take boy give-PAST

'He gave the boy the crabs.'

The serial verb construction is able to express many more semantic relationships between two verbs (such as instrumental 'take a knife and cut the tree', consequential 'go to the market, buy a fish and cook (it)', or manner 'go around and search'). (100) shows an example of change of location in the SVO-type. Here, the first verb introduces the agent and the theme, which function as the shared object, while the second verb adds the goal. The goat in the example is the being that is pushed and thereby caused to fall into the hole.

(100) Change of location: serial verbs in Edo, left-headed (Baker \& Stewart 1999:20)

Úyì sùá èwé lá ùvún.

Uyi push goat enter hole

'Uyi pushed the goat into the hole.'

The function of the serial verb construction is to offer additional argument positions in case of a triadic predicate. This is obvious in examples that repeat the same predicate concept or even the same verb. In Oaxaca Chontal, a Hokan language of Mexico, the two 'give' verbs are sligthly different (101), whereas Cantonese repeats the same verb in just one construction (102). In both examples the recipient is added by the second verb.

(101) Double-give in Oaxaca Chontal (Sedlak 1975, Waterhouse 1962: 25)

kúpa elmel ${ }^{\mathrm{y}} \mathrm{u}$ páypa liw’á.

3sg.gave the.money 3sg.gave.to his.son

'He gave the money to his son.' 
(102) Double-give in Cantonese (Sedlak 1975:146)

yo pei ts'in pei koey.

1 sg give money give $3 \mathrm{sg}$

'I give money to him.'

If serial verbs are a means to realize additional arguments, one expects that one of the verbs can get grammaticalized to a marker for a specific additional argument. In this connection it is interesting to note that Mandarin Chinese allows such a generalized marker in both verb positions: in the second position 'give' serves as recipient marking, while in the first position it serves as beneficiary marking, as shown by the alternation in (56).

(103) Alternation between recipient und beneficiary marking in Mandarin (Luo 1999:4)
a. Lisi xie xin gei wo.
(Recipient or goal) write letter give $1 \mathrm{sg}$

Lisi wrote me a letter.
b. Lisi gei wo xie xin. give 1 sg write letter
(Beneficiary)
Lisi wrote a letter for me.

\section{Noun incorporation}

Another, totally different way of reducing the number of syntactic arguments is noun incorporation. A verb can integrate its lowest argument by lexical incorporation so that a more complex verb is yielded whose valency is reduced by one: a transitive verb shifts to intransitive, and a ditransitive verb shifts to transitive. This makes it possible to account for all ditransitive verbs by the same grammatical means that are used in transitives. One such a language is Arizona Tewa (see also section 4.3 above). The example in (104) shows that the theme argument is incorporated, so that the PAT prefix can successfully refer to the recipient.

(104) Ditransitive verbs in Arizona Tewa
na:'in dí-k'ú:wá-mégí
we 1.PAT-sheep-give
'We were given sheep (by you or some third person).')

Yukatek Maya is another language with incorporation. The examples in (105) illustrate that in both change of possession and change of location first the respective theme is integrated by incorporation, and then the resulting verb undergoes applicative, which allows a further argument. This further argument is a recipient realized by a suffix in (105a), while it is a goal realized syntactically by a noun phrase in (105b).

(105) Noun incorporation, followed by applicative, in Yukatek (Krämer \& Wunderlich 1999: 466f)
a. $\operatorname{taan}=\mathrm{u}$
kon-lol -t-ik-eťs
INCOMPL $=3 . E R G$
sell-flower -APPL-IMPF-2.NOM
'He is selling flowers to you.'
b. h b b in-etš a lam $-k^{2} \mathrm{ak}^{2}-\mathrm{t}$ le kòl-o?
COMPL go-2.NOM 2.ERG stick.into-fire-APPL DEF cornfield-DEM
'You went to set fire to the cornfield.'


These examples show that, similarly to the serial verb construction, change of possession and change of location can be treated alike. Both require a third argument: the argument which is added by the second verb (of the serial verb construction) or by applicative (after noun incorporation) is either a recipient or a goal. This is predicted by the templates given in (84a) and (84b).

At the first glance, the paleosibiric language Nivkh seems to constitute a counterexample to our prediction. Surprisingly, the third argument is always incorporated into the verb, regardless of whether there is a change of possession, as in (106), or a change of location, as in (107). Under the assumption that only the lowest argument of a verb can be incorporated, one expects that a goal can be incorporated, as in (107), but not a recipient because a recipient is not the lowest argument.

(106) Change of possession in Nivkh (Mattissen 2001:158ff.)

a. əmək karandas p'-овla-k'im-d.

mother pencil REFL-child-give-INDIC

'The mother gave a pencil to her child.'

b. ก̃i to hə-ñivx-ar-d.

$1 \mathrm{sg}$ fish that-person-feed-INDIC

'I am feeding fish to him/her.'

(107) Change of location in Nivkh

a. ñi seta yir-t'i-d.

1sg sugar dish-put-INDIC

'I put the sugar into the cup.'

b. ma t'om-hupu-d.

dried_fish fat-dip-INDIC

'I dipped dried fish into fat.'

The only possible way to account for data such as those in (106) is to assume that recipients are treated as goals. More precisely, one has to assume that the dominant relation in Nivkh is LOC, even if other languages would prefer POSS. One piece of evidence comes from the fact that Nivkh does not have any possession verb. In order to express simple possession (or lack of possession), existential verbs are used with locative case (108a). On the other hand, locations (being goal or not) are easily incorporated. (108b) shows an example with locative incorporation into a stative intransitive verb.

(108) Possession verb and locative incorporation in Nivkh (Mattissen)

a. ñ-uin hə-bityə q'au-d.

1sg-LOC that-book not_exist-INDIC

'I do not have that book.'

b. p'-rəu-овla parta-ñv-d.

REFL-teach-child desk-sit(down)-INDIC

'The pupil sits at a desk.'

In Nivkh, the only relevant mechanism to indicate the role of an argument is noun incorporation, and in this respect, Nivkh is really unique. Moreover, such a mechanism has an obvious advantage. Given that a ditransitive verb expressing a change of possession has two animate arguments, it is most felicitous to make a clear distinction between these two arguments. The answer of Nivkh is: an incorporated animate argument cannot be an agent, so it must be a recipient or a beneficiary. 
Let us finally see how causative and noun incorporation can interact. The causative adds an argument, and noun incorporation binds an argument. This can be done in either order, and even iteratively, as shown by the following examples from Alutor, a paleosibiric language of Kamchatka. (109a) shows that a normal transitive verb derives if first the object of the underlying verb is incorporated and then causative is applied (literally 'I made my wife meat-eat'). If, however, causative applies first (109b), a ditransitive verb is derived, the theme of which must be realized obliquely (here: by instrumental case); finally, by incorporating the causee, the verb becomes intransitive, as seen by the nominative marking of the agent (literally 'I wife-fed with meat'). (Note that the final slot of the intransitive verb repeats the information about the subject.)

(109) Differing ordering of causative and noun incorporation in Alutor (KoptjevskajaTamm)
a. gəm-nan tə-nə-tərgə-?awəj-at-ən
I-ERG 1sg.S-CAUS-meat-eat-SUFF-3SG.O
'I fed my wife with meat.'
yavə
b. gəmmə tə-navə-n-awəj-at-ək
I.NOM 1sg.S-wife-CAUS-eat-SUFF-1sg.S
'I fed my wife with meat.'
wife.NOM
tərg-a
meat-INSTR

In Alutor, causative can be applied iteratively, and following it, also noun incorporation can be repeated. Thus, as the result of such iterative operations an intransitive verb is derived in (110a). One also sees that the composition starts from the lexical core (the stative verb 'dry') by adding the meaningful operations to the left, whereby each causative also fills a suffix position to the right. Like in Nivkh, it is the lack of argument-realizing means that enforces noun incorporation. In this respect, (110b) is not really a counter-example, although the recipient is marked by dative. This dative probably is not a structural case in the sense of section 6.5 (below); note that the common effects of causative and noun incorpation yield a ditransitive verb, the lowest argument of which is the recipient however, it is the causee that remains as the object of a transitive verb. Presumably, the simple sentence 'I gave books to the mother' would be expressed by something like 'I-ERG mother.NOM book-give'.

(110) Causative and noun incorporation in Alutor (Koptjevskaja-Tamm )
a. gəmmə t-akka-n-nalgə-n-kuww-at-avə-tk-ən
I.NOM 1sg.S-son-CAUS-skin-CAUS-dry-SUFF-SUFF-PRES-1sg.S
'I am making my son dry skins.'
b. gəm-nan akək tə-kənyiga-n-nyəl-av-ən əlla?ə-N
I-ERG Son-NOM 1sg.S-book-CAUS-give-SUFF-3sg.O mother-DAT
'I made the son give a book/books to the mother.'

\subsection{The recipient is treated like the object of a transitive verb}

In this section, we consider various ways to encode the recipient, the prototypical third argument, similarly to the object of a transitive verb. In a system based on animacy, the recipient is most similar to an animate object. Then there are two options to make the recipient the most prominent object: either the recipient is marked by accusative like the transitive object, or conversely, the theme is demoted by oblique marking. In the positional linking type, the recipient takes the verb-adjacent position like the transitive object. Several tests such as passive and object agreement show that the recipient indeed occupies the 
grammatical role of transitive objects. Therefore this solution of the third-argument problem can best be characterized by the term 'primary object', first introduced by Dryer (1986). Such a clarification is needed because much confusion has arisen by the undifferentiated use of 'direct' and 'indirect' object.

Argument hierarchy seems again to be the best background on which the several notions of 'object' can be based. First one has to delimit the set of objects, which all are different from the highest argument (the subject) and therefore designated as $+\mathrm{hr}$. Then, a primary object is the highest object, whereas a direct object is the lowest object. In this section we are concerned with the primary-object solution.

\section{The recipient is the more salient object semantically}

For a language in which animacy plays a crucial role it is expected that the recipient is treated alongside with (prototypically animate) transitive objects, so that the theme argument remains unmarked. This indeed can be observed in languages of the activeinactive type, as well as in languages with inverse marking.

In section 3.4, we discussed the active-inactive type, and have already seen in (29) that recipients are marked by inactive affixes on the Dakota verb. Another example that illustrates this is (111).

(111) Inactive recipient marking in Lakhota (Faltz 1978:81, Van Valin, p.19)

$\begin{array}{ll}\text { Bill wówapi kin (miye) ma-k'u } & \text { ' } \\ \text { Bill book DEF 1sg } & 1 \text { sg.INACT-give } \\ \text { 'Bill gave me the book.' } & \end{array}$

In an inverse system (discussed in section 4.1), the grammatical role of animate arguments is determined by the direct vs. inverse marking. With direct marking, the less salient person is the object, whereas with inverse marking it is the subject, thus shifting its grammatical role. The two animate arguments involved are either agent/patient of a transitive verb or agent/recipient of a ditransitive verb. (112) illustrates a direct form of Fox (Algonquian) which marks $3 \mathrm{pl}$ recipient. That the theme markers affect the recipient is also shown in (113) from Ojibwa (Algonquian): here, the 1st person, which is more salient than a 3rd person, is agent in the direct form (113a), but recipient in the inverse form (113b).

(112) Recipient in Fox (Dahlstrom 1995: 4)

ne-mināw-aki ne-šisēh-aki mēšomakini.

1 -give-3pl 1-uncle-pl that(obv).which.I.shot

'I gave my uncles the game which I killed.'

(113) Recipient in Ojibwe (Dryer 1986: 812; Rhodes 1976:139)
a. n-gi:-mi:n-a: mzinhigan za:bdi:s.
1-PAST-give-3.ANIM
book
John
'I gave John a book.'
b. n-gi:-mi:n-ik-a:
1-PAST-give-INV-3.ANIM book John
'John gave me a book.'

In Plains Cree, ditransitive verbs are productively formed by adding the applicative -amaw to an inanimate transitive stem (osi:ht-amaw 'make something for a person', kimot-amaw 'steal something from a person'). The resulting ditransitives are classified as transitive animate, with the added argument as the primary object (Dahlstrom 1991: 137). 
The Algonquian languages also exhibit a rich system of valency-increasing markers, deriving ditransitive verbs if they are applied on transitive ones, see (114). However, the result is always classified as transitive animate because only one object can be marked on the verb. In the causative it is the causee that is co-indexed on the verb, while in the applicative it is the applied object. (115) illustrates that a 1st person beneficiary only becomes object with an inverse verb.

(114) Some derived ditransitives in Ojibwe (Valentine 2001: 435, 463, 465)
a. Causative
baak-nam-oo-h
b. Comitative
wiid-oopo-m
open-TRANS.ANIM-epenth-CAUS
WITH-eat-WITH
'get someone to open something'
'eat with someone'
c. Benefactive
short-stringlike.object-BEN
'shorten something (stringlike) for someone'

(115) Beneficiary in Ojibwe (Valentine 2001:700)

Aw kwe n-dazht-amaa-g n-babgiwyaan.

that woman 1-make-BEN-INV 1P-shirt

'That woman is making me a shirt.'

\section{The recipient is marked by accusative}

'Accusative' is the name of a case that marks the object of a transitive verb. Khasi, a MonKhmer language of Assam, uses ya for this purpose, as shown in (116a). With a ditransitive verb, however, the accusative marker ya switches to the third argument (the Beneficiary, i.e. the person who profits from the action of teaching), while the original object remains unmarked (116b).

(116) Accusative marking in Khasi (Dryer 1986: 816, Rabel 1961:77)

a. Puu hiikay ya ka ktien pharen.

he teach ACC the language English

'He teaches English.'

b. Puu hiikay ya ya ka ktien pharen.

he teach ACC 1sg the language English

'He teaches me English.

In the West-Tibetan language Kham, a $3^{\text {rd }}$ person subject is ergative-marked, and an animate object is accusative-marked, while an inanimate object remains unmarked $(117 \mathrm{a}, \mathrm{b})$; furthermore, the verb agrees with a $1^{\text {st }}$ person object $(117 \mathrm{c})$. Now, turning to a ditransitive verb, exactly these options are combined: the 1 st person recipient is marked like the corresponding patient, and the (inanimate) theme argument remains unmarked (117d). Ditransitive verbs thus show the case pattern ERG-ACC-NOM, which is typical for a mixed ergative-accusative language lacking dative.

(117) Accusative-marking and object agreement in Kham (Dryer 1986:817, Watters 1973:44, 46, 50)

a. nga: zihm nga-jxy-ke

$1 \mathrm{sg}$ house 1sg-build-PAST

(inanimate object)

'I built a house.' 

b. no-e ka:h-lay poh-ke-o. (animate object)
3sg-ERG dog-ACC beat-PAST-3sg
'He beat the dog.'
c. no-e nga-lay cyu:-na-ke-o.
3sg-ERG 1sg-ACC watch-1sg-PAST-3sg
'He watched me.'
d. no-e nga-lay bxhtanji ya-n-ke-o.
3 sg-ERG 1 sg-ACC potato give-1sg-PAST-3sg
'He gave me a potato.'

Another possibility for ditransitive verbs is double accusative, which one finds in Yaqui, a Uto-Aztecan language of Mexico (118a). The passive data given in $(118 \mathrm{~b}, \mathrm{c})$ reveal that it is the recipient that behaves as primary object under passivization.

(118) Double accusative and passive in Yaqui (Van Valin 2002:20; Guerrero 2000)
a. Joan Peo-ta Puka vaci-ta miika-k.
Juan Pedro-ACC DET.ACC corn-ACC give-PERF
'Juan gave Pedro the corn.'
b. Peo Puka vaci-ta miik-wa-k.
Pedro DET.ACC corn-ACC give-PASS-PERF
'Pedro was given the corn.'
c. *UPu vaci Peo-ta miik-wa-k.
DET.NOM corn Pedro-ACC give-PASS-PERF

'The corn was given to Pedro.'

Moreover, a ditransitive verb can be causativized, which then yields three accusatives in series (119a). Again, only the highest object (which in this case is the causee) can become nominative under passive (119b).

(119) Triple accusative and passive in Yaqui (Van Valin 2002:20; Guerrero 2000)
a. UPu maejto usi-ta mansana-ta yoem-ta miik-tua-k. DET.NOM teacher child-ACC apple-ACC man-ACC give-CAUS-PERF
'The teacher made the child give the man the apple.'
b. UPu usi mansana-ta yoem-ta miik-tua-wa-k. DET.NOM child apple-ACC man-ACC give-CAUS-PASS-PERF
'The child was made to give the man the apple.'

Yindjibarndi, a Pama-Nyungan language of Australia, behaves similarly: The two objects of a ditransitive verb are realized by double accusative (120a), but only the recipient can become nominative under passive $(120 \mathrm{~b}, \mathrm{c})$.

(120) Double accusative and passive in Yindjibarndi (Dryer 1986: 829, Wordick 1982: 174)

a. Ngaarta yungku-nha ngayu murla-yi.

man give-past 1sg.ACC meat-ACC

A man gave me the meat.

b. Ngayi yungku-nguli-nha murla-yi ngaarta-lu.

$1 \mathrm{sg}$.NOM give-PASS-PAST meat-ACC man-INST

I was given the meat by a man.

c. *Murla yungku-nguli-nha ngayu ngaarta-lu. meat give-PASS-PAST 1sg.ACC man-INST

The meat was given to me by a man. 


\section{The Theme is marked obliquely}

Another way to treat recipients as primary objects is to mark the theme argument. In Tahitian, a Polynesian language with the basic word order VSO, the theme of a ditransitive verb is marked by the preposition $R i$, while the recipient remains the unmarked object (121).

(121) Tahitian (Sedlak 1975: 153, Tryon 1970)

Pua horo?a a:tu vau [?i te ho:Pe tao?a $]$ Pia:na.
PAST give away 1sg OBL the one present
'I gave him the present.'

\section{The recipient is the primary object in a double object construction (DO)}

Many languages that have positional SVO marking construe ditransitive verbs by means of a double object construction $\mathrm{SVO}_{1} \mathrm{O}_{2}$, in which $\mathrm{O}_{1}$ counts as the primary object, and $\mathrm{O}_{2}$ as the secondary object. As a rule, the primary object $\mathrm{O}_{1}$ is the more prominent object, e.g., it promotes to $\mathrm{S}$ under passive, can be relativized or topicalized, or can be co-indexed with an object affix. Languages with this property, among others, are Chinese, Vietnamese, the Oceanic and the Bantu languages, as well as most of the creoles.

For English we know two alternative constructions with ditransitive verbs, one is the double object (DO) construction, in which the recipient is the primary object, and the other is the prepositional object (PO) construction, in which the theme is the primary object, while the recipient (or goal) is marked by the preposition to. As predicted by the above-mentioned rule, only the object adjacent to the verb (the primary object) is affected by passive, and it is the preferred object for relativization and topicalization, as shown in $(80 \mathrm{a}, \mathrm{b})$.

(122) The alternating ditransitive constructions of English

a. He gave the woman a book. (double object: DO)

Passive: The woman was given a book.

Relative clause: The woman he gave a book is over there.

Topicalization: The woman, he gave a book.

b. He gave the book to the woman. (prepositional object: PO)

Passive: The book was given to the woman.

Relative clause: The book he gave to the woman is over there.

Topicalization: The book, he gave to the woman.

The same is true for many other languages. However, Bresnan \& Moshi (1990) have pointed out that apart from Bantu languages with assymetric objects (Kikuyu, Chichewa, Swahili) there exist also Bantu languages with symmetric objects (Sesotho, Kichaga, Kinyarwanda, Marathi). In the asymmetric object languages only the primary object is affected by passive or can be marked by object agreement, while in the symmetric object languages both objects can be affected. Notice that there is no language in which the secondary object promotes under passive while the primary object does not. Moreover, the possibility of a secondary object to become affected is mostly controlled by further semantic factors in order to avoid ambiguity.

Indeed, in a language with strict symmetric objects (both being animate) a certain amount of ambiguity is unavoidable. (123) shows for Sesotho of South Africa that the patient and the beneficiary (the latter introduced by the applicative operation) can appear in either order, which invites for two interpretations. In the passive, illustrated in (124), each of the two objects can advance to subject, which again produces ambiguity, i.e., both (124a) 
and (124b) have two interpretations. Thus, Sesotho is one of the very rare languages that seem to have no clear grammatical mechanism to distinguish between a second and a third argument. One expects, however, that the speakers will avoid these ambiguities by contextual means, or by encoding different information structures (topic, focus).

(123) Symmetric objects in Sesotho, inviting for two interpretations (Lee 2000)

Sello o-shap-el-a Lineo bashanyana. / bashanyana Lineo.

Sello I.SBJ-beat-APPL-FV Lineo boys

i. 'Sello beats the boys for Lineo.'

ii. 'Sello beats Lineo for the boys.'

(124) Symmetric passive in Sesotho, inviting for two interpretations (Lee 2000)
a. Morena ó-bítsel-íts-o-é baná.
chief I.SBJ-call-APPL-PASS-PAST children
b. Baná ba-bítsel-íts-o-é morena.
children II.SBJ-call-APPL-PASS-PAST chief
i. 'The children benefitted from having the chief called.'
ii. 'The chief benefitted from having the children called.'

By contrast, the asymmetric object languages of Bantu make a clear distinction between primary and secondary object. In Kikuyu, the beneficiary object (introduced by the applicative operation) must be verb-adjacent, thus, the reading of (125a) crucially differs from that of (125b).

(125) Asymmetric objects in Kikuyu (Lee 2000)

a. Karioki o:n-e-ire gari dereba.

Karioki SBJ.find-APPL-PAST car driver

'Karioki found a driver for the car.'

b. Karioki o:n- $\varepsilon$-ire dereba gari.

Karioki SBJ.find-APPL-PAST driver car

'Karioki found a car for the driver.'

However, if it comes to the passive, alternating passive is possible, provided that the semantic role of the participants can be inferred from the meaning of the verb. In (126) it is clear that the flower is given to the teacher because it would be bizarre to give a teacher to a flower.

(126) Alternating passive in Kikuyu (Lee 2000)

a. Moarimo ne a-he-ir-us ihoa ne mo:do. teacher FOC SBJ-give-PAST-PASS flower by man 'The teacher was given the flower by the man.'

b. Ihoa ne re-he-ir-us moarimo ne mo:do. flower FOC SBJ-give-PAST-PASS teacher by man

'The flower was given to the teacher by the man.'

As one can observe, the positional linking of Bantu is supported by subject agreement, and, under special circumstances, also by object agreement. This may be the reason why these languages admit so much structural variation under the influence of topic and focus. In the symmetric languages it is even possible that SVO switches with OSV, see the possible readings of (124). More precisely, we probably have it do here with $\mathrm{S}_{\mathrm{T}} \mathrm{VO}_{\mathrm{F}}$ vs. $\mathrm{O}_{\mathrm{T}} \mathrm{VS}_{\mathrm{F}}$, 
where the topic is preverbal and the focus postverbal, regardless of what is the subject and what the object.

We should ask us here also a more principled question: Can we account for primary objects in a more formal way? I think that a simple logical consideration offers us the way. Recall from (70), section 4.4 above, that the minus value -hr characterizes the highest argument, and the minus value - $1 \mathrm{r}$ the lowest argument from two different perspectives (what is higher, and what is lower?). This yields the representation in (127b) below, in which the medial argument is the most marked $(+\mathrm{hr},+\mathrm{lr})$; it is therefore called 'indirect' object according to a long tradition, based on case-marking languages such as Latin or Greek. That is an excellent solution in the presence of generalized case, which doesn't care about linear ordering.

Positional argument linking, however, uses linear ordering, which is always from left to right, which makes a second perspective from left to right dubious. Thus, the feature $+\mathrm{lr}$ seems to be unsuitable. The concept of linear ordering rather suggests to apply something like the feature $+\mathrm{hr}$ iteratively. In the first step, all objects are assigned $+\mathrm{hr}$, and the highest argument remains $-\mathrm{hr}$. In the second step, all lower objects are assigned tho ('there is a higher object'), and the highest object remains -ho. (127a) shows how this procedure yields the intended result. The lowest object comes out to be the most marked ( $+\mathrm{hr},+$ ho), so that the medial argument can truly be characterized as the primary object. Notice that most of the grammatical constructions affecting objects pick out the least-marked object, be it the primary or the direct object.

(127) Encoding primary vs. indirect object

\begin{tabular}{|c|c|c|c|}
\hline a $\lambda z$ & $\lambda y$ & $\lambda x$ & $\{\mathrm{ACT}(\mathrm{x}) \& \operatorname{BECOME} \operatorname{POSS}(\mathrm{y}, \mathrm{z})\}$ \\
\hline$+\mathrm{hr}$ & $+\mathrm{hr}$ & $-\mathrm{hr}$ & \\
\hline +ho & -ho & & \\
\hline second. & primary & & \\
\hline object & object & & \\
\hline b $\lambda z$ & $\lambda y$ & $\lambda x$ & $\{\mathrm{ACT}(\mathrm{x}) \&$ BECOME $\operatorname{POSS}(\mathrm{y}, \mathrm{z})\}$ \\
\hline$+\mathrm{hr}$ & $+\mathrm{hr}$ & $-\mathrm{hr}$ & \\
\hline$-1 \mathrm{r}$ & $+\operatorname{lr}$ & $+\operatorname{lr}$ & \\
\hline direct & indirect & & \\
\hline object & object & & \\
\hline
\end{tabular}

There can be only these two ways of encoding a hierarchy, so that a fourth or fifth argument would not alter the typology based on the choice between +ho and $+\mathrm{lr}$ as the second feature. Usually speakers do not like too much complexity, even it is possible by the grammar. However, constructions with four structural arguments have been tested by researchers, see example (119) above, and also chapter 6 of Joppen-Hellwig (2001).

Given this more precise concept of primary object, how can we integrate the various observations made in this section? In a Bantu language with symmetric objects, the feature tho is ignored, so that both objects are undistinguishably + hr. In a language with double or even triple accusative such as Yaqui (118) (119), the feature value -ho is decisive to single out the highest object. A language in which the theme is obliquely marked as in Tahitian (121), obviously is compatible with this account because the lowest argument is most marked. The same is true for Khasi (116), which picks out the highest object to be marked by accusative. 
If, however, the language has ergative (+lr), the feature + lr must be present. Therefore, the ERG-ACC-NOM pattern shown above for Kham (116) is not an instance of primary object marking in the sense of (127a), it rather follows from the role of animacy in this language. In terms of animacy, the recipient mostly is higher than the theme. Therefore, the primary object status of the recipients in active or inverse type languages follows from independent reasons. One could even speculate that animacy is the source for generalizing the structural notion of primary object. This conclusion makes the introduction of an indirect object, to be discussed in the next section, a puzzle. As we will see, there are at least two forces working against the primary object solution: the existence of ergative (and the kind of feature marking it implies), and the fact that recipients are added to transitive verbs, hence more marked.

\subsection{The recipient is treated differently from the object of a transitive verb}

In this section we are concerned with various solutions of the third-argument problem, in which a special status of the third argument is accepted. It is either marked as a goal, or indirectly as a possessor of the theme, or by an extra case, the dative. The two latter solutions indeed justify us to speak of an indirect object. Every mechanism of realizing transitive verbs remains as before, but is augmented by an additional mechanism.

\section{The recipient is marked as goal by means of a preposition}

A very common way is marking the recipient as a goal, i.e. by means of a local preposition. Such a device usually exists independently of ditransitive verbs, but can be generalized to cover also recipients. This is illustrated by an example from Tamazight, a Berber language, in (128). The same option is found in the English PO construction.

(128) Goal-marking in Tamazight (Faltz 1978:77)

i-ša urgaz leš $\theta a \beta$ i $\theta$ mattutt

3msg-give man book to woman

'The man gave the book to the woman.'

\section{The recipient is marked as an alienable possessor of the theme}

By contrast, the option in which the recipient is realized as a possessor of the theme is very rare cross-linguistically. It is found in Tongan, a Polynesian language, as a second option, which in this language, however, is not rare. The construction in (129b) literally means ' $I$ give your food'; $h a$ 'o is an alienable possessor which syntactically belongs to the following noun.

(129) Tongan: Alternation between goal and possessor marking (Broschart, Lambert p.c.)

a. na'e 'oange 'e Pita ha tohi [kia Mele $]_{P P}$.

PAST give.away ERG Peter ART.UNSPEC book DIR Mary

'Peter gave Mary a book.'

b. 'oua mu'a ke u 'oatu [ha'o me'atokoni $]_{\mathrm{NP}}$.

wait first ERG 1sg give 2sg.POSS.AL food.POLITE

'Wait first before I give you some food.'

A similar 'recipient lowering' construction is discussed by Van Valin (2002) for Dyirbal, an Australian language. Dyirbal allows the alternation between dative (130a) (see also below), oblique (instrumental) marking of the theme (130b), and marking the recipient as the possessor of the theme (130c). Here, 'the woman gave the man's beans' exactly means what 
English expresses by the sentence the woman gave the beans to the man. The endings on the demonstratives refer to the nominal class to which the following noun belongs (I, II, or III).

(130) Dyirbal (Van Valin 2002: 14, 22; Dixon 1972)
a. Ba-la-m miran ba-ngu-n dyugum DEM-NOM-III beans DEM-ERG-II woman-ERG give-TNS DEM-DAT-I
yara-gu. 'The woman gave the beans to the man.'
b. Ba-yi yara wuga-n ba-ngu-n dyugumbi-ru ba-ngu-m miran-dyu. DEM-NOM.I man give-TNS DEM-ERG-II woman-ERG DEM-INST-I beans-INST 'The woman gave the man beans.'
c. Ba-la-m miran ba-ngu-n dyugumbi-ru wuga-n ba-ngu-l yara-nu. DEM-NOM-III beans DEM-ERG-II woman-ERG give-TNS DEM-INST-I man-GEN 'The woman gave the $\operatorname{man}_{\mathrm{i}}$ 's beans (to himi $)$.'

Conversely, it is also possible that the theme is marked as possessed by the recipient, provided that the language disposes of a proprietive case, which however is rare and only found in some Australian languages, for example, in Kayardild. In (131), nguki-wuru has to be translated as 'water, which belongs to someone', so that the construction literally means '(I) give the water which belongs (to them ${ }_{i}$ ) to the men $_{i}$ '.

(131) Kayardild (Australian, Van Valin 2002: 24; Evans 2000)

...nguki-wuru wuu-ja dangka-y.
water-PROP give-ACT person-MLOC
'... [and I] will provide mankind with water'

At a first glance, both constructions, the possessor marking of the theme and the proprietive marking of the recipient, support our analysis that recipients are intended possessors. It is not totally unexpected that the realization of a component of the verb is delegated to one of the arguments. The proprietive solution of Kayardild can best be compared with the delegation of LOC to an external PP, which we found in (81) above. The respective compositions are schematized in (132). The proprietive in this function is so rare because the proprietive itself is rare, compared to local prepositions.

(132) Composition with a delegated predicate
a. $\operatorname{PUT}(\mathrm{x}, \mathrm{z}) \& \mathrm{P}(\mathrm{z})$ yields
$\operatorname{PUT}(\mathrm{x}, \mathrm{z})$ \& BECOME LOC(z, AT y)
b. $\operatorname{GIVE}(\mathrm{x}, \mathrm{y}) \& \mathrm{P}(\mathrm{y})$ yields
$\operatorname{GIVE}(\mathrm{x}, \mathrm{y}) \&$ BECOME POSS(y,z) (or $\operatorname{WITH}(\mathrm{y}, \mathrm{z}))$

However, such a composition is not possible for the possessor marking of the theme because the possessor is the higher argument of POSS, and the noun that bears the possessor is a sister argument of the recipient. We have to conclude that some inference must be done: 'A possessor of the theme can be identified with the intended possessor.' A possessor of an argument is often delegated to the verb (by the so-called possessor raising), which is the opposite of recipient lowering. Consider the following examples from Chocktaw, a Muskogean language. Each of the verbs in (133) has four arguments; the dative that is nearer to the stem marks the recipient, and the other marks the possessor of the theme. (The word order of the syntactic arguments follows the argument hierarchy; only the subject is marked by nominative case, all other structural arguments can be left unmarked.) 
(133) Possessor raising in Chocktaw (Davies 1986:54)
a. Hattak-at ohoyo iskali am-im-a:-tok. man-NOM woman money 1.DAT-3.DAT-give-PAST
'The man gave my money to the woman.'
b. Alla towa chim-i-pila-li-tok. child ball 2.DAT-3.DAT-throw-1.NOM-PAST 'I threw your ball to the child.'

We have good reason to believe that possessor raising is a generalization enabled by the existence of a recipient dative. On the other hand, possessors found on nouns are not readily be generalized to cover also recipients, that is, sister arguments. Summarizing, this option is not especially advantegous, in contrast to what we will consider now.

\section{The recipient is realized by dative}

The introduction of dative as a special case for the 'indirect object' is very common, not only in the Indo-European languages. The following two examples show that dative is compatible with both a pure accusative and a pure ergative system. Japanese is an accusative language of the SOV-type; all cases are marked by a postposition, and $n i$ is a postposition that marks certain locative arguments but also the recipient of ditransitive verbs (134a), as well as the causee of a causativized transitive verb (134b). In contrast, Basque is an ergative language of the SOV-type; ergative and dative are marked by a suffix on the noun, and the final auxiliary agrees with all three arguments. Again, the recipient of a 'give' verb (135a) and the causee of a causativized transitive verb (135b) are encoded by dative.

(134) Dative marking in Japanese
a. otoka-ga onna-ni hon-o age-ta. man-NOM woman-DAT book-ACC give-PAST 'The man gave the book to the woman.'
b. John-ga Mary-ni sakana-o tabe-sase-ta. John-NOM Mary-DAT fish-ACC eat-CAUS-PAST 'John let Mary eat the fish.'

(135) Dative marking in Basque (Joppen)
a. Ni-k pobre-ei diru-a ema-ten diet. 1sg-ERG poor-pl.DAT money-DET give-IMPERF AUX.3N.3pD.1E 'I give money to the poor.'
b. Ama-k haurr-a-ri zopa jan-araz-ten dio. mother-ERG child-DET-DAT soup.DET eat-CAUS-IMPERF AUX.3N.3D.3E 'The mother lets the child eat the soup.'

Dative is also possible in a pure head-marking language such as Yimas, a polysynthetic language of New Guinea that lacks morphological case. In Yimas, pronominal affixes are attached to the verb; they belong to different sets realizing the function of case. Dative affixes are restricted to 3rd person (136a), otherwise the recipient is marked by an accusative affix (136b). (The nominative affixes agree with the respective class of the noun, such as IV or VI.) 
(136) Alternation between dative and accusative marking in Yimas (Foley 1991)
a. irpm mu- ka- tkam-t -nakn.
coconut palm.IVsg IVsg-1sgE-show-PERF-3sgD
'I showed him a coconut palm.'
b. uran k- mpu- na- tkam-t
coconut.VIsg VIsg-3plE-1sgA-show-PERF
'They showed me the coconut.'

Many more languages display a canonical case pattern for ditransitive verbs, in the sense outlined above in (70) (section 4.4): NOM - DAT - ACC in accusative systems, and ERG - DAT - NOM in ergative systems. On the basis of the two features $+h r$ and $+\mathrm{lr}$, dative is indeed maximal; it is not possible to encode a fourth argument by a further structural case. We claim that the feature lattice shown in (137) and based on argument hierarchy is complete for structural cases,

(137) Four possible structural cases

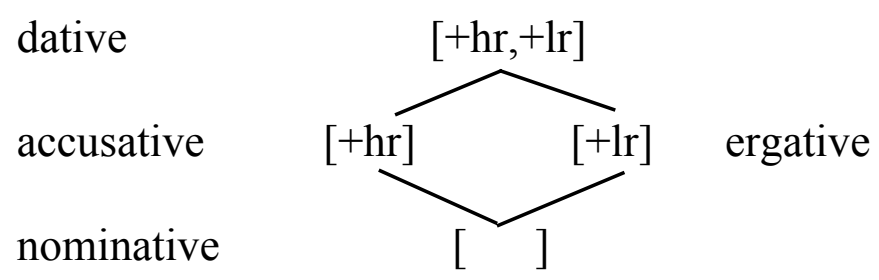

The reader may ask about genitive: Isn't it a structural case, too? We consider genitive to be encoded like accusative but restricted to nouns; usually it marks the possessor of the noun (see Stiebels this volume). Only if the genitive enters the verbal system in addition to accusative, it has to offer some semantic advantage, for instance, a partitive or a negative polarity reading. In languages such as Russian and Finnish, the genitive has acquired many functions of the accusative, which can happen because the two cases bear the same feature + hr.

In the rest of this section I will first discuss a case in which dative is only one option, and then, two instances of dative-accusative syncretism, where dative and accusative have collapsed into one marker.

\section{Alternative options for ditransitive verbs}

As I said in the beginning of section 6, many languages have more than one option to express a third argument. One example is Dyirbal, demonstrated in (130). The two case patterns shown in $(130 \mathrm{a}, \mathrm{b})$ are also found in Inuit (West Greenlandic), in which this alternation is subject to a certain restriction. The basic ditransitive verbs of Inuit encode the recipient like the object of a transitive verb, and the theme argument is marked by instrumental (as in Dyirbal (130b)), see (138a). This seems to be a lexical property of these verbs because all derived ditransitives verbs mark the medial argument by dative, thereby showing the canonical case pattern of ditransitives. Surprisingly, all basic ditransitives can be shifted into this canonical pattern, too, by suffixation with -ut, as shown in (138b). It is questionable whether - $u t$ has any semantic contribution. The portmanteau agreement suffixes on the verb relate to the NPs showing ERG/NOM. In the examples below, the verb ending therefore shifts from $3 \mathrm{pl}$ in (138a) to $3 \mathrm{sg}$ in (138b). 
(138) Basic ditransitives in Inuit (Bittner 1994: 20)

a. Juuna-p miiqqa-t atuakka-mik nassip-p-a-i.

J.-ERG child-PL book-INST send.IND-TR-3sg/3pl

'Juuna sent the children a book.'

b. Juuna-p atuagaq miiqqa-nut nassi-up-p-a-a.

J.-ERG book child-PL.DAT send-UT-IND-TR-3sg/3sg

'Juuna sent a book to the children.'

Both variants of such a ditransitive verb can be causativized. The causee, then, is expressed by dative, and the theme argument is realized by either instrumental or nominative, depending on whether -ut is applied or not. The preferred position of arguments is always ERG - NOM (the two arguments the verb agrees with), followed by the other objects according to their hierarchy. Therefore, (139a) exhibits the ordering ERG - NOM - DAT INST, and (139b) the ordering ERG - NOM - DAT - DAT. Because of this strict ordering, the double dative in (139b) does not lead to any confusion.

(139) Causative in Inuit (Bittner 1994:86)

a. Kaali-p qimmi-t irnir-mi-nut puisi-mik nirlir-sip-p-a-i. K.-ERG dog-PL son-3sgP-DAT seal-INST feed-CAUS-IND-TR-3sg/3pl 'Kaali let his son feed the dogs seal meat.'

b. Kaali-p puisi irnir-mi-nut qimmi-nut nirli-ut-sip-p-a-a. K.-ERG seal son-3sgP-DAT dog-PL.DAT feed-UT-CAUS-IND-TR-3sg/3sg 'Kaali let his son feed the dogs seal meat.'

A suffixal verb of Inuit adds some other higher predicate (such as 'believe', 'want', 'think'), so that the subject of the embedded predicate becomes medial: it is always realized by dative. Again, an instrumental appears if a basic ditransitive verb is affected. (140a) illustrates the embedding of a transitive verb, which leads to the surface pattern ERG - NOM - DAT, while (140b) illustrates the embedding of a simple 'give'.

(140) Suffixal verbs in Inuit (Bittner 1994: 59f)

a. Aani-p miiqqa-t Juuna-mut paasi-sur-a-i.

A.-ERG child-PL J.-DAT understand-think.IND-TR-3sg/3pl

'Aani thinks that Juuna understands children.'

b. Kaali-p miiqqa-t Maala-mut atuakka-mik tuni-qqu-va-a-i.

K.-ERG child-PL M.-DAT book-INST give-want-IND-TR-3sg/3pl

'Kaali wants Maalat to give the children a book.'

A summary is given in (141).

(141) Ditransitive verbs in Inuit (West-Greenlandic): the verb agrees with ERG and NOM

\begin{tabular}{|l|ccc|l|}
\hline & $\lambda z$ & $\lambda y$ & $\lambda x$ & VERB $(\mathrm{x}, \mathrm{y}, \mathrm{z})$ \\
& $+\mathrm{hr}$ & $+\mathrm{hr}$ & $-\mathrm{hr}$ & \\
& $-\mathrm{lr}$ & $+\mathrm{lr}$ & $+\mathrm{lr}$ & \\
\hline derived & NOM & DAT & ERG & \\
\hline basic 'give' & INSTR & NOM & ERG & \\
\hline
\end{tabular}

As we have seen, Inuit is a further language in which dative indicates the medial position of an argument. If typologically and genetically different languages behave so similar, there is reason to believe that the correlation dative $\sim$ medial argument belongs to the stronger properties of human language. Our explanation is that the encoding of argument hierarchy 
yields two possible features $(+\mathrm{hr}$ and $+\mathrm{lr}$ ), which, when they are combined, automatically lead to such a correlation.

\section{Dative-accusative syncretism}

We briefly show for two languages (Hindi and Georgian) that even if the distinction between dative and accusative disappears, the language can remain its indirect object type (where the recipient is treated differently from the object of a transitive verb). In Hindi there is only one overt object clitic ko, which traditionally is called either accusative or dative, depending on the further context (Mohanan 1994, Butt 1995). Similarly, Georgian shows only one overt object suffix $-s$, which traditionally is called dative. For the sake of clarity, I will cite these morphological elements as accusative markers, specified as $+\mathrm{hr}$.

Both Hindi and Georgian show an accusative-ergative split (see (65) for Hindi), which might have influenced the collapse of dative and accusative. In both languages it is the passive that can indicate the indirect object. Note that in the passive of a ditransitive verb in languages such as German or Japanese the indirect object (the medial argument) remains dative, whereas the direct object (the lowest and therefore less marked argument) is shifted to nominative, as shown in (142). (The shift to nominative is explained by the assumption that at least one argument should be realized by nominative.) Similarly, in both Hindi and Georgian the accusative of the medial argument remains in the passive.

(142) Passive of ditransitive verbs in German and Japanese ${ }^{11}$

a. Ihm wurde ein Orden überreicht.

he.DAT AUX.PASS a decoration presented

'A decoration was presented to him.'

b. Hon-ga onna-ni age-rare-ta.

book-NOM woman-DAT give-PASS-PAST

'A book was given to the woman.'

Let us first consider the case-marking of ditransitive verbs in Hindi. (143a) shows a basic ditransitive in the perfect, whereas (143b) shows a derived ditransitive verb in the perfect. Finally, (143c) shows the imperfect. The reader will at once observe that the various salience conditions (such as animacy and definiteness) determining the alternation between accusative and nominative, discussed above with regard to (65), do not apply here; in the opposite, the lowest argument is always marked nominative, and the medial argument is always marked accusative. The explanation is that double accusative (which could result from the salience conditions) is forbidden in Hindi, so that the more marked argument role (the medial one) is uniformly preferred to be associated with the more marked case (the accusative).

(143) Ditransitive verbs in Hindi (Mohanan 1994)
a. Ravii-ne baalak-ko/*baalak baccaa/*bacce-ko Ravi-ERG boy-ACC/*boy.NOM child.NOM/*child-ACC 'Ravi gave a/the child to a/the boy.'
b. Ravii-ne gaay-ko/*gaay kelaa/*kele-ko
Ravi-ERG cow-ACC/*cow.NOM 'Ravi fed a/the cow a/the banana.'

$$
\begin{aligned}
& \text { diy-aa. } \\
& \text { give.PERF-M }
\end{aligned}
$$
$\mathrm{k}^{\mathrm{h}}$ ilaay-aa
eat.CAUS.PERF-M

\footnotetext{
11 Japanese passive has several functions. It is also possible that the indirect argument becomes nominative, similar to the German kriegen-passive: Er (NOM) kriegte einen Orden (ACC) verehrt 'he got presented a decoration'.
} 

c. Ravi mãã-ko baccaa
Ravi.NOM mother-ACC child.NOM
'Ravi gives a/the child to the mother'
detaa hai.
give.IMPERF be.PRES

In the passive of these verbs, nothing changes in the realization of case, except that the highest argument is unrealized.

(144) Passive of ditransitive verbs in Hindi
$\begin{array}{ll}\text { mãã-ko baccaa diyaa } \\ \text { mother-ACC child.NOM } & \text { give.PERF }\end{array}$
gayaa.
'The mother was given a/the child'
go.PERF

Thus, the lack of a distinctive dative and the ban against double accusative lead to a simplification of the canonical ditransitive patterns, summarized in (145). Note that the perfect still exhibits three distinct cases, which may have played a role for the dativeaccusative collapse to emerge.

(145) Ditransitive verbs in Hindi: the verb agrees with the higher NOM

\begin{tabular}{|l|ccc|l|}
\hline & $\lambda \mathrm{z}$ & $\lambda \mathrm{y}$ & $\lambda \mathrm{x}$ & $\operatorname{VERB}(\mathrm{x}, \mathrm{y}, \mathrm{z})$ \\
& $+\mathrm{hr}$ & $+\mathrm{hr}$ & $-\mathrm{hr}$ & \\
& $-\mathrm{lr}$ & $+\mathrm{lr}$ & $+\mathrm{lr}$ & \\
\hline perfect & NOM & ACC & ERG & \\
\hline non-perfect & NOM & ACC & NOM & \\
\hline passive & NOM & ACC & $*$ & \\
\hline
\end{tabular}

Let us now turn to Georgian, which behaves in many respects similar to Hindi. Like Hindi, Georgian has developed an ergative that is restricted to some sort of past or completion. The Georgian ergative is exclusively found in the so-called aorist series (of possible tenseaspect-mood combinations), exemplified in (146a). In all other combinations the ergative is blocked. Differently from Hindi, the present series of Georgian allows double accusative (146b). However, in the passive it is the recipient that remains accusative (146c).

(146) Aorist, present and passive in Georgian (Joppen-Hellwig 2001: 50)

a. Ketino-m Eka-s xalitša a-čuk-a.

Ketino-ERG Eka-ACC carpet V-present-AOR.3N

'Ketino presented Eka with a carpet.'

b. Ketino Eka-s xalitša-s s-čukni-s.

Ketino Eka-ACC carpet-ACC 3D-present-PRES.3N

'Ketino presents Eka with a carpet.'

c. xalitša e-čuk-eb-a Eka-s.

carpet PASS-present-TH-PRES.3N Eka-ACC

'The carpet is presented to Eka.'

Georgian exhibits a third series of tense-aspect-mood, which is best described as evidential (encoding a hear-say constellation) and illustrated in (147). Here, the highest argument is marked by + hr (a situation that we found above - in section 5.1 - as characteristic for experiencer verbs). Since Georgian does not allow the combination of two accusatives of animate nouns, the medial argument gets instead expressed by a semantic case.

(147) Evidential in Georgian

Ketino-s Eka-tvis xalitša u-čuk-eb-i-a.

Ketino-ACC Eka-for carpet V-present-TH-EVID-3N 
'As one says, Ketino presented Eka with a carpet.'

The agreement facts of Georgian would deserve their own chapter (see Wunderlich 19XX). It is enough to say that the agreement system is always accusative-based: the verb agrees with the subject and a 1st or 2nd person (highest) object. However, consonant-initial verb stems show dative agreement for the 3rd person, see (146b). Because of the case reversal in the evidential, forced by a lexical feature of this mood, the agreement gets reversed in this mood, too.

The table in (148) summarizes the case patterns of ditransitive verbs found in Georgian. As in Hindi, the aorist pattern exhibits three distinct structural cases.

(148) Ditransitive verbs in Georgian: the verb agrees with NOM and the higher ACC

\begin{tabular}{|l|ccc|l|}
\hline & $\lambda \mathrm{z}$ & $\lambda \mathrm{y}$ & $\lambda \mathrm{x}$ & VERB $(\mathrm{x}, \mathrm{y}, \mathrm{z})$ \\
& $+\mathrm{hr}$ & $+\mathrm{hr}$ & $-\mathrm{hr}$ & \\
& $-\mathrm{lr}$ & $+\mathrm{lr}$ & $+\mathrm{lr}$ & \\
\hline aorist & NOM & ACC & ERG & \\
\hline present & ACC & ACC & NOM & \\
\hline passive & NOM & ACC & $*$ & \\
\hline evidential & NOM & $\begin{array}{c}\text { semantic } \\
\text { case }\end{array}$ & ACC & \\
& & & \\
\hline
\end{tabular}

Georgian also allows derived ditransitive verbs: the initial vowel of a verb can function as an applicative morpheme. In the literature on Georgian, a distinction is made between the objective version, in which a possessor or beneficiary is added (149a), and the superessive version, in which an object on which something is placed is added (149b). As expected, we find double accusative in the present.

(149) Objective and superessive version in Georgian (Joppen-Hellwig 2001: 117)

a. mzia u-cmend-s da-s pexsacml-eb-s.

Mzia APPL-clean-PRES.3N sister-ACC shoe-PL-ACC

'Mzia cleans her sister the shoes.'

b. Mama a-cer-s misamart-s konvert-s.

father APPL-write-PRES.3N address.ACC envelope-ACC

'Father writes an address on the envelope.'

In the passive of these applicatives, again the case of the medial argument is preserved, which is illustrated in (150) and (151). Thus, the medial argument indeed is more marked than the lowest argument. Another, so far unmentioned fact of Georgian is the behavior of plural agreement: in this regard, the verb always agrees with the highest argument rather than with a nominative one, that is, in the passive the verb has to agree with the higher object. Therefore, the verb is plural in (150a), but singular in (150b), complying with the number of the beneficiary, and in opposition to what the respective nominative phrases reveal about number.

(150) Passive of the objective version in Georgian (Joppen-Hellwig 2001:132)

a. deb-s pexsacmel-i e-cmind-eb-a-t. sister.PL-ACC shoe-NOM APPL.PASS-clean-TH-PRES.3N-PL

'The shoe is cleaned for the sisters.'

b. da-s pexsacml-eb-i e-cmind-eb-a. sister-ACC shoe-PL-NOM APPL.PASS-clean-TH-PRES.3N

'The shoes are cleaned for the sister.' 
The same choice of number agreement can be observed in the passive of the superessive version, shown in (151).

(151) Passive of the superessive version in Georgian (Joppen-Hellwig 2001: 133)

a. konvert-eb-s misamart-i e-cer-eb-a-t.

envelope-PL-ACC address-NOM APPL.PASS-write-TH-PRES.3N-PL

'The address is written on the envelopes.'

b. konvert-s misamart-eb-i e-cer-eb-a.

envelope-ACC address-PL-NOM APPL.PASS-write-TH-PRES.3N

'The addresses are written on the envelope.'

This clearly indicates that 'envelope' is a higher argument than 'address', and thus behaves as a 'possessor' of the address rather than its location, contrary to what the notion 'superessive' suggests. Again we see that structural generalization can exceed semantic boundaries. Above we observed (with respect to Nivkh) that the grammatical effects of the predicate LOC are generalized to instances of change of possession, and here we can observe that the predicate POSS is generalized to instances of change of location. Both is unexpected from a purely semantic perspective.

Circumstances like these make the study of languages a fascinating topic: it is not only the surface forms that differ from language to language but also the semantic templates framing the contents. Within certain limits, languages differ in their semantic perspectives. We discussed two alternatives of expressing three-place concepts, which have to find corresponding grammatical means for realizing the three arguments. We claimed that the predicates POSS and LOC offer the basic semantic machinery to perform this task. Consequently, each language has to find a proper generalization about constructions based on either POSS or LOC, therefore, the borderline between a POSS field and a LOC field is not determined by independent semantic considerations but rather by language-specific grammaticalization. However, grammaticalization processes are not arbitrary. If a language develops alternative constructions, there is usually some inherent division of labor at work. English has developed two constructions for ditransitive verbs (based on POSS, and LOC), and the choice between them follows a clear semantic gradience, as we will see in the next section.

\subsection{The English 'dative' alternation}

Above we postulated two types of ditransitive verbs from a semantic point of view, change of possession and change of location verbs. Usually these two types are distinguished by formal means. English uses these means not only for a distinction between two classes of ditransitives, but also as alternative realizations for most individual verbs. The two alternatives are the double object (DO) construction and the prepositional object (PO) construction, and the alternating verbs are said to undergo the 'dative alternation' (a somewhat misleading term because English doesn't have a dative.) A question much discussed in the literature is whether this alternation follows from the semantic difference between change of possession and change of location. Pinker (1989), Krifka (2004) and others have argued that this indeed is the case. However, other authors are sceptical. How can it be possible that the verb give shifts it semantic reading from (152a) to (152b)?

(152) DO-PO alternation in English

a. Anna gave Max a photo.

b. Anna gave a photo to Max. (PO) 
The DO-PO alternation is found rather frequently. Bresnan \& Nikitina (2003) observed that there are only few verbs that totally resist the DO-PO alternation. The DO construction often is possible with a pronominal recipient (153c), while it is blocked with a nominal recipient (153a). Conversely, the PO construction can be possible with pronouns (154c), while it is blocked with nouns (154a).

(153) DO is only possible with pronouns in verbs of imparting a force (push, pull, carry, lift, lower), and verbs of communication (whisper, yell, mumble, mutter) (Bresnan \& Nikitina 2003)
a. *Susan pushed John the box.
*Susan whispered Rachel the news.
b. Susan pushed the box to John.
Susan whispered the news to Rachel.
c. Susan pushed him the chips.
Susan whispered me the answer.

(154) PO is only possible with pronouns (Bresnan \& Nikitina 2003)
a. The car cost Beth $\$ 5000$.
b. *The car cost $\$ 5.000$ to Beth.
c. It would cost nothing to the government.

Similar observations can be made with respect to definiteness, topichood, length of expression etc. The more definite, topical or shorter the expression of the recipient is the better it fits with the DO construction. Bresnan \& Nikitina (2003) therefore argue that the choice of construction has to do with other factors than a difference in meaning.

On the contrary, I think that it is exactly the difference in the semantic representations that helps us to understand the observations made by Bresnan \& Nikitina. Let me first say that these authors overestimate the difference in meaning. The predicates $\operatorname{POSS}(\mathrm{y}, \mathrm{z})$ and LOC $(\mathrm{z}, \mathrm{AT} \mathrm{y})$ are weakly equivalent because usually if one of them comes true, the other comes true, too. If $\mathrm{z}$ is located at $\mathrm{y}$, then $\mathrm{y}$ is able to exert some possessorship on $\mathrm{y}$. Conversely, if $y$ has possession of $\mathrm{z}$, than $\mathrm{z}$ must be located in some neighborship to $\mathrm{y}$ for $\mathrm{y}$ being able to exert his possessorship. For this reason, many languages successfully express possession by means of a locative preposition. (155) shows this for Russian.

(155) Possession in Russian:
a. U menja kniga.
at me.GEN book
'I have the book.'
b. U nego bylo mnogo druzej. at him.GEN was many friends.GEN
'He had many friends.'

Moreover, the POSS $\approx$ LOC alternation is generally possible in languages such as German and English, as exemplified in (156).

(156) POSS $\approx$ LOC alternation in German and English
a. Das Haus hat drei Bäder.
b. In dem Haus sind drei Bäder.
The house has three bathrooms.
There are three bathrooms in the house.

Therefore, no logical reasons prevent us from interpreting a change of possession as a change of location, and vice versa, given that the verbs allow a certain alternation. The difference in meaning mainly reduces to a difference in argument hierarchy. The possessor is the higher argument of POSS, while it participates in the lower argument of LOC. (Because the possessor only participates in the lower argument of LOC, the predicates POSS and LOC have to be considered as weakly equivalent.)

In German, dative verbs compete with verbs that have a full PP argument (with LOC being external to the verb), which has been exemplified with schicken 'send' in (83) above (section 6.1). The dative verb has three nominal arguments, with the recipient as the medial 
one (157a), while the PP verb has a prepositional phrase (related to the goal) as the third argument (157b). Generally, a PP argument occupies the lowest position.

(157) Dative verbs vs. PP verbs in German

$\begin{array}{lllll}\text { a. Dat: } & \lambda \mathrm{z} & \lambda \mathrm{y} & \lambda \mathrm{x} & \{\operatorname{ACT}(\mathrm{x}) \& \operatorname{BEC} \operatorname{POSS}(\mathrm{y}, \mathrm{z})\} \\ & \text { ACC } & \text { DAT } & \text { NOM } & \\ \text { b. PP: } & \lambda \mathrm{P} & \lambda \mathrm{z} & \lambda \mathrm{x} & \{\operatorname{ACT}(\mathrm{x},) \& \mathrm{P}(\mathrm{z})\} \\ & \text { PP } & \text { ACC } & \text { NOM } & \end{array}$

In the English PO construction, the preposition is fixed, which can be considered a formal reflex of LOC being incorporated in the semantic representation of the verb. Hence, both variants of English have three nominal arguments, with the only difference that the recipient is medial in DO (158a), but the lowest argument (framed as a goal) in PO (158b).

(158) Double object and prepositional object in English :
a. $\mathrm{DO}$
$\lambda z$ $\operatorname{secO}$
$\lambda \mathrm{y} \quad \lambda \mathrm{x}\{\mathrm{ACT}(\mathrm{x}) \& \operatorname{BEC} \operatorname{POSS}(\mathrm{y}, \mathrm{z})\}$
b. PO: $\lambda y$
to primO
$\lambda \mathrm{z} \quad \lambda \mathrm{x} \quad$ ACT(x) \& BEC LOC(z, AT y)\} primO

These decomposed representations allow us to make some important predictions. In the DO construction, the recipient should behave consistently as the higher object: it can bind a reflexive theme, can license a negative polarity item (such as any), can be moved in multiple questions, etc., which comes true according to the several tests applied by Larson (1988). In contrast, in the PO construction the recipient (construed as a goal) should behave consistently as the lower argument: it can be bound by a theme, cannot be moved in multiple questions, etc.

This is demonstrated here for binding and scope. A quantifier in the higher argument can bind the possessor of a lower argument, but not vice versa, as shown in (159) and (160). The recipient binds the possessor of the theme in the DO construction (159a), and the theme binds the possessor of the recipient=goal in the PO construction (160a), while the respective reversed bindings are excluded (159b, 160b).

(159) DO construction

a. He gave every woman ${ }_{i}$ her ${ }_{i}$ baby. Which woman $_{i}$ did you give her ${ }_{i}$ baby?

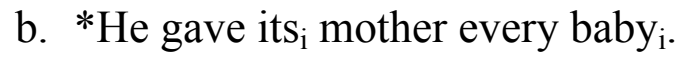

(160) PO construction

a. He gave every baby $y_{i}$ to its $s_{i}$ mother. Which baby did $_{\mathrm{i}}$ you give to its $\mathrm{s}_{\mathrm{i}}$ mother?

b. *He gave her ${ }_{i}$ baby to every woman ${ }_{i}$.

Similarly, the higher argument has scope over the lower argument; scope reversal is a highly marked option and scarcely acceptable, as shown in (161) and (162). The theme can be distributed to multiple recipients in the DO construction, where each girl gets her own telescope in (161a). Conversely, the recipient (=goal) can be distributed to multiple themes in the PO construction, where each telescope ends up at some girl in (162a).

(161) DO construction (Bresnan \& Nikitina 2003)

a. Ozzy gave each girl a telescope. $\forall \mathrm{y} \exists \mathrm{z}\{\mathrm{ACT}($ ozzy $) \& \operatorname{BEC} \operatorname{POSS}(\mathrm{y}, \mathrm{z})\}$ 
b. *Ozzy gave a (different) girl each telescope. $\forall \mathrm{z} \exists \mathrm{y}\{\operatorname{ACT}(o z z y) \& \operatorname{BEC} \operatorname{POSS}(\mathrm{y}, \mathrm{z})\}$

(162) PO construction (Bresnan \& Nikitina 2003)

a. Ozzy gave each telescope to a girl. $\forall \mathrm{z} \exists \mathrm{y}\{\mathrm{ACT}($ ozzy $) \&$ BEC LOC(z,AT y)

b. ??Ozzy gave a (different) telescope to each girl. $\forall \mathrm{y} \exists \mathrm{z}\{\mathrm{ACT}(o z z y) \&$ BEC LOC(z,AT y)\}

The examples in (159) to (162) clearly indicate that both constructions have their own semantic potential to express more complex states of affairs, and therefore it is justified to represent them differently. We are now in the position to come back to the observations made by Bresnan \& Nikitina.

The representations given in (158) predict an asymmetric distribution of the two constructions according to the contextual features listed in (163).

(163) Differential object marking in ditransitive verbs

\begin{tabular}{ll} 
less marked & more marked \\
\hline animate & inanimate \\
1st or 2nd person & 3rd person \\
pronoun & full noun \\
definite & indefinite \\
short expression & long expression \\
topic & focus
\end{tabular}

Each of these contextual feature forms a scale (less marked - more marked), which has to be associated with the argument hierarchy found in the DO or PO construction. The concept of harmonic alignment of scales then suggests the following: The more marked an argument is the lower should be its position in argument hierarchy, given that we have a choice. This amounts to the competition scenario in (164).

(164) DO-PO competition:

a. If the recipient is less marked than the theme, DO is chosen (alternatively, PO is blocked).

b. If the recipient is more marked than the theme, PO is chosen (alternatively, DO is blocked).

This prediction turns out to be true. Collins (1995) calculated several factors determining the choice of construction on a broad text basis. He found the following distribution in the DO construction. (In the PO construction, the (reversed) preferences are less striking around 1.5).

(165) Preferences in the DO construction (Collins 1995:47)

$\begin{array}{lll} & \text { Recipient } & \text { Theme } \\ \text { focus } & 1 & 90 \\ \text { topic } & 14 & 1 \\ \text { pronoun } & 11 & 1 \\ \text { definite } & 4.5 & 1 \\ \text { longer } & 1 & 3\end{array}$

In the DO construction the recipient is preferred over the theme to be topic (14 times), pronoun (11 times), or definite (4.5 times), but it is dispreferred to be focus or the longer 
expression. Bresnan \& Nikitina (2003) present much more data inclining to the same direction, but they are still arguing for one underlying semantic representation. However, the fact that these asymmetries can be predicted by harmonic alignment should convince us that different argument hierarchies play a role. The essential function of the lexical decompositions given in (158) is to provide us with a principled way of stating argument hierarchies: the recipient is the higher object in the DO construction but the lower object in the PO construction.

Collins' data also indicate that DO is the marked alternative because it leads to a sharper profile under varying contextual circumstances. For this reason, a child who is confronted with a mixed input of DO and PO data could detect the advantage of the DO construction (in the sense outlined in (164)) more easily than that of the PO construction. This is in accordance with the observations made by Adone (2002), who found that Creole-speaking children of the Seychelles overgeneralized the DO construction more readily than the PO construction.

Another more general conclusion can be drawn. The existence of two alternative constructions has the advantage that the speakers can give different contextual weights to an argument. In the choice between DO and PO the speakers weigh the relative salience of the two objects, which is similar to the choice between active and passive, where they weigh the relative salience of subject versus object. It would be interesting to study other types of alternatives under this perspective. For instance, only little is known so far about the competition between the serial verb construction and DO.

Sedlak (1975) reports a few observations about West-African languages. Twi, which is a dialect of Akan, a Kwa-language of Ghana, prefers the DO construction with a nominal or indefinite theme $(166 a, b)$, while a pronominal or definite theme leads to a serial verb construction $(167 \mathrm{a}, \mathrm{b})$.

(166) Double object in Twi (Sedlak 1975: 142f., Stewart 1963: 145ff)

a. o-fধmm me ne pônkó nó.

3 sg-lent $1 \mathrm{sg} 3 \mathrm{sgP}$ horse that

'He lent me his horse.'

a. o-maa me siká bí.

3 sg-gave 1 sg money some

'He gave me some money.'

(167) Serial verbs in Twi (Sedlak 1975: 142f., Stewart 1963: 145ff)
a. o-de nó femm me.
3 sg-take that lent 1 sg
'He lent it to me.'
b. o-de siká nó maa me.
3 sg-take money the gave 1 sg
'He lent me the money.'

Examples like these suggest that the serial verb construction offers the ranking theme $>$ recipient; it is therefore optimal for expressing a theme with a less marked contextual value. The fact that the serial verb construction is similar to PO is not surprising, given the possibility that prepositions can emerge from a serial verb (see section 4.3). However, as I said, we need more and elaborated studies to see what exactly governs the choice between serial verb and double object construction. 


\section{Summary}

This survey might suggest the view that the structural profiles of languages are more different and more complicated than one would like to imagine. However, despite of all necessary differentiations along the way, this impression is superficial. Languages could be much more diverse and chaotic as they actually are. I have tried to show that structural generalizations determine the design of a language and hence the actual classifications of verbs one can find cross-linguistically. Structural generalizations are based on certain semantic similarities and extend them. Once these generalizations have been made, the conditions for further generalizations, and thus for an optimal design, can differ. It is like a journey: if you have started in a certain direction, the conditions for making further choices have changed.

The most obvious classification of verbs is that they can have one, two, three (or even more) arguments. If a verb has only one argument, a further classification is based on semantic factors. The common property of all linguistic types, however, is the fact that they base their design on the asymmetry of transitive verbs, which is both semantical and structural in nature. It is semantical insofar as the difference between agent and patient (or control and affected) is concerned, and it is structural in that this difference is generalized to argument hierarchy, with the agent higher than the patient. As has been shown, the semantic asymmetry of transitive verbs can be used to import a classification in the set of intransitive verbs.

The concept of argument hierarchy plays the major role. Several constructional devices either translate hierarchy (e.g., into linear order) or react on it. Serial verb constructions and the SVO positional type translate hierarchy, whereas noun incorporation, generalized case, as well as the choice of syntactic pivot, react on hierarchy. 'Syntactic pivot' is the name for an argument that determines syntactic constructions in that it, for instance, can be left out in subordination or coordination. Cross-linguistically, either the most salient (unmarked) argument or the highest argument are syntactic pivots, and sometimes both under different conditions. It is, moreover, an advantage if in principle every argument can be promoted to achieve this function.

Another important factor are sortal properties (such as person and animacy) as well as referential properties (such as specificity or definiteness) of the arguments, whereas their information status only plays a minor role.

There are various possibilities to react on these two demands, i.e., to make visible argument hierarchy and to account for the individual properties of arguments. In the way of a taxonomy I have argued that the following argument linking types have been established.

1. The active type grammaticalizes the semantic factors that lead to subject-object asymmetry.

2. The inverse type grammaticalizes person hierarchy in the context of argument hierarchy, so that in the end subject-object asymmetry gets neutralized.

3 . The voice type grammaticalizes the semantic roles of arguments.

4. The generalized case type grammaticalizes argument hierarchy by a closed feature set, but makes the realization of these features sensitive to semantic factors .

5. The positional type grammaticalizes argument hierarchy by linearization, independent of semantic factors but possibly dependent on information status. 
Each of these types favors different subclassifications of verbs. The active type, the voice type, and the generalized case type also allow the expression of noncanonical verb classes by a certain 'deviant' use of their features, i.e., by means of lexical marking .

When it comes to the integration of a third argument, one can see the different potential of the individual types. By and large, the taxonomy gets much more differentiated, but only a few principled ways are added. Particularly interesting are serial verbs (which are on the borderline between morphology and syntax) and noun incorporation (which can even constitute an own argument linking type, see section 6.3 above). It is also interesting that languages often have alternative means to realize a third argument, so that the study of the choice between these alternatives (such as the English 'dative' alternation) becomes a worthwhile topic.

Above, I listed five argument linking types. There could be more types, or different types. Only future research will show us how many different types are possible and in what respect each type constitutes an optimal solution under certain conditions. One might believe that some types are less optimal than others, so that in the long only a few types will survive, say the generalized case type and the positional type. I am sceptical about it. The Philippine voice type is quite an elegant solution, and even more is that true for the inverse type. If a linguist without knowledge of Algonquian would have been asked to characterize which argument linking types are possible, I am quite certain that the inverse type would not have been included in his list. This shows the difficulty: even the best linguists are unable to imagine the range of constructions that perform a comparatively simple task. But the actual problem lies even deeper because the inverse type is more than a construction, it offers an ingenious solution in which the syntactic subject-object asymmetry, one of the cornerstones of generative grammar, is sacrificed. In acknowledging this fact many introductory books to generative grammar would have to be rewritten. Thus, one aim of my survey is to pledge for more liberality towards typological richness, and at the same time to encourage future research.

\section{References}

Aissen, Judith (1987) Tzotzil clause structure. Dordrecht: Reidel.

Aissen, Judith (1999) Markedness and subject choice in Optimality Theory. Natural Language and Linguistic Theory 17: 673-711.

Andrews, Avery (1985) The major functions of the noun phrase. In Timothy Shopen (ed.) Language typology and syntactic description, vol. I: Clause structure, 62-154. Cambridge University Press.

Baker, Mark (1991) On the relation of serialization to verb extension. In Claire Lefebvre (ed.) Serial verbs: Grammatical, comparative and cognitive approaches, 79-102. Philadelphia: John Benjamins.

Baker, Mark \& O.T. Stewart (2001) A serial verb construction without constructions. Ms., Rutgers University.

Barss, Andrew \& Howard Lasnik (1986) A note on anaphora and double objects. Linguistic Inquiry 17: 347-354.

Bittner, Maria (1994) Case, scope, and binding. Dordrecht: Kluwer.

Bresnan, Joan \& Lioba Moshi. 1990. Object asymmetries in comparative Bantu syntax. Linguistic Inquiry 21: 147-185.

Bresnan, Joan \& Tatiana Nikitina. 2003. On the gradience of the dative alternation, Ms. Univ. of Stanford. 
Broschart, Jürgen (1995) Why Tongan does it differently: Categorial distinctions in a language without nouns and verbs. Working papers SFB 282 'Theorie des Lexikons', No.70.

Burzio, Luigi (1981) Intransitive verbs and Italian auxiliaries. Ph.D. dissertation MIT.

Burzio, Luigi (1986) Italian syntax: A government binding approach. Dordrecht: Reidel.

Butt, Miriam. 1995. The Structure of Complex Predicates in Urdu. Stanford: CSLI publications.

Chung, Sandra (1983) An object-creating rule in Bahasia Indonesia. In David M. Perlmutter (ed.) Studies in Relational Grammar 1, 219-271. University of Chicago Press.

Collins, Peter. 1995. The indirect object constructions in English: an informational approach. Linguistics 33: 35-49.

Comrie, Bernard (1985) Causative verb formation and other verb-deriving morphology. In Timothy Shopen (ed.) Language typology and syntactic description. vol. III Grammatical categories and the lexicon, 309-348. Cambridge University Press.

den Besten; Hans (1984) The ergative hypothesis. In Jindrich Toman (ed.) Studies in German Grammar, 23-64. Dordrecht: Foris.

Dahlstrom, Amy. 1988. Morphological change in Plains Cree verb inflection. Folia Linguistica Historica 9/2, 59-71.

Dahlstrom, Amy. 1991. Plains Cree Morphosyntax. New York: Garland.

Dahlstrom, Amy. 1991. Topic, focus and other word order problems in Algonquian. Winnipeg: Voices of Rupert's Land.

Davies, William D. (1986) Chocktaw verb agreement and universal grammar. Dordrecht: Reidel.

Dixon 1972 (Dyirbal)

Dixon, R. M. W. 1994, Ergativity. Cambridge University Press.

Dixon, R. M. W. (2000) A typology of causatives: form, syntax, and meaning. In Dixon \& Alexandra Y. Aikhenvald (eds.) Changing valency. Case studies in transitivity, 30-83. Cambridge University Press.

Dowty, David R. 1979. Word meaning and Montague Grammar: The semantics of verbs and times in Generative Semantics and in Montague's PTQ. Dordrecht: Reidel.

Dowty, David. 1991. Thematic proto-roles and argument selection. Language 67:547-619.

Dryer, Matthew S. (1986) Primary objects, secondary objects, and antidative. Language 62: 808845.

Fabri, Ray. 1996. The inverse morphology of Plains Cree (Algonquian). In Geert Booij \& Jaap van Marle (eds.) Yearbook of Morphology 1995, 17-41. Dordrecht: Kluwer.

Faltz, Leonard M. (1978) On indirect objects in universal syntax. CLS 14, 76-87.

Foley, William A. (1991) The Yimas language of New Guinea. Stanford University Press.

Foley, William A. and Robert D. van Valin Jr. 1984. Functional Syntax and Universal Grammar. Cambridge University Press.

Gamerschlag, Thomas. 2003. Komposition, Köpfigkeit und Argumentstruktur komplexer Verben. Doctoral dissertation, University of Düsseldorf.

Goddard, Ives (1979) Delaware verbal morphology. New York (???): Garland.

Grimshaw, Jane. 1990. Argument Structure. Cambridge, Mass.: The MIT Press.

Haider, Hubert (1985) Über sein und nicht sein: Zur Grammatik des Pronomens sich. In Werner Abraham (ed.) Erklärende Syntax des Deutschen, 221-252. Tübingen: Narr.

Haspelmath, Martin (XXX)

Jackendoff, Ray. 1990. Semantic Structures. MIT Press.

Joppen, Sandra \& Dieter Wunderlich (1995) Argument linking in Basque. Lingua 97: 123-169.

Joppen-Hellwig, Sandra (2001) Verbklassen und Argumentlinking. Tübingen: Niemeyer.

Kaufmann, Ingrid (1995a) O- and D-predicates. A semantic approach to the unaccusative-unergative distinction. Journal of Semantics 12, 377-427. 
Kaufmann, Ingrid (1995b) What is an (im)possible verb? Restrictions on semantic form and their consequences for argument structure. Folia Linguistica 29, 67-103.

Kaufmann, Ingrid (2004) Medium und Reflexiv. Eine Studie zur Verbsemantik. Tübingen: Niemeyer.

Kaufmann, Ingrid and Dieter Wunderlich. 1998. Cross-linguistic patterns of resultatives. Working papers 'Theory of the lexicon' 109. Ubiversity of Düsseldorf.

Keyser, Samuel Jay \& Thomas Roeper (1984) On the middle and ergative constructions in English. Linguistic Inquiry 15: 381-416.

Kiparsky, Paul. 1992. Structural case. Ms., Institute for Advanced Study, Berlin.

Kiparsky, Paul (1998?) Remarks on denominal verbs. In Alex Alsina et al. (eds.) Complex Predicates, 473-499. Stanford: CSLI Publications.

Klaiman, M. H. 1993. The relationship of inverse voice and head-marking in Arizona Tewa and other Tanoan languages. Studies in Language 17: 343-370.

Koptjevskaja-Tamm, Maria \& Irina A. Muravjova. 1993. Alutor causatives, noun incorporation and the Mirror Principle. In Bernard Comrie \& Maria Polinsky (eds.) Causatives and Transitivity, 287-313. Amsterdam: Benjamins.

Kratzer, Angelika (1996) Severing the external argument from its verb. In J. Rooryck \& L. Zaring (eds.) Phrase structure and the lexicon, 109-138. Dordrecht: Kluwer.

Krifka, Manfred. 2004. Lexical representations and the nature of the dative alternation. Korean Journal of English language and linguistics 4, 1-32.

Kroskrity, Paul. 1985. A holistic understanding of Arizona Tewa passives. Language 61:306-328.

Lee, Hanjung. 2000. Bidirectional optimality and ambiguity in argument expression. Ms., Univ. Stanford.

Luo 1999 (Chin)

Mattissen. Johanna. 2003. Dependent-head synthesis in Nivkh. A contribution to a typology of polysynthesis. Amsterdam: Benjamins (PhD dissertation, U Cologne)

Mithun, Marianne (1991) Active/agentive case marking and its motivations. Language 67, 510-546.

Mohanan, Tara. 1994. Argument structure in Hindi. Stanford: CSLI Publications.

O'Grady, W. (1990) Categories and case. Philadelphia: John Benjamins.

Paul, Hermann (1919) Deutsche Grammatik, Bd. III: Syntax.

Perlmutter, David M. \& Paul M. Postal (1984) The 1-advancement exclusiveness law. In David M. Perlmutter \& Carol G. Rosen (eds.) Studies in Relational Grammar 2, 81-125. The University of Chicago Press.

Peyraube, Alain (1996) Recent issues in Chinese historical syntax. In C.-T. James Huang \& Y.-H. Audrey Li (eds.) New Horizons in Chinese Linguistics, 161-213. Dordrecht: Kluwer.

Pinker, Steven. 1989. Learnability and cognition. The acquisition of argument structure. Cambridge, Mass.: MIT Press.

Pustejovsky, James. 1991b. The syntax of event structure. Cognition 41:47-81.

Sasse, Hans-Jürgen (1992) Das Nomen - eine universale Kategorie? Working papers SFB 282 'Theorie des Lexikons', No.27.

Sasse, Hans-Jürgen (1993) Syntactic categories and subcategories. In Joachim Jacobs et al. (eds.) Syntax. Ein interdisziplinäres Handbuch zeitgenössischer Forschung, 646-686. Berlin: de Gruyter.

Schwartz, Linda J. (1979) The order of Dakota person affixes: an evaluation of alternatives. Glossa $13,3-12$.

Schulze, Wolfgang. 2001. The Udi Language: A grammatical description. Online, Univ. München.[http://www.lrz-muenchen.de/ w wschulze/]

Sedlak, Philip A. S. (1975) Direct/indirect object word order: a cross-linguistic analysis. Working Papers on Language Universals 18, 117-164. Stanford University. 
Stewart, O. T. (2001) The serial verb construction parameter. New York: Garland.

Stiebels, Barbara (1996) Lexikalische Argumente und Adjunkte: Zum semantischen Beitrag von verbalen Präfixen und Partikeln. Berlin: Akademie Verlag.

Stiebels, Barbara (1998) Complex denominal verbs in German and the morphology-semantics interface. In Geert Booij \& Jaap van Marle (eds.) Yearbook of Morphology 1997, 265-302. Kluwer.

Stiebels, Barbara (2000) Linker inventories, linking splits and lexical economy. In Barbara Stiebels \& Dieter Wunderlich (eds.) Lexicon in Focus, 211-245. Berlin: Akademie Verlag.

Stiebels, Barbara (2002) Typologie des Argumentlinkings: Ökonomie und Expressivität. Berlin: Akademie Verlag.

Van Valin, Robert D. (1977) Aspects of Lakhota syntax. Ph.D. dissertation. University of California, Berkeley.

Van Valin, Robert D. (2002) The role and reference grammar analysis of three-place predicates. Ms.

Watkins, Laurel (1984) A grammar of Kiowa. Lincoln: Univ. of Nebraska Press.

Williamson (1965) (Ijo)

Wolfart, H. Christoph. 1973. Plains Cree: A grammatical study. Transactions of the American Philosophical Society, New Series, Vol. 63, Part 5.

Wolfart, H. Christoph \& Janet F. Carroll. 1981. Meet Cree. A guide to the language. Lincoln: Univ. of Nebraska Press.

Wunderlich, Dieter (1996) Lexical categories. Theoretical Linguistics 22: 1-48.

Wunderlich, Dieter (1997a) Cause and the structure of verbs. Linguistic Inquiry 28, 27-68.

Wunderlich, Dieter (1997b) Argument extension by lexical adjunction. Journal of Semantics 14, 95-142.

Wunderlich, Dieter (2000a) Predicate composition and argument extension as general options. In Barbara Stiebels \& Dieter Wunderlich (eds.) Lexicon in Focus, 247-270. Berlin: Akademie Verlag.

Wunderlich, Dieter (2000b) Optimal case in Hindi. Ms., University of Düsseldorf.

Wunderlich, Dieter (2001a) How gaps and substitutions can become optimal: the pronominal affix paradigms of Yimas. Transactions of the Philological Society 99, 315-366.

Wunderlich, Dieter (2001b) Prelexical syntax and the voice hypothesis. In Carline Féry \& Wolfgang Sternefeld (eds.) Audiatur Vox Sapientiae, 487-513. Berlin: Akademie Verlag.

Wunderlich, Dieter (2002) On the nature of dative in Hungarian. In István Kenesei \& Péter Siptár (eds.) Papers from the Budapest conference (=Approaches to Hungarian, Vol. 8), 161-184. Budapest: Akadémiai Kiadó.

Wunderlich, Dieter (2003) Optimal case patterns: German and Icelandic compared. In Ellen Brandner and Heike Zinsmeister (eds.) New Perspectives on Case Theory, 331-367. CSLI publications.

Wunderlich, Dieter (2004) Why assume UG? In Martina Penke and Anette Rosenbach (eds.) What counts as evidence in linguistics? - The case of innateness. Special issue of Studies in Language 28, 615-647.

Wunderlich, Dieter (to appear) Argument hierarchy and other factors of argument realization. To appear in Ina Bornkessel et al. (eds.) Semantic role universals: perspectives from linguistic theory, language typology and psycho-/neurolinguistics. Mouton-de Gruyter.

Valentine, J. Randolph (2001) Nishnaabemwin reference grammar. Univ. of Toronto Press.

Zúñiga, Fernando (2002) Inverse system in indigenous languages of the Americas. Ph.D. dissertation, University of Zurich. 